\title{
Exchange-Rate Dark Matter
}

\author{
Martin D. D. Evans \\ Department of Economics, Georgetown University; \\ the NBER; and Research Department, IMF* \\ First Draft: January 17, 2012 \\ Second Draft: February 2, 2012
}

\begin{abstract}
Dark matter is believed to account for 83 percent of the matter in the universe and plays a central role in cosmology modeling. This paper argues that an analogous form of dark matter plays a similarly important role in international macroeconomics. Like its cosmological counterpart, exchange-rate dark matter cannot be directly observed, but its existence can be inferred from observations on the real exchange rates and interest rates. In the first part of this paper I show that dark matter is the dominant driver of short- and medium-term changes in real exchange rates for the G-7 countries; accounting for more than 90 percent of the variance at the five-year horizon. Although standard models stress the role of real interest differentials as the proximate drivers of real exchange-rate variations, my findings indicate that they are empirically unimportant.

To understand the nature of exchange-rate dark matter, the second part of the paper develops an open-economy DSGE model in which the risk shocks driving households' habits interact with collateral constraints and incomplete markets. The model not only shows that risk shocks can account for the role of dark matter as a driver of real exchange-rate dynamics, but also that these same shocks have significant macroeconomic implications. My analysis suggests that exchange rates appear disconnected from traditional macroeconomic fundamentals because they are particularly susceptible to risk shocks that play an important role in international macroeconomics.
\end{abstract}

Keywords: Exchange Rate Dynamics, Open-Economy Macro Models, Habits, Incomplete Markets, Collateral Constraints.

JEL Codes: F3; F4; G1.

\footnotetext{
* Email: evansmdd@gmail.com. This paper was written while the author was visiting the Research Department of the IMF. The views expressed here are solely those of the author and should not be reported as representing the views of the IMF. I am very grateful to the Research Department for their hospitality and financial support.
} 


\section{Contents}

1 Introduction 1

2 Dark Matter and Depreciation Rates $\quad 4$

2.1 Depreciation Rate Accounting . . . . . . . . . . . . . . . . . . . . . . 4

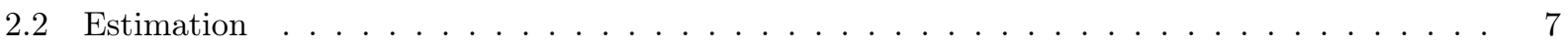

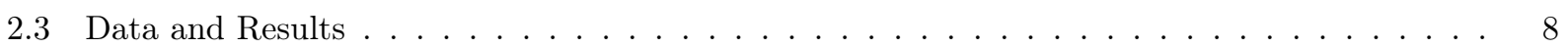

2.4 The UIP Perspective . . . . . . . . . . . . . . . . . . . . . . . . . 14

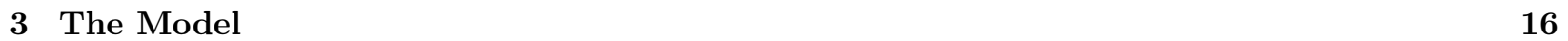

3.1 Model Details . . . . . . . . . . . . . . . . . . . . . . . . . . . . 17

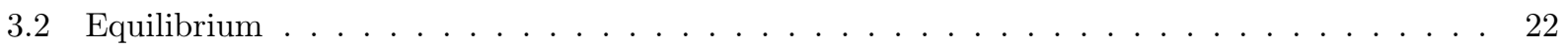

4 Results $\quad 29$

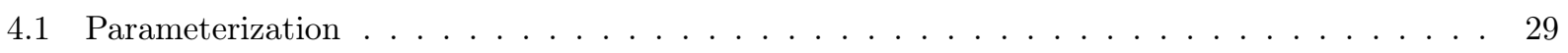

4.2 Model Moments . . . . . . . . . . . . . . . . . . . . . . . . . . . . . . 31

4.3 Identifying Dark Matter . . . . . . . . . . . . . . . . . . . . . 33

4.4 Dark Matter and Macroeconomics . . . . . . . . . . . . . . . . . . . 34

5 Conclusion $\quad 42$ 


\section{Introduction}

In cosmology, "dark matter" is a mysterious material that exerts a gravitational pull but does not emit light or other electromagnetic radiation. As such, it cannot be directly detected with a telescope but its existence is inferred from observations on the movements of galaxies and other astrological phenomena. Dark matter is believed to account for 83 percent of the matter in the universe and plays a central role in cosmology modeling (see Trimble, 1987). This paper argues that an analogous form of dark matter plays an important role in international macroeconomics.

Like its cosmological counterpart, economic dark matter cannot be directly observed, but its existence can be inferred from observations on key variables. In particular, the first part of this paper shows that dark matter is the dominant driver of changes in real exchange rates for the G-7 currencies over shortand medium-term horizons; accounting for more than 90 percent of the variance at the five-year horizon. This finding is not based on any economic model. Instead it is derived from the discrepancy between the observed dynamics of real exchange rates and those that can be attributed to the behavior of real interest differentials. As a matter of accounting, the current real exchange rate reflects: (i) current and expected future real interest differentials, (ii) expected future excess returns on foreign currency positions, and (iii) expectations concerning the long-run real exchange rate. Consequently, any discrepancy between the observed depreciation rate and the change attributable to the behavior of real interest differentials must

reflect variations in expected excess returns and/or the expected long-run real exchange rate. Exchange-rate dark matter exerts a force on these expectations but not on current and future real interest differentials.

The empirical importance of dark matter as a driver of real exchange rates poses an important question: Is the nature of the dark matter such that it only affects exchange rates, or does it play a central role in the determination of international macroeconomic relationships? I take up this question in the second part of the paper. Here I present a DSGE model in which households' preferences are subject to risk shocks that affect their degree of risk aversion. In equilibrium, these risk shocks change the risk premia embedded in real exchange rates and other asset prices, as well as households' consumption, saving and portfolio decisions. Importantly, they also represent a possible source of exchange-rate dark matter because they change the excess currency returns households expect without significantly affecting real interest differentials.

I calibrate the model to match the moments of real depreciation rates, consumption growth rates and real interest differentials and use the equilibrium dynamics to compute the contribution of dark matter to the variance of real depreciation rates over a range of horizons. The results of these calculations are similar to the estimates found in the G-7 data: Dark matter accounts for 87 percent of the variance in real depreciation rates at the five-year horizon. I then show that risk shocks have significant macroeconomic effects; they are the main driver of consumption growth, real interest rates and trade flows. Indeed, risk shocks play the dominant role in determining economic activity throughout the world economy. Thus, in a model where risk shocks are important enough to account for the role dark matter plays in driving exchange-rate dynamics, they also are the primary source of international macroeconomic dynamics. This result brings a different perspective to the widely-held view that exchange rates are largely disconnected from macroeconomic fundamentals (Obstfeld and Rogoff, 2001). It suggests that exchange-rates appear 
disconnected from traditional macroeconomic fundamentals because they are particularly susceptible to risk shocks that drive variations in expected excess currency returns, but these same shocks also have significant macroeconomic implications.

This paper contributes to the literature on exchange-rates and international macroeconomics in several ways. First, it provides a new perspective on some long-standing exchange-rate puzzles. Since Meese and Rogoff (1983), researchers have found it very difficult to consistently and reliably relate short- and mediumterm variations in exchange rates to changing macroeconomic variables. For example, recent models by Mark (2009), Engel and West (2006) and Engel, Mark, and West (2008) link short-term spot rate movements to changing expectations concerning the future path of interest rates controlled by central banks, but they account for a small faction of actual spot rate volatility over months and quarters (see Evans, 2011). The empirical results in Section 1 show how the poor empirical performance of these models reflects the importance of dark matter. More specifically, I find that the fraction of the variance in real depreciation rates for the G-7 countries (verses the U.S.) attributable to expectations and news concerning future real interest differentials falls from (a cross-country average) of four percent at the one month horizon to below two percent at five years. In effect, then, variations in real interest rates have little relevance for understanding real exchange rate behavior among the G-7 countries.

My analysis also contributes to the literature on the Forward Premium Puzzle. Traditionally, researchers have focused on the factors affecting the estimated coefficient on the interest differential in the Fama (1984) regression. For example, Moore and Roche (2009), Verdelhan (2010) and Bansal and Shaliastovich (2010) develop models where variations in the foreign exchange risk premium induce omitted variable bias in the coefficient estimate; while others, including Froot and Thaler (1990), Evans and Lewis (1995) and Bacchetta and Van Wincoop (2010) consider the effects of informational frictions. In contrast, my results provide perspective on the regression $R^{2}$ statistics. If dark matter were absent, the small values for the $R^{2}$ statistics we typically observe could be viewed as evidence that news concerning future interest differentials dominates variations in the current differential. My results show that this interpretation is only partially correct. News concerning future differentials does dominate the variations in the current differential, but the small $R^{2}$ statistics arise because future depreciation rates are primarily driven by dark matter in a manner that cannot be forecast by the current interest differential. News may account for the difficulty in forecasting depreciation rates, but it is not news related to future interest differentials.

The model presented in Section 2 draws on several lines of research from the asset-pricing and openeconomy macro literatures. The core of the model is entirely standard. There are two countries, each populated by a continuum of infinitely-lived households with preferences defined over the consumption of two perishable traded goods. For the sake of clarity, the world supply of each traded good follows an exogenous endowment process and there are no impediments to international trade. To this simple structure I add three key features: external habits, incomplete markets and collateral constraints. This is a novel combination of features to find in an open-economy DSGE model, but they are all necessary to provide a rationale for the role that dark matter plays in exchange-rate determination.

I introduce external habits into the specification of households' preferences for a simple reason. Campbell and Cochrane (1999) (hereafter CC) first showed how the presence of habits could account for behavior of 
equity prices in a model where the equilibrium real interest rates was constant, so it is natural to conjecture that a model with habits could produce exchange-rate dynamics without large variations in interest differentials. I adapt the CC habit specification to an open-economy setting. In their model the consumption surplus ratio varies in response to consumption shocks which are entirely determined by an exogenous endowment process. ${ }^{1}$ This makes little sense in an open-economy setting because the composition of households' consumption basket varies endogenously with the terms of trade. I assume, instead, that the consumption surplus ratios for households in each country are subject to exogenous shocks. These shocks have the natural interpretation of risk-shocks because they change the local curvature of the households' utility. As in the CC model, this specification implies that habits vary with changes in aggregate consumption, but the relationship is derived endogenously allowing for the effects of risk shocks on consumption via the terms of trade.

The macroeconomic effects of risk shocks are influenced by two restrictions of households' asset holdings. There are four asset markets in the model; two for real bonds and two for equities. Domestic (foreign) bonds provide the holder with a known return measured in terms of the domestic (foreign) consumption basket, while domestic (foreign) equity represents a claim on the endowment stream for the domestic (foreign) good. ${ }^{2}$ To impede international risk-sharing, I prohibit households from holding foreign equity. If this restriction were absent, markets would be complete and risk shocks would produce a negative correlation between the consumption surplus ratio and aggregate consumption via variations in the terms of trade. This would make habits more volatile than consumption - a counterintuitive implication. ${ }^{3}$ There is, of course, a long literature studying open economy models with incomplete markets and a single bond. My model adds to a newer line of research that examines DSGE models with multiple assets and incomplete markets (see, e.g., Evans and Hnatkovska, 2005a, 2005b, 2007; Van Wincoop and Tille, 2007; Hnatkovska, 2010; Devereux and Sutherland, 2010; and Pavlova and Rigobon, 2010).

The model places an additional restriction on households' asset holdings: a collateral constraint that limits the extent to which they can accumulate international debt. Specifically, I assume that households must hold foreign bonds as collateral against the value of their international liabilities (i.e. their short position in domestic bonds). This constraint plays a critical role in the international transmission of risk

\footnotetext{
${ }^{1}$ The consumption surplus ratio is defined as the difference between the level of current consumption and habit divided by current consumption: $\left(C_{t}-H_{t}\right) / C_{t}$.

${ }^{2}$ Consumption baskets differ across countries because households' preferences are biased towards the consumption of the domestically endowed goods. Consequently, the real bonds are imperfect substitutes in households' portfolios. Domestic bonds offer a risk-free real return to domestic households but a risky return to foreign households because variations in the real exchange rate affect the return measured in terms of foreign consumption.

${ }^{3}$ Verdelhan (2010) uses the CC habit specification in a two-country model to account for the forward premium puzzle. He assumes that markets are complete and that households only consume domestically produced goods. This extreme form of home bias allows him to circumvent the problems induced by variations in the terms of trade under complete risk-sharing but at the cost of eliminating international trade. Bansal and Shaliastovich (2010) also assume an extreme form of home bias to avoid a similar problem in their adaption of the long-run risk framework proposed by Bansal and Yaron (2004). In more recent research, Moore and Roche (2010) use a model with habits and complete markets to account for the forward premium anomaly. They assume that habits are relate to the consumption of individual goods (sometime called deep-habits) and are driven by endowment shocks. This means that the habit level for each good is perfectly correlate across countries without regard to the international differences in consumption. Jonen and Scheuring (2011) propose a habit-based model that is more closely related to the CC specification in which habits respond to consumption that is determined endogenously. This model assumes that households consume a basket comprising a single traded and nontraded good so variations in the terms of trade cannot cause any problems. Of course this also means that all the variations in real exchange rates reflect changes the relative prices of nontraded to traded goods, an implication that is at odds with the empirical evidence; see, e.g., Engel (1999).
} 
shocks. As in the CC model, variations in the consumption surplus ratio affect the prices of risky assets via a change in the curvature of households' utility, but here these valuation effects are concentrated in a few asset markets because the prohibition on holding foreign equity inhibits international risk-sharing. For example, a risk shock that increases domestic risk aversion induces a fall in home equity prices that pushes domestic households towards their collateral constraint. As a result, domestic households adjust their portfolios in a way that puts downward pressure on the foreign exchange risk premium inducing an immediate depreciation in the real exchange rate. Thus the collateral constraints play the central role of translating domestically induced capital gains and losses in local asset markets into the portfolio shifts that change the risk premia embedded in the exchange rates. This role for the collateral constraints differs from that found in the recent literature on sudden stops (see, e.g., Mendoza, 2010). In those models the presence of collateral constraints cuts off foreign borrowing following adverse shocks. Here households take the pre-emptive measure of shifting their portfolios as they move closer to the point where the constraint would bind. Notice, also, that this mechanism linking risk shocks to the exchange rate via portfolio shifts and variations in the risk premium is foreshadowed in Kollmann (2001), Devereux and Engel (2002), Obstfeld and Rogoff (2003), Duarte and Stockman (2005) and Blanchard, Giavazzi, and Sa (2005). It is also reminiscent of work on portfolio balance models by Kouri (1976) and Henderson and Rogoff (1982).

The remainder of the paper is divided into three sections. Section 1 describes my empirical analysis of the role played by dark matter in the determination of real depreciation rates for the G-7 currencies. Section 2 presents the model with risk shocks. In Section 3 I examine whether risk-shocks can be a possible source of exchange-rate dark matter, and whether they have significant effects on the real economy beyond the foreign exchange market. Section 4 concludes.

\section{Dark Matter and Depreciation Rates}

In this section, I first present a method for estimating the importance of real interest differentials as drivers of real depreciation rates over a wide range of horizons. I then use data from the G-7 countries during the post Bretton-Woods era to estimate the contribution of real interest rate variations to the volatility of depreciation rates with horizons of one month to five years. These estimates produce a remarkably consistent picture: Real interest rates have been a minor driver of depreciation rates during the floating-rate period. Indeed for major currency pairs, they are a very minor driver. Most of the volatility in real exchange rates we have observed for the past 35 years reflects the effects of changing expectations concerning excess current returns and long-run real exchange rates. Exchange-rate dark matter exerts a force on these expectations but not on current and future real interest differentials.

\subsection{Depreciation Rate Accounting}

I use an accounting identity to identify all the factors driving the real depreciation rate. Let $\varepsilon_{t}$ denote the $\log$ real exchange rate defined as the log relative price of the foreign consumption basket in terms of the home consumption basket at the start of period $t$. Throughout I will designate the U.S. as the home country, so 
a rise (fall) in $\varepsilon_{t}$ signifies a real depreciation (appreciation) of the U.S. dollar. The identity is based on the definition of the expected log excess real return on holding foreign currency between the start of periods $t$ and $t+1$ :

$$
\delta_{t}=\mathbb{E}_{t} \varepsilon_{t+1}-\varepsilon_{t}+\hat{r}_{t}-r_{t}
$$

where $r_{t}$ and $\hat{r}_{t}$ denote the log of the U.S. and foreign gross real interest rate (hereafter, hats " " identify foreign variables) and $\mathbb{E}_{t}$ denotes expectations conditioned on information known at the start of period $t$. I will refer to $\delta_{t}$ as the foreign exchange risk premium, although, strictly speaking, $\delta_{t}$ also contains a Jensen inequality term to account for the fact that we are dealing with log rather than gross returns.

To derive the accounting identity, I rewrite (1) as a difference equation in the log real exchange rate and solve forward. Applying the Law of Iterated Expectations to the resulting expression produces

$$
\varepsilon_{t}=\mathbb{E}_{t} \sum_{i=0}^{\infty}\left\{\hat{r}_{t+i}-r_{t+i}\right\}-\mathbb{E}_{t} \sum_{i=0}^{\infty} \delta_{t+i}+\mathbb{E}_{t} \bar{\varepsilon},
$$

where $\bar{\varepsilon} \equiv \lim _{t \rightarrow \infty} \varepsilon_{t}$. Thus, the real exchange rate reflects current and expected future real interest differentials, $\hat{r}_{t+i}-r_{t+i}$; current and expected future risk premia, $\delta_{t+i}$; and expectations concerning the long-term real exchange rate, $\bar{\varepsilon}$. Any change in the real exchange rate must come from variations in at least one of these factors.

For empirical purposes it proves useful to consider the implications of (2) for the $h$-period depreciation rate, $\Delta^{h} \varepsilon_{t+h} \equiv \varepsilon_{t+h}-\varepsilon_{t}$. By definition, this $h$-period rate equals the sum of expected depreciation rate, $\mathbb{E}_{t} \Delta^{h} \varepsilon_{t+h}$, and the $h$-period-ahead forecast error, $\varepsilon_{t+h}-\mathbb{E}_{t} \varepsilon_{t+h}$. Both components can be directly computed from (2) as

$$
\begin{aligned}
\mathbb{E}_{t} \Delta^{h} \varepsilon_{t+h} & =\mathbb{E}_{t} \sum_{i=0}^{h-1}\left(r_{t+i}-\hat{r}_{t+i}\right)+\mathbb{E}_{t} \sum_{i=0}^{h-1} \delta_{t+i} \quad \text { and } \\
\varepsilon_{t+h}-\mathbb{E}_{t} \varepsilon_{t+h} & =\left(\mathbb{E}_{t+h}-\mathbb{E}_{t}\right) \sum_{i=h}^{\infty}\left(\hat{r}_{t+i}-r_{t+i}\right)-\left(\mathbb{E}_{t+h}-\mathbb{E}_{t}\right) \sum_{i=h}^{\infty} \delta_{t+i}+\left(\mathbb{E}_{t+h}-\mathbb{E}_{t}\right) \bar{\varepsilon}
\end{aligned}
$$

Substituting these expressions into the identity $\Delta \varepsilon_{t+h}^{h}=\mathbb{E}_{t} \Delta^{h} \varepsilon_{t+h}+\varepsilon_{t+h}-\mathbb{E}_{t} \varepsilon_{t+h}$ produces

$$
\begin{aligned}
\Delta^{h} \varepsilon_{t+h}=\mathbb{E}_{t} & \sum_{i=0}^{h-1}\left(r_{t+i}-\hat{r}_{t+i}\right)+\left(\mathbb{E}_{t+h}-\mathbb{E}_{t}\right) \sum_{i=h}^{\infty}\left(\hat{r}_{t+i}-r_{t+i}\right) \\
& +\mathbb{E}_{t} \sum_{i=0}^{h-1} \delta_{t+i}-\left(\mathbb{E}_{t+h}-\mathbb{E}_{t}\right) \sum_{i=h}^{\infty} \delta_{t+i}+\left(\mathbb{E}_{t+h}-\mathbb{E}_{t}\right) \bar{\varepsilon}
\end{aligned}
$$

Equation (5) identifies all the factors that can drive the $h$-period depreciation rate. The expression follows simply from the Law of Iterated Expectations and the definition of the risk premium in (1). It contains no assumptions about the behavior of interest rates, the expected long-run real exchange rate, or anything else about the structure of the economy. Consequently, (5) provides us with a framework for studying the empirical drivers over real depreciation rates without reference to a particular economic model. 
We can use equation (5) to decompose observed variations in depreciation rates along two dimensions. The first concerns the split between anticipated and unanticipated variations. As (3) and (4) show, variations in the depreciation rate will be largely unanticipated when news between $t$ and $t+h$ concerning future interest rates, risk premia and/or the long-term real exchange rate dominates the changes in the expected near-term path for the interest differential and risk premium. Insofar as short-horizon depreciation rates appear largely unforecastable with standard macro variables, we should expect to find that news accounts for most of the variations in $\Delta^{h} \varepsilon_{t+h}$ at short horizons $h$.

The second dimension concerns the split between the role of the real interest differential and the other factors. In principle, the differential can drive the depreciation rate via both expectations as in (3) and news as in (4). The total contribution is therefore given by the first two terms on the right-hand-side of (5). Equation (5) makes clear that depreciation rates could also be driven by other factors that affect the risk premia and revisions in the expected long-run real exchange rate, $\bar{\varepsilon}_{t+h}-\mathbb{E}_{t} \bar{\varepsilon}_{t+h}$. In macro models where the variations in $\delta_{t}$ are small, and $\bar{\varepsilon}$ is pinned down by a unique steady state value for the real exchange rate (e.g. via PPP), the terms in the second row of (5) are unimportant, so the real interest differentials are the prime driver of the real depreciation rate at all horizons.

To investigate whether this macro perspective on the driver of depreciation rates is supported in the data, I compare actual real depreciation rates for major currency pairs against estimates of the first two terms on right-hand-side of (5) computed from Vector Autogression (VAR) models. More specifically, we can rewrite (5) as

$$
\begin{gathered}
\Delta^{h} \varepsilon_{t+h}=\nabla r_{t, h}^{\mathrm{E}}+\nabla r_{t+h}^{\mathrm{U}}+\zeta_{t+h}, \\
\text { where } \quad \nabla r_{t, h}^{\mathrm{E}}=\mathbb{E}_{t} \sum_{i=0}^{h-1}\left(r_{t+i}-\hat{r}_{t+i}\right), \quad \nabla r_{t+h}^{\mathrm{U}}=\left(\mathbb{E}_{t+h}-\mathbb{E}_{t}\right) \sum_{i=h}^{\infty}\left(\hat{r}_{t+i}-r_{t+i}\right), \\
\text { and } \quad \zeta_{t+h}=\mathbb{E}_{t} \sum_{i=0}^{h-1} \delta_{t+i}-\left(\mathbb{E}_{t+h}-\mathbb{E}_{t}\right) \sum_{i=h}^{\infty} \delta_{t+i}+\left(\mathbb{E}_{t+h}-\mathbb{E}_{t}\right) \bar{\varepsilon}
\end{gathered}
$$

I refer to $\zeta_{t+h}$ as exchange-rate dark matter in the sense that it exerts a force on the real depreciation rate that is not detectable from data on interest differentials.

At this stage I will be agnostic about whether the effects of dark matter are transmitted through the risk premia on long-term exchange rate expectations. My goal is simply to infer its empirical importance by estimating the variance contribution of the interest differential. For this purpose, I use (6) to compute the following variance ratios:

$$
\mathcal{R}_{h}^{\nabla r}=\frac{\mathbb{V}\left(\nabla r_{t, h}^{\mathrm{E}}+\nabla r_{t+h}^{\mathrm{U}}\right)}{\mathbb{V}\left(\Delta^{h} \varepsilon_{t+h}\right)}, \quad \mathcal{R}_{h}^{\nabla r^{\mathrm{E}}}=\frac{\mathbb{V}\left(\nabla r_{t, h}^{\mathrm{E}}\right)}{\mathbb{V}\left(\Delta^{h} \varepsilon_{t+h}\right)}, \quad \text { and } \quad \mathcal{R}_{h}^{\nabla r^{\mathrm{U}}}=\frac{\mathbb{V}\left(\nabla r_{t+h}^{\mathrm{U}}\right)}{\mathbb{V}\left(\Delta^{h} \varepsilon_{t+h}\right)},
$$

where $\mathbb{V}($.$) denotes the population variance. Here \mathcal{R}_{h}^{\nabla r}$ measures the fraction of the variance in the $h$-period depreciation rate that can be attributed to variations in the interest differential, while $\mathcal{R}_{h}^{\nabla r^{e}}$ and $\mathcal{R}_{h}^{\nabla r^{u}}$ identify the faction operating via variations in expected future differentials, $\nabla r_{t, h}^{\mathrm{E}}$, and news concerning future differentials, $\nabla r_{t+h}^{\mathrm{U}}$, respectively. Below I report estimates of these ratios for horizons $h$ ranging from 
one month to five years.

\subsection{Estimation}

It is straightforward to estimate the ratios in (7) from a VAR. Let the vector

$$
x_{t}=\left[\hat{\imath}_{t}-i_{t}, \Delta \hat{p}_{t}-\Delta p_{t}, \Delta \varepsilon_{t}, \operatorname{spr}_{t}, \widehat{s p r}_{t}\right]^{\prime}
$$

follow a $k^{\prime}$ th. order VAR :

$$
x_{t}=a_{1} x_{t-1}+a_{2} x_{t-2}+\ldots . a_{k} x_{t-k}+u_{t}
$$

where the $a_{i}$ 's are matrices of coefficients from each of the VAR equations, and $u_{t}$ is a vector of mean-zero shocks. The $x_{t}$ vector contains the interest differential on one-period nominal bonds, $\hat{i}_{t}-i_{t}$; the inflation differential, $\Delta \hat{p}_{t}-\Delta p_{t}$; the real depreciation rate, $\Delta \varepsilon_{t}$; and the spreads between long- and short-term nominal rates, $s p r_{t}$ and $\widehat{s p r}_{t}$. To compute the variance ratios, the VAR is written in companion form

$$
\left[\begin{array}{c}
x_{t} \\
\vdots \\
\vdots \\
x_{t-k+1}
\end{array}\right]=\left[\begin{array}{cccc}
a_{1} & \cdots & \cdots & a_{k} \\
I & & & \\
& \ddots & & \\
& & I & 0
\end{array}\right]\left[\begin{array}{c}
x_{t-1} \\
\vdots \\
\vdots \\
x_{t-k}
\end{array}\right]+\left[\begin{array}{c}
u_{t} \\
0 \\
\vdots \\
0
\end{array}\right]
$$

or, more compactly,

$$
X_{t}=A X_{t-1}+U_{t}
$$

Multi-period forecasts are easily computed from (8) as $\mathbb{E}\left[X_{t+i} \mid X_{t}\right]=A^{i} X_{t}$, where $A^{i}$ denotes $i$ multiplications of the companion matrix $A$.

Several features of the VAR deserve mention. First, the specification includes the monthly real depreciation rate rather than the log real exchange rate, $\varepsilon_{t}$. It is well-known that the time series for $\varepsilon_{t}$ displays a great deal of persistence across many currency pairs. Indeed, the econometric evidence on the presence or absence of a unit root is not clear cut. By contrast, depreciation rates display very little persistence, so the VAR estimates will not be vulnerable to the statistical issues associated with the presence of a unit root in $\varepsilon_{t}$. The second feature concerns the inclusion of the interest and inflation differentials, $\hat{\imath}_{t}-i_{t}$ and $\Delta \hat{p}_{t}-\Delta p_{t}$; and the spreads between long- and short-term rates, $s p r_{t}$ and $\widehat{s p r}$. These differentials and spreads exhibit much less persistence than do nominal interest rates and inflation rates separately. Again, the use of these variables effectively side-steps any issues related to the presence of unit roots in the VAR. The third feature concerns timing. By construction, all the variables in $x_{t}$ are publicly known at the start of period $t$. This means that expectations conditioned on $X_{t}$ are conditioned on a true subset of the information available to agents at the start of the period.

To compute the variance ratios in (7) let the vectors

$$
\imath_{i}=\left[\begin{array}{lllll}
1 & 0 & 0 & \cdots & 0
\end{array}\right], \quad \imath_{\Delta p}=\left[\begin{array}{lllll}
0 & 1 & 0 & \cdots & 0
\end{array}\right] \quad \text { and } \quad \imath_{\varepsilon}=\left[\begin{array}{llllll}
0 & 0 & 1 & 0 & \cdots & 0
\end{array}\right]
$$


select $\hat{\imath}_{t}-i_{t}, \Delta \hat{p}_{t}-\Delta p_{t}$ and $\Delta \varepsilon_{t}$ from $X_{t}$. We can now compute estimates of the real interest rate differential as $\hat{r}_{t}-r_{t}=\imath_{r} X_{t}$, where $\imath_{r}=\imath_{i}-\imath_{\Delta p} A$. The interest rate elements in the variance ratios are now calculated as

$$
\begin{aligned}
\nabla r_{t, h}^{\mathrm{E}} & =-\imath_{r} \sum_{i=0}^{h-1} A^{i} X_{t}=-\imath_{r}(I-A)^{-1}\left(I-A^{h}\right) X_{t}, \quad \text { and } \\
\nabla r_{t+h}^{\mathrm{U}} & =\imath_{r}(I-A)^{-1}\left(B U_{t+h}+A B U_{t+h-1}+\ldots . . A^{h-1} B U_{t+1}\right),
\end{aligned}
$$

while the $h$-period depreciation rate is given by

$$
\begin{aligned}
\Delta^{h} \varepsilon_{t+h} & =\iota_{\varepsilon} \sum_{i=1}^{h} A^{i} X_{t}+\iota_{\varepsilon}(I-A)^{-1} \sum_{i=1}^{h}\left(I-A^{i}\right) B U_{t+i} \\
& =\iota_{\varepsilon}(I-A)^{-1}\left(I-A^{h}\right) X_{t}+\iota_{\varepsilon}(I-A)^{-1} \sum_{i=1}^{h}\left(I-A^{i}\right) B U_{t+i}
\end{aligned}
$$

Finally, let $\Sigma_{u}$ denote the variance of $U_{t}$, the vector of shocks in the VAR. Since the specification of the VAR insures that $X_{t}$ is covariance stationary process, the variance of $X_{t}, \Sigma_{x}$, solves $\Sigma_{x}=A \Sigma_{x} A^{\prime}+\Sigma_{u}$. We can now use the expressions above to compute

$$
\begin{aligned}
& \mathbb{V}\left(\nabla r_{t, h}^{\mathrm{E}}\right)=\iota_{r}(I-A)^{-1}\left(I-A^{h}\right) \Sigma_{x}\left(I-A^{h}\right)^{\prime}(I-A)^{-1 \prime} \imath_{r}^{\prime}, \\
& \mathbb{V}\left(\nabla r_{t+h}^{\mathrm{U}}\right)= \iota_{r}(I-A)^{-1}\left(\sum_{i=0}^{h-1} A^{i} B \Sigma_{u} B^{\prime}\left(A^{i}\right)^{\prime}\right)(I-A)^{-1 \prime} \imath_{r}, \quad \text { and } \\
& \mathbb{V}\left(\Delta^{h} \varepsilon_{t+h}\right)=\iota_{\varepsilon}(I-A)^{-1}\left(I-A^{h}\right) \Sigma_{x}\left(I-A^{h}\right)^{\prime}(I-A)^{-1 \prime} \imath_{\varepsilon}^{\prime} \\
& \quad+\imath_{\varepsilon}(I-A)^{-1}\left(\sum_{i=1}^{h}\left(I-A^{i}\right) B \Sigma_{u} B^{\prime}\left(I-A^{i}\right)^{\prime}\right)(I-A)^{-1 \prime} \imath_{\varepsilon}^{\prime} .
\end{aligned}
$$

The ratios in (7) are calculated from these three variances.

\subsection{Data and Results}

My empirical results use monthly data spanning 1975:01 to 2007:12, subject to the availability of individual series. I deliberately omitted the 2008 financial crises from the sample period in order to focus on the role played by interest differentials under normal market conditions. Since basic arbitrage conditions, such as covered interest parity, broke down at the height of the crisis, we might anticipate that risk premia played a larger role in driving depreciation rates during this period than at other times. Consequently, extending the sample period to include the 2008 financial crisis could well lead me to under-estimate the importance of real interest differentials under normal conditions.

I examine the behavior of real depreciation rates for the U.S. relative to Canada, France, Germany, Italy, Japan, and the U.K.. The VARs are estimated using monthly data on spot rates, Eurodeposit rates, and consumer price indices obtained from Datastream. The real exchange rate at the start of month $t$, $\mathcal{E}_{t} \equiv \exp \left(\varepsilon_{t}\right)$, is computed as $S_{t} \hat{P}_{t} / P_{t}$, where $S_{t}$ is the spot price (USD/FC) at the end of trading (i.e. 12:00 
noon E.S.T.) on the last trading day (Monday - Friday) in month $t-1 . P_{t}$ and $\hat{P}_{t}$ are the last reported levels for the U.S. and foreign country consumer price indices before the start of month $t$. The value of $\mathcal{E}_{t}$ is therefore public information at the start of month $t$. I use two sets of interest rates in the VAR. The real interest differential is computed from inflation and the one month nominal rates on Eurodeposits. Specifically, I compute the one month U.S. real rate at the start of month $t, r_{t}$, as $i_{t}-\tilde{\mathbb{E}}_{t}\left(p_{t+1}-p_{t}\right)$, where $i_{t}$ is the midpoint of the bid and offer rates on the last trading day of month $t-1$, and $\tilde{\mathbb{E}}_{t}\left(p_{t+1}-p_{t}\right)=\imath_{\Delta p} \tilde{A} X_{t}$ is an estimate of inflation during month $t$ computed from the VAR. The one month real rate in the foreign country is computed analogously as $\hat{r}_{t}=\hat{\imath}_{t}-\tilde{\mathbb{E}}_{t}\left(\hat{p}_{t+1}-\hat{p}_{t}\right)$. I also use the spread between the one year and one month Eurodeposit rates, $s p r_{t}=i_{t}^{12}-i_{t}$ and $\widehat{s p r}_{t}=\hat{\imath}_{t}^{12}-\hat{\imath}_{t}$ where $i_{t}^{12}$ and $\hat{\imath}_{t}^{12}$ are the midpoints for the 12-month Eurodeposit rate on the last trading day of month $t-1$.

Table 1 reports summary statistics for the estimated VARs used to compute the variance ratios. The first two rows of Panel A show the sample period and number of observations used to estimate the VAR for each currency pair. The third row reports the order of the VAR that minimizes the Akaike Information criterion. This is the number of lags included in the VAR used to estimate the variance ratios discussed below, but computing the ratios from VARs with one more or less lag does not materially affect the results.

Panel B reports the $R^{2}$ statistics from the depreciation and interest differential equations in the VARs. As one would expect, very little of the variance in monthly real depreciation rates is accounted for by lagged variables in the VAR. The $R^{2}$ statistics are generally in the five to six percent range, with the exception of the US/FF rate that is nine percent. The second row in Panel reports the $R^{2}$ for the real interest differential implied by the estimated equations for the nominal interest rate and inflation differentials. This statistic is computed as the estimated variance of the one-month-ahead forecast for the real differential relative to the estimated variance of the differential; i.e., $\left.\mathbb{V}\left(\tilde{\mathbb{E}}^{2} \hat{r}_{t}-r_{t} \mid X_{t-1}\right]\right) / \mathbb{V}\left(\hat{r}_{t}-r_{t}\right)$. These statistics are a good deal larger than their counterparts for the depreciation rate. They show that the variables in the VAR have an economically significant degree of forecasting power for future real interest rate differentials.

Further statistical evidence on the forecasting power of the variables in the VAR is provided in Panel C where I report the p-values for Granger Causality tests on the nominal interest and inflation differentials. There is very strong evidence rejecting the null hypothesis that spreads do not Granger Cause interest differentials across all currency pairs. The spreads appear to have significant incremental forecasting power for future interest differentials beyond that contained in their own history, so including them in the VAR improves the precision of the forecasts of future interest differentials used in computing the variance ratios. The results of the other Granger Causality tests are less clear cut. Lagged depreciation rates have some incremental forecasting power for future interest differentials and inflation differentials in some of the currency pairs. Similarly, lagged interest differentials and spreads have forecasting power for future inflation differentials in some cases, but there is no uniform pattern.

Table 2 reports estimates of the variance ratios, $\mathcal{R}_{h}^{\nabla r}$ and $\mathcal{R}_{h}^{\nabla r^{u}}$, for horizons ranging from one month to five years (i.e., $h=1, . .60$ ), computed from the VARs for each currency pair. The table also reports the 5 'th. and $95^{\prime}$ th. percentiles of the bootstrap distribution of the ratio at each horizon. To compute this distribution, I first generating a pseudo data series for the vector of variables $x_{t}$ equal to the span of the data sample using the VAR parameter estimates and a bootstrap sample of the VAR residuals. I then 
Table 1: VAR Summary Information

\begin{tabular}{|c|c|c|c|c|c|c|c|}
\hline $\mathrm{USD} / \mathrm{FC}$ & CAN & GBP & JPY & EUR & DEM & $\mathrm{FF}$ & ITL \\
\hline A: Sample start & $75: 05$ & $75: 04$ & $78: 10$ & $99: 05$ & $75: 05$ & $75: 06$ & $78: 09$ \\
\hline Sample end & $07: 12$ & $07: 12$ & $07: 12$ & $07: 12$ & 99:01 & 99:01 & 99:01 \\
\hline Observations & 392 & 393 & 351 & 104 & 285 & 284 & 245 \\
\hline Var Order $k$ & 2 & 1 & 1 & 2 & 2 & 3 & 2 \\
\hline \multicolumn{8}{|l|}{ B: $R^{2}$ Stats. } \\
\hline$\Delta \varepsilon$ eqn. & 0.051 & 0.023 & 0.050 & 0.061 & 0.061 & 0.092 & 0.054 \\
\hline$\hat{r}-r$ eqn. & 0.710 & 0.499 & 0.926 & 0.549 & 0.692 & 0.633 & 0.728 \\
\hline \multicolumn{8}{|l|}{ C: Granger Tests } \\
\hline$\hat{\imath}-i$ eqn. & & & & & & & \\
\hline$\Delta \varepsilon$ & 0.048 & 0.067 & 0.849 & 0.748 & 0.212 & 0.033 & 0.512 \\
\hline spr & 0.000 & 0.000 & 0.003 & 0.000 & 0.000 & 0.000 & 0.000 \\
\hline$\widehat{s p r}$ & 0.000 & 0.000 & 0.000 & 0.672 & 0.000 & 0.000 & 0.000 \\
\hline$\Delta \hat{p}-\Delta p$ & 0.137 & 0.546 & 0.716 & 0.751 & 0.035 & 0.000 & 0.147 \\
\hline \multicolumn{8}{|l|}{$\Delta \hat{p}-\Delta p$ eqn. } \\
\hline$\Delta \varepsilon$ & 0.049 & 0.034 & 0.428 & 0.020 & 0.058 & 0.079 & 0.186 \\
\hline spr & 0.046 & 0.183 & 0.017 & 0.300 & 0.062 & 0.463 & 0.022 \\
\hline$\widehat{s p r}$ & 0.252 & 0.707 & 0.008 & 0.791 & 0.611 & 0.009 & 0.655 \\
\hline$\hat{\imath}-i$ & 0.010 & 0.007 & 0.914 & 0.119 & 0.007 & 0.002 & 0.904 \\
\hline
\end{tabular}

Notes: The variables in the VAR are the one-month nominal interest differential, $\hat{\imath}-i$; the one month inflation differential, $\Delta \hat{p}-\Delta p$, the one month real depreciation rate, $\Delta \varepsilon$; the US one-year one-month nominal spread, spr; and the foreign country spread, $\widehat{s p r}$. Panel B reports the $R^{2}$ from the real depreciation equation, and the implied $R^{2}$ for the real interest differential computed as $\left(\imath_{\hat{r}}-\imath_{r}\right) \tilde{A} \tilde{\Sigma}_{x} \tilde{A}^{\prime}\left(\imath_{\hat{r}}-\imath_{r}\right)^{\prime} /\left(\imath_{\hat{r}}-\imath_{r}\right) \tilde{\Sigma}_{x}\left(\imath_{\hat{r}}-\imath_{r}\right)^{\prime}$, where $\tilde{A}$ and $\tilde{\Sigma}_{x}$ are the estimated companion matrix and covariance matrix of $X_{t}$. Panel C reports the p-value for the null hypothesis that lags of the variable shown in the left hand column does not Granger Cause the equation variable shown at the top of each list. P-values are computed from the $\chi^{2}$ statistics using heteroskedasticity consistent estimates of the coefficient covariance matrix.

re-estimate the VAR with this pseudo data and compute the variance ratios for $h=1, . .60$. This procedure is repeated 5000 times to generate a bootstrap distribution of the variance ratios at each horizon from which the percentiles are calculated.

Panel A of Table 2 reports estimates of the variance contribution of the real interest differential, $\mathcal{R}_{h}^{\nabla r}$, at horizons of one month, one quarter, one, two and five years. Two features immediately stand out: The estimates of $\mathcal{R}_{h}^{\nabla r}$ are surprisingly small for every currency pair and they decline as the horizon increases. At the one month horizon, the largest estimate for $\mathcal{R}_{h}^{\nabla r}$ is just 0.264 for the USD/ITL, while for major currencies like, the USD/EUR and USD/GBP, the estimates are as small as 0.042. At the five year horizon, the estimates are even smaller, in several cases well below 0.05. Of course, all these estimates for $\mathcal{R}_{h}^{\nabla r}$ contain sampling error and so may, to some degree, understate the actual contribution of the real depreciation rate. One way to assess this possibility is to examine the $95^{\prime}$ th percentiles of the bootstrap distribution for $\mathcal{R}_{h}^{\nabla r}$, 


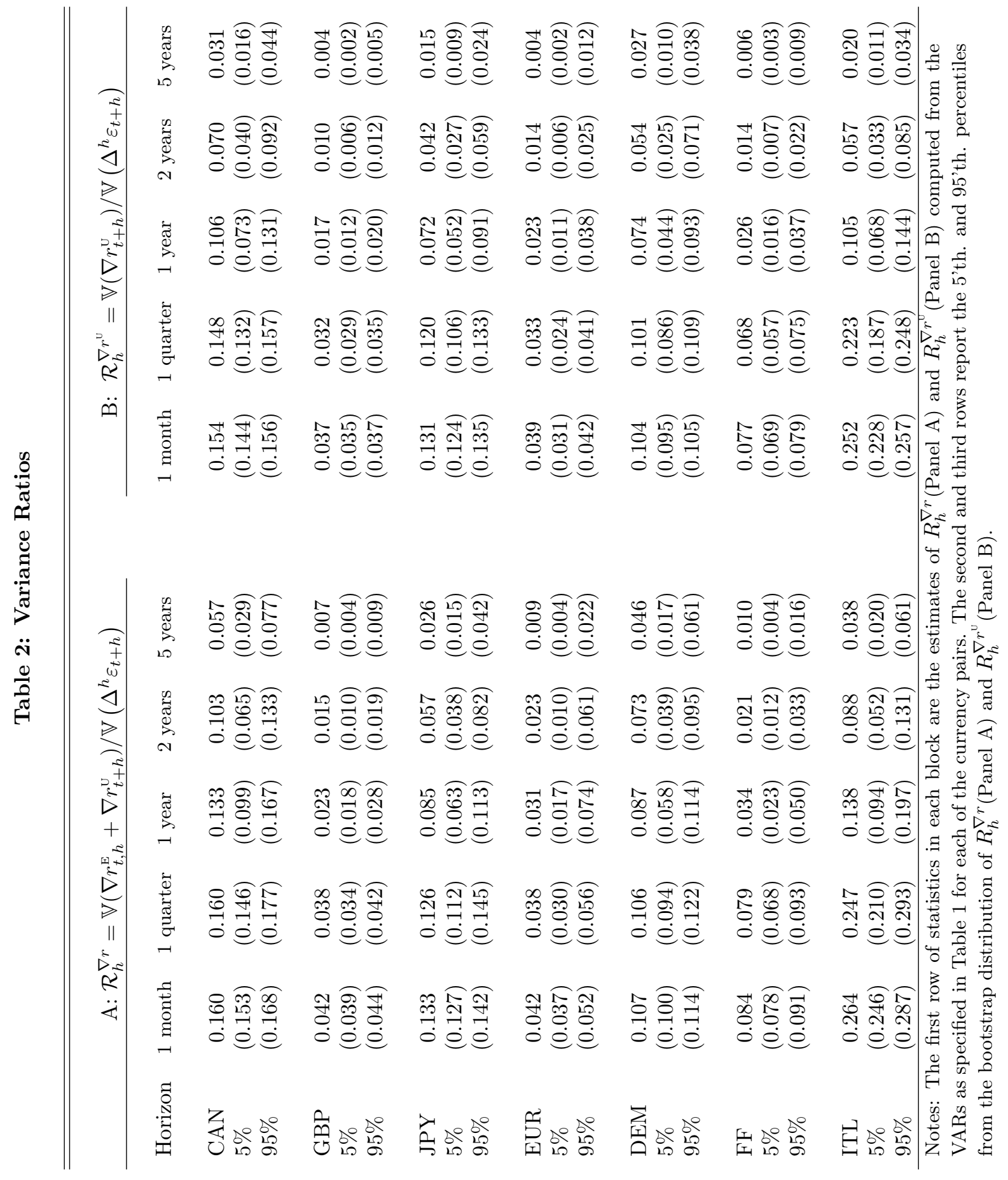


which are reported in the third row of each block in the panel. These percentiles can be view as an optimistic upper bound on the importance of real interest differentials as a driver of depreciation rates. However, as the table shows, these bounds are not significantly above the estimates of $\mathcal{R}_{h}^{\nabla r}$. Thus, the simple message from panel $\mathrm{A}$ is that real interest differentials play a decidedly minor role in driving real depreciation rates up to a five year horizon.

Panel B reports estimates of $\mathcal{R}_{h}^{\nabla r^{\mathrm{u}}}$, the ratio that measures the variance contribution of news concerning future differentials. By definition $\mathcal{R}_{h}^{\nabla r}=\mathcal{R}_{h}^{\nabla r^{\mathrm{E}}}+\mathcal{R}_{h}^{\nabla r^{\mathrm{U}}}$ so the estimates of $\mathcal{R}_{h}^{\nabla r^{\mathrm{U}}}$ provide information on the relative importance of variations in expected future differentials, $\nabla r_{t, h}^{\mathrm{E}}$, verses news concerning future differentials, $\nabla r_{t+h}^{\mathrm{U}}$, as drivers of depreciation rates. As the table shows, news is comparatively more important at short horizons than at long horizons. For every currency pair, the estimates of $\mathcal{R}_{h}^{\nabla r^{v}}$ are at most a couple of percentage points less than the estimates of $\mathcal{R}_{h}^{\nabla r}$ for $h=1,3$. This finding is consistent with well-know difficulty in forecasting short-term depreciation rates. If $\mathcal{R}_{h}^{\nabla r} \cong \mathcal{R}_{h}^{\nabla r^{\mathrm{E}}}$ for small $h$, interest differentials would have more forecasting power for short-term depreciation rates than we observe in the data. As the horizon rises beyond a couple of months, the estimates of $\mathcal{R}_{h}^{\nabla r^{\mathrm{v}}}$ fall more quickly than the estimates of $\mathcal{R}_{h}^{\nabla r}$. This is most readily seen in Figure 1 which plots the estimates of $\mathcal{R}_{h}^{\nabla r}$ and $\mathcal{R}_{h}^{\nabla r^{u}}$ against $h$ for all seven currency pairs. The vertical distance between the two plots identifies the estimated value for $\mathcal{R}_{h}^{\nabla r^{\mathrm{E}}}$. The shaded band shows the 90 percent confidence band for $\mathcal{R}_{h}^{\nabla r}$ from the bootstrap.

The estimated variance ratios in Table 2 and Figure 1 depend on the specifications of the VAR, so it is important to assess their robustness with respect to alternative specifications. To this end, I repeated all the calculations using one more lag of $x_{t}$ in the estimated VAR and one less lag (for specifications with $k>1$ in Table 1). In all cases, the estimated variance ratios were very similar to those reported above. In particular, the estimates of $\mathcal{R}_{h}^{\nabla r}$ are typically well below 0.15 at short horizons and decline sharply as the horizon rises.

The results may also be sensitive to the amount of information available to agents in the economy. It is possible that agents revise their long-horizon forecasts for the real interest differential on the basis of information that is uncorrelated with current interest rates, inflation rates and spreads. Such information would induce volatility in $\nabla r_{t+h}^{\mathrm{U}}$ (for large $h$ ) and contribute to the variance of the real depreciation rate, but is unlikely to be reflected in the VAR estimates unless variance of the dark matter, $\zeta_{t+h}$, is small. Intuitively, variations in depreciation rates provide a signal on the information flow affecting long-term differential forecasts, but the signal-to-noise ratio is very low when there are significant movements in $\zeta_{t+h}$. Consequently, although the VAR estimates of $\nabla r_{t+h}^{\mathrm{U}}$ condition on depreciation rates, they may not fully reflect the information agents use to revise their long-horizon forecasts of differentials when dark matter is present. Of course, this observation does not undermine my central finding. If dark matter were not present, the estimates of $\mathcal{R}_{h}^{\nabla r}$ should be close to one. Clearly, the evidence is inconsistent with this implication. Furthermore, since the VARs include the spreads which strongly Granger Cause interest differentials, and the VAR estimates account for a large fraction of the variance in real interest differentials, it is unlikely that my results would materially change with the addition of other variables. 

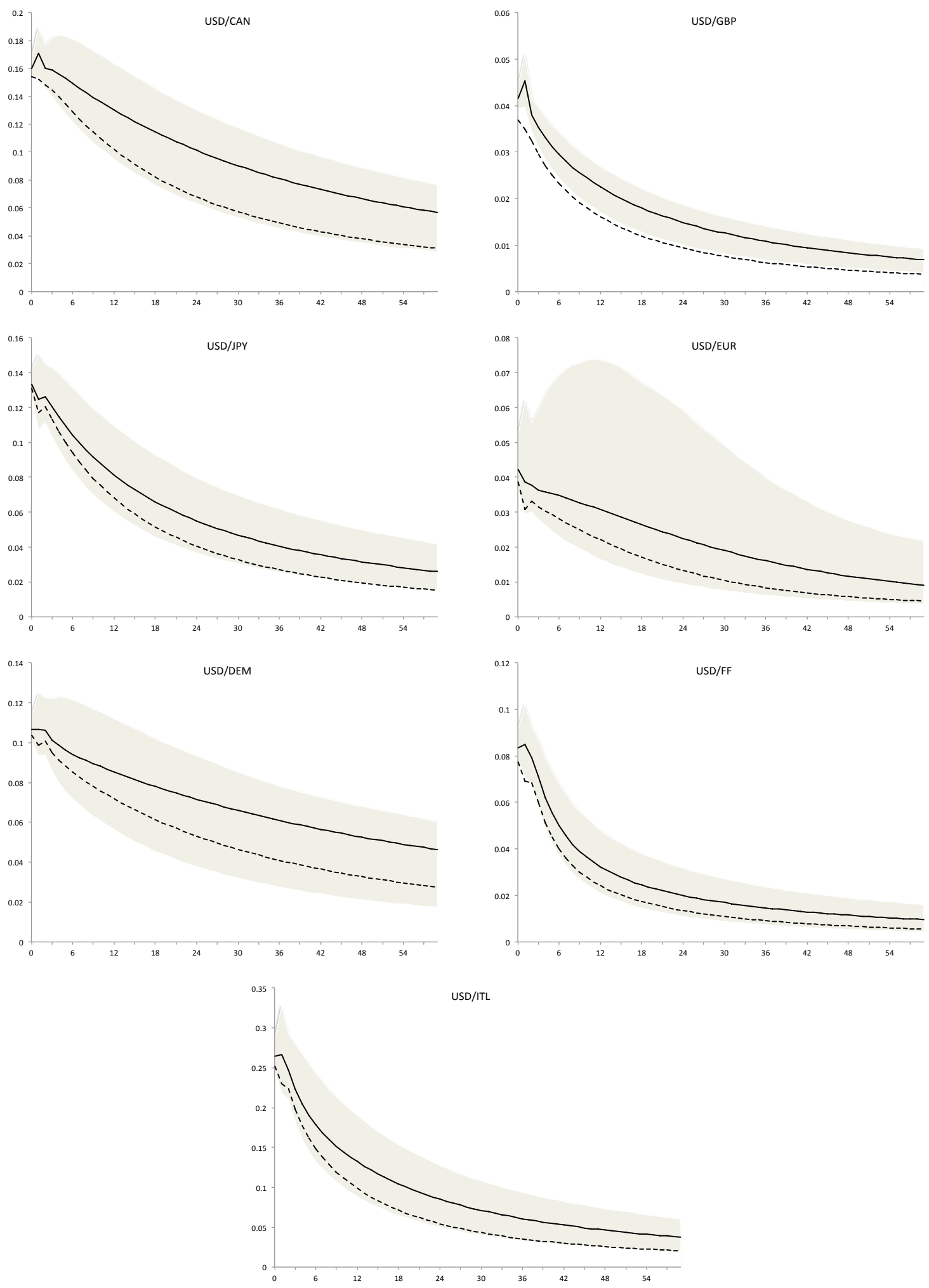

Figure 1: Plots of $R_{h}^{\nabla r}$ (solid) and $R_{h}^{\nabla r^{\mathrm{u}}}$ (dashed). 


\subsection{The UIP Perspective}

These findings are new to the exchange-rate literature so it is useful to place them in perspective relative to the well-known results on Uncovered Interest Parity (UIP). In particular, the results in Table 2 compliment the information contained in regressions of real depreciation rates on real interest differentials. To see why, consider the regression of the future one-period depreciation rate on the current differential; i.e., the Fama (1984) regression for real rates:

$$
\Delta \varepsilon_{t+1}=\beta_{0}+\beta_{1}\left(r_{t}-\hat{r}_{t}\right)+u_{t+1}
$$

Using the decomposition of the depreciation rate in (6) (with $h=1$ ), we can compute the population values of $\beta_{1}$ and the regression $R^{2}$ statistic as

$$
\beta_{1}=1+\frac{\mathbb{C V}\left(\zeta_{t+1}, r_{t}-\hat{r}_{t}\right)}{\mathbb{V}\left(r_{t}-\hat{r}_{t}\right)}
$$

and

$$
R^{2}=\beta_{1}^{2} \frac{\mathbb{V}\left(\nabla r_{t, 1}^{\mathrm{E}}\right)}{\mathbb{V}\left(\nabla r_{t, 1}^{\mathrm{E}}+\nabla r_{t+1}^{\mathrm{U}}\right)} \frac{\mathbb{V}\left(\nabla r_{t, 1}^{\mathrm{E}}+\nabla r_{t+1}^{\mathrm{U}}\right)}{\mathbb{V}\left(\Delta \varepsilon_{t+1}\right)}=\beta_{1}^{2}\left(\frac{\mathcal{R}_{1}^{\nabla r^{\mathrm{E}}}}{\mathcal{R}_{1}^{\nabla r}}\right) \mathcal{R}_{1}^{\nabla r}
$$

Consider the expression for $\beta_{1}$ in equation (10). Under rational expectations $\mathbb{C V}\left(\zeta_{t+1}, r_{t}-\hat{r}_{t}\right)=$ $\mathbb{C V}\left(\delta_{t}, r_{t}-\hat{r}_{t}\right)$, so $\beta_{1}$ differs from one when the current risk premium is correlated with the interest differential. Understanding the source of this correlation is the focus of recent research on the origins of real UIP deviations (see, e.g., Verdelhan, 2010). The role of the variance ratios is displayed in equation (11). Here we see that a low $R^{2}$ reflects a combination of three factors: a small absolute value for $\beta_{1}$; a low ratio for $\mathcal{R}_{1}^{\nabla r^{\mathrm{E}}} / \mathcal{R}_{1}^{\nabla r}$; and a small value for $\mathcal{R}_{1}^{\nabla r}$. Obviously, information on $\beta_{1}$ is available from estimating (9), but beyond that we cannot interpreted the value for $R^{2} / \beta_{1}^{2}$. To illustrate, suppose that the estimated value for $R^{2}$ is small (e.g. $<0.05$ ) and we cannot reject the null that $\beta_{1}=1$. In this case, although interest differentials appear to provide unbiased forecasts of future depreciation rates, they lack significant forecasting power from an economic perspective. Is this because news concerning future interest differentials dominates variations in current differentials so that $\mathcal{R}_{1}^{\nabla r^{\mathrm{E}}} / \mathcal{R}_{1}^{\nabla r}$ is small? Or, does it reflect variations in dark matter that are uncorrelated with current differentials so that $\mathcal{R}_{1}^{\nabla r}$ is small? Estimates of the variance ratios in Table 2 allow us to answer these questions. More generally, the variance ratios provide us with information on the drivers of future depreciation rates that are uncorrelated with current interest differentials.

Table 3 reports estimates of the Fama regression in (9) for the seven currency pairs in my data sample. The real interest differential on the right-hand-side is computed as $i_{t}-\hat{i}_{t}-\tilde{\mathbb{E}}\left[\Delta p_{t+1}-\Delta \hat{p}_{t+1} \mid X_{t}\right]$, where $\tilde{\mathbb{E}}\left[\Delta p_{t+1}-\Delta \hat{p}_{t+1} \mid X_{t}\right]$ denotes the forecasts computed from the VARs. Panel A of the table reports the coefficient estimates and standard errors (in parenthesis) that account for heteroskedasticity in the regression errors and the fact that the real differential is estimated from the VAR. ${ }^{4}$ Panel B reports the p-values for

\footnotetext{
${ }^{4}$ Following Pagan (1984), I use an IV procedure akin to 2SLS to estimate (9) that accounts for sampling error in $i_{t}-\hat{i}_{t}-$ $\tilde{\mathbb{E}}\left[\Delta p_{t+1}-\Delta \hat{p}_{t+1} \mid X_{t}\right]$. This procedure replaces $i_{t}-\hat{i}_{t}-\tilde{\mathbb{E}}\left[\Delta p_{t+1}-\Delta \hat{p}_{t+1} \mid X_{t}\right]$ by $i_{t}-\hat{i}_{t}-\left[\Delta p_{t+1}-\Delta \hat{p}_{t+1}\right]$ in $(9)$ and then uses $i_{t}-\hat{i}_{t}-\tilde{\mathbb{E}}\left[\Delta p_{t+1}-\Delta \hat{p}_{t+1} \mid X_{t}\right]$ as an instrument for $i_{t}-\hat{i}_{t}-\left[\Delta p_{t+1}-\Delta \hat{p}_{t+1}\right]$. The resulting coefficient estimates are identical to OLS. The standard errors are computed from the IV procedure with the White (1980) covariance estimator that allows for the presence of heteroskedasticity.
} 
Table 3: Real UIP Regressions

\begin{tabular}{lccccccc}
\multicolumn{7}{c}{$\Delta \varepsilon_{t+1}=\beta_{0}+\beta_{1}\left(r_{t}-\hat{r}_{t}\right)+u_{t+1}$} \\
\hline \hline $\mathrm{USD} / \mathrm{FC}$ & $\mathrm{CAN}$ & $\mathrm{GBP}$ & $\mathrm{JPY}$ & $\mathrm{EUR}$ & $\mathrm{DEM}$ & $\mathrm{FF}$ & ITL \\
\hline $\mathrm{A}:$ & & & & & & & \\
$\beta_{0}$ & 0.723 & -0.354 & -1.441 & 3.851 & -3.397 & 3.598 & 1.687 \\
& $(1.048)$ & $(2.123)$ & $(2.503)$ & $(3.078)$ & $(2.351)$ & $(2.456)$ & $(4.562)$ \\
$\beta_{1}$ & 0.845 & -1.502 & 3.375 & -2.955 & 2.192 & 1.220 & -0.542 \\
& $(0.613)$ & $(0.852)$ & $(1.336)$ & $(1.797)$ & $(1.247)$ & $(1.061)$ & $(0.612)$ \\
$R^{2}$ & & & & & & & \\
& 0.041 & 0.017 & 0.014 & 0.022 & 0.019 & 0.022 & 0.045 \\
$\mathrm{~B}:$ & & & & & & & \\
$\mathrm{H}_{0}: \beta_{1}=1$ & 0.801 & 0.003 & 0.076 & 0.028 & 0.339 & 0.836 & 0.012 \\
$R^{2} / \beta_{1}^{2}$ & & & & & & & \\
$\mathcal{R}_{1}^{\nabla r^{\mathrm{E}}} / \mathcal{R}_{1}^{\nabla r}$ & 0.058 & 0.008 & 0.001 & 0.003 & 0.004 & 0.015 & 0.154 \\
$\mathcal{R}_{1}^{\nabla r}$ & 0.162 & 0.180 & 0.009 & 0.060 & 0.037 & 0.178 & 0.581 \\
& 0.042 & 0.133 & 0.042 & 0.107 & 0.084 & 0.264
\end{tabular}

Notes: Panel A reports coefficient estimates and asymptotic standard errors that account for heteroskedasticity and sample variation in the estimated real interest differential. The upper row in panel $\mathrm{B}$ reports the asymptotic p-values for the t-test of $\mathrm{H}_{0}: \beta_{1}=1$. The remaining rows decompose the $R^{2}$ statistics from the regression using the VAR ratios computed from the VARs, as reported in Table 2. Here $R_{1}^{\nabla r^{\mathrm{E}}} / R_{1}^{\nabla r}=\mathbb{V}\left(\nabla r_{t, 1}^{\mathrm{E}}\right) / \mathbb{V}\left(\nabla r_{t, 1}^{\mathrm{E}}+\nabla r_{t+1}^{\mathrm{U}}\right)$ and $R_{1}^{\nabla r}=\mathbb{V}\left(\nabla r_{t, 1}^{\mathrm{E}}+\nabla r_{t+1}^{\mathrm{U}}\right) / \mathbb{V}\left(\Delta \varepsilon_{t+1}\right)$.

the null $H_{0}: \beta_{1}=1$ and decomposes the $R^{2}$ statistics into the variance ratios as discussed above. These ratios are computed from the statistics in Table 2 for the cases where $h=1$.

Three features of Table 3 stand out. First, the estimates of $\beta_{1}$ vary considerably from currency to currency, and have comparatively large standard errors. Consequently, in three of the seven cases we cannot reject the null of $\beta_{1}=1$ at the conventional five percent level. The second feature concerns the $R^{2}$ statistics. As one would expect, they are small. Real interest differentials have little economically significant forecasting power for short-term depreciation rates. Third, the drivers of depreciation rates vary across currency pairs. In particular, the estimates of $\mathcal{R}_{h}^{\nabla r^{\mathrm{E}}} / \mathcal{R}_{h}^{\nabla r}$ are much lower for the USD/JPY, USD/EUR and USD/DEM than for the other currency pairs. In these cases the effects of news concerning future interest differentials dominates variations in current differentials. It is also striking that both $\mathcal{R}_{h}^{\nabla r^{\mathrm{E}}} / \mathcal{R}_{h}^{\nabla r}$ and $\mathcal{R}_{h}^{\nabla r}$ are extremely small in the case of the USD/EUR, the world's most actively traded currency pair. Although news about future US and EU interest rates drives the USD/EUR depreciation rate to some extent, most of the variations we observe reflect the influence of dark matter. Finally, notice that even in cases where we cannot reject the null of $\beta_{1}=1$, (i.e., for the USD/CAN, USD/DEM and USD/ITL) the values for $\mathcal{R}_{h}^{\nabla r}$ indicate that real interest differentials are far from the dominant drivers of real depreciation rates. Remember that $\beta_{1}=1$ 
under rational expectations when the risk premium is uncorrelated with the interest differential but not necessarily constant. The low values for $\mathcal{R}_{h}^{\nabla r}$ we see across all currency pairs suggest that the risk premia could be a significant driver of depreciation rates even in instances where we cannot reject $\beta_{1}=1$.

These findings compliment recent results reported by Engel (2011). He uses the accounting identity in equation (2) to study the relationship between the real interest differential and the present value of expected excess currency returns, $\mathbb{E}_{t} \sum_{i=0}^{\infty} \delta_{t+i}$, under the assumption that long-run exchange-rate expectations, $\mathbb{E}_{t} \bar{\varepsilon}$, are constant. Since $\mathbb{C V}\left(\delta_{t}, r_{t}-\hat{r}_{t}\right)$ must be negative if variations in the risk premium account for the downward bias in the estimates of $\beta_{1}$, one would expect that $\mathbb{C} \mathbb{V}\left(\mathbb{E}_{t} \sum_{i=0}^{\infty} \delta_{t+i}, r_{t}-\hat{r}_{t}\right)$ is also negative. Surprisingly, Engel's estimates of this covariance are positive, suggesting that expectations of future risk premia (i.e., $\mathbb{E}_{t} \delta_{t+i}$, for some $i>0$ ) are positively correlated with the interest differential. In contrast, my findings focus on variations in $\mathbb{E}_{t} \sum_{i=0}^{\infty} \delta_{t+i}$ that are unrelated to changes in the interest differential.

The results in Tables 2 and 3 show that real interest differentials are a rather minor driver of real depreciations rates over horizons up to five years. It appears, instead, that dark matter driving changes in long-horizon real exchange-rate expectations and variations in risk premia account for the lion's share of real exchange rate movements. This finding represents a major challenge to existing theoretical models of exchange-rate determination. Traditional macro models either assume that risk premia are constant, or are calibrated so that variations in the premia are quite minor. Thus, from the perspective of these models, the dark matter must mainly reflect variations in expectations concerning the long-term real exchange rate. Such variations could reflect Balassa-Samuelson effects (see, Balassa, 1964 and Samuelson, 1964), but if that were the case we would expect to see evidence of significant variation in the (weighted) difference between the relative prices of nontraded to traded goods across countries over long, but finite horizons. This is not what we observe. For example, Engel (1999) finds remarkably little evidence that Balassa-Samuelson type effects contribute significantly to depreciation rates at the five-year horizon. So, even if Balassa-Samuelson effects give rise to some variations in expectations concerning the long-term real exchange rate, it seems implausible to attribute all the influence of dark matter to driving such expectations.

In the remainder of this paper I pursue an alternative explanation for the findings in Tables 2 and 3. Namely, that dark matter influences exchange rates by driving variations in the risk premia. I begin this task in the next section by presenting an open-economy DSGE model in which households' preferences are subject to risk shocks that affect their degree of risk aversion (i.e., the curvature of their utility functions). These shocks represent a possible source of exchange-rate dark matter because they change the excess currency returns households expect without significantly affecting real interest differentials.

\section{The Model}

The model is designed to examine the interplay between incomplete risk-sharing and collateral constraints in a world where households' risk aversion varies stochastically. The world comprises two symmetric countries, which I refer to as the U.S. and Europe. Each country is populated by infinitely-lived households with preferences defined over the consumption of two perishable traded goods. For simplicity, there are no nontraded goods or impediments to trade in goods between the two countries. I also assume that the world 
supply of each traded good follows an exogenous endowment process, one located in each country. To this simple structure I add three key features: external habits, incomplete markets and collateral constraints. As I argued in the introduction, this combination of features is necessary to provide a rationale for the role that dark matter plays in exchange-rate determination.

\subsection{Model Details}

\section{Household Preferences}

Each country is populated by a continuum of identical households distributed on the interval $[0,1]$. Households' preferences are defined over a basket of traded consumption goods. In particular, the expected utility of a representative U.S. household $i \in[0,1]$ in period $t$ is given by

$$
\mathbb{U}_{i, t}=\mathbb{E}_{t} \sum_{j=0}^{\infty} \beta^{j} \mathcal{U}\left(C_{i, t+j}, H_{t+j}\right), \quad \text { with } \quad \mathcal{U}\left(C_{i, t}, H_{t}\right)=\frac{1}{1-\gamma}\left\{\left(C_{i, t}-H_{t}\right)^{1-\gamma}-1\right\}
$$

where $1>\beta>0, \gamma>0$ and $\mathbb{E}_{t}$ denotes expectations conditioned on period- $t$ information, which is common to all U.S. and E.U. households. Each household's sub-utility $\mathcal{U}\left(C_{i, t}, H_{t}\right)$ depends on current consumption, $C_{i, t}$, and the subsistence level of consumption, or external habit level, $H_{t}$. The habit level is treated as exogenous by individual households but varies with past aggregate U.S. consumption via an autoregressive process for the $\log$ surplus ratio, $s_{t}=\ln \left(S_{t}\right)$, with $S_{t}=\left(C_{t}-H_{t}\right) / C_{t}$ :

$$
s_{t+1}=(1-\phi) \bar{s}+\phi s_{t}+\omega\left(s_{t}\right) v_{t+1},
$$

where $1>\phi>0$ and $\bar{s}$ is the steady state value of $s_{t}$. The i.i.d. mean-zero, unit variance $v_{t+1}$ shocks affect the surplus ratio via a non-negative sensitivity function $\omega\left(s_{t}\right)$, which I discuss below. Notice that $H_{t}=\left[1-\exp \left(s_{t}\right)\right] C_{t}$ so negative $v_{t}$ shocks raise habit relative to current aggregate consumption, but they cannot push habit above current consumption. In the CC habit specification, the $v_{t}$ shocks are identified by shocks to the endowment process for aggregate consumption. Here aggregate consumption in each country comprises an basket of traded goods that are optimally chosen by households. I therefore treat shocks to the surplus ratio process as exogenous, and derive the correlation between $s_{t}$ and aggregate consumption as part of the equilibrium.

The U.S. consumption basket comprises U.S. and E.U. traded goods:

$$
C_{i, t}=\mathcal{C}\left(C_{i, t}^{\mathrm{US}}, C_{i, t}^{\mathrm{EU}}\right)=\left(\eta^{\frac{1}{\theta}} C_{i, t}^{\mathrm{US}} \frac{\theta-1}{\theta}+(1-\eta)^{\frac{1}{\theta}} C_{i, t}^{\mathrm{EU}} \frac{\theta-1}{\theta}\right)^{\frac{\theta}{\theta-1}}
$$

where $C_{i, t}^{\mathrm{US}}$ and $C_{i, t}^{\mathrm{EU}}$ identify the consumption of U.S. and E.U. goods by U.S. household $i$. The parameter $\eta \in(0,1)$ governs the desired share of each good in the basket and $\theta$ is the elasticity of substitution between goods. I follow standard practice in the literature and focus on the case where $\eta>1 / 2$, so that households' preferences exhibit consumption home-bias. 
E.U. household $i \in[0,1]$ has analogous preferences:

$$
\widehat{\mathbb{U}}_{i, t}=\mathbb{E}_{t} \sum_{j=0}^{\infty} \beta^{j} \mathcal{U}\left(\hat{C}_{i, t+j}, \hat{H}_{t+j}\right)
$$

defined on the gap between the foreign consumption basket, $\hat{C}_{i, t}$, and habit, $\hat{H}_{t}$, where

$$
\hat{C}_{i, t}=\mathcal{C}\left(\hat{C}_{i, t}^{\mathrm{EU}}, \hat{C}_{i, t}^{\mathrm{US}},\right)=\left(\eta^{\frac{1}{\theta}} \hat{C}_{i, t}^{\mathrm{EU}} \frac{\theta-1}{\theta}+(1-\eta)^{\frac{1}{\theta}} \hat{C}_{i, t}^{\mathrm{Us}} \frac{\theta-1}{\theta}\right)^{\frac{\theta}{\theta-1}}
$$

The log surplus ratio, $\hat{s}_{t}=\ln \hat{S}_{t}$, with $\hat{S}_{t}=\left(\hat{C}_{t}-\hat{H}_{t}\right) / \hat{C}_{t}$, follows

$$
\hat{s}_{t+1}=(1-\phi) \bar{s}+\phi \hat{s}_{t}+\omega\left(\hat{s}_{t}\right) \hat{v}_{t+1},
$$

where $\hat{v}_{t+1}$ are i.i.d. mean-zero, unit variance shocks.

Shocks to the surplus ratios affect the local curvature of households' utility functions. In particular, for a representative U.S. and E.U household

$$
-\frac{C_{i, t} \mathcal{U}_{c}\left(C_{i, t}, H_{t}\right)}{\mathcal{U}_{c c}\left(C_{i, t}, H_{t}\right)}=\gamma \exp \left(-s_{t}\right) \quad \text { and } \quad-\frac{\hat{C}_{i, t} \mathcal{U}_{c}\left(\hat{C}_{i, t}, \hat{H}_{t}\right)}{\mathcal{U}_{c c}\left(\hat{C}_{i, t}, \hat{H}_{t}\right)}=\gamma \exp \left(-\hat{s}_{t}\right) .
$$

Thus negative shocks to the log surplus ratios in (13) and (17) increase the local curvature making households more risk-averse, ceteris paribus. Hereafter, I therefore refer to $v_{t}$ and $\hat{v}_{t}$ as risk shocks. Following CC, I assume that the sensitivity function, $\omega($.$) , is decreasing in the surplus ratio:$

$$
\omega(\mathrm{s})=\left\{\begin{array}{cc}
\sqrt{\omega\left(s_{\max }-\mathrm{s}\right)} & \mathrm{s} \leq s_{\max } \\
0 & \mathrm{~s}>s_{\max }
\end{array}\right.
$$

where $\omega$ is a positive parameter. In the continuous time limit, $s_{t}$ and $\hat{s}_{t}$ never exceed the upper bound of $s_{\max }$, so there is a corresponding lower limit on households' risk-aversion.

\section{Prices and Exchange Rates}

I focus on two international relative prices: the terms of trade and the real exchange rate. These prices are linked through the consumption price indices in each country. Let $P_{t}^{\mathrm{us}}$ and $P_{t}^{\mathrm{EU}}$ denote the prices of the U.S. and E.U. goods in dollars, while $\hat{P}_{t}^{\mathrm{us}}$ and $\hat{P}_{t}^{\mathrm{EU}}$ denote their prices in euros, respectively. The U.S. and E.U. price indices corresponding to the consumption baskets in (14) and (16) are

$$
P_{t}=\left(\eta\left(P_{t}^{\mathrm{US}}\right)^{1-\theta}+(1-\eta)\left(P_{t}^{\mathrm{EU}}\right)^{1-\theta}\right)^{\frac{1}{1-\theta}} \quad \text { and } \quad \hat{P}_{t}=\left(\eta\left(\hat{P}_{t}^{\mathrm{EU}}\right)^{1-\theta}+(1-\eta)\left(\hat{P}_{t}^{\mathrm{US}}\right)^{1-\theta}\right)^{\frac{1}{1-\theta}} .
$$

The real exchange rate is defined as the relative price of the E.U. consumption basket in terms of the U.S. basket, $\mathcal{E}_{t}=\mathcal{S}_{t} \hat{P}_{t} / P_{t}$, where $\mathcal{S}_{t}$ denotes the dollar price of euros. There are no impediments to international trade between the U.S. and the E.U. so the law of one price applies to both the U.S. and E.U. goods: i.e., 
$P_{t}^{\mathrm{us}}=\mathcal{S}_{t} \hat{P}_{t}^{\mathrm{us}}$ and $P_{t}^{\mathrm{EU}}=\mathcal{S}_{t} \hat{P}_{t}^{\mathrm{EU}}$. Combining these expressions with the definitions of the real exchange rate and the price indices gives

$$
\mathcal{E}_{t}=\left(\frac{\eta \mathcal{T}_{t}^{1-\theta}+(1-\eta)}{\eta+(1-\eta) \mathcal{T}_{t}^{1-\theta}}\right)^{\frac{1}{1-\theta}}
$$

where $\mathcal{T}_{t}$ is the U.S. terms of trade, defined as the relative price of imports in terms of exports, $P_{t}^{\mathrm{EU}} / P_{t}^{\mathrm{US}}$. When there is home bias in consumption $(\eta>1 / 2)$, a deterioration in the U.S. terms of trade (i.e. a rise in $\mathcal{T}_{t}$ ) is associated with a real depreciation of the dollar (i.e. a rise in $\mathcal{E}_{t}$ ).

Equation (18) makes clear that the model attributes all variations in real exchange rates to changes in the relative prices of traded goods via the terms of trade. This implication of the model is consistent with the data. When real exchange rates are computed from retail prices, almost all the variations in real depreciation rates originate from changes in the relative prices of traded goods rather than changes in the difference between the relative prices of traded and nontraded goods across countries at horizons of five years or less (Engel, 1999). Thus, the exclusion of nontraded goods from the model will not materially impair its ability to account for the short- and medium-term dynamics of real depreciation rates. Equation (18) also implies that the real depreciation rate is strongly correlated with changes in the terms of trade when there is home bias in consumption. This implication is also consistent with the data. Real depreciation rates are very strongly correlated with changes in terms of trade over short horizons (see, e.g., Evans, 2011).

\section{Assets and Goods Markets}

There are four financial markets: a market for U.S. equities, E.U. equities, U.S. bonds and E.U. bonds. U.S. equity represents a claim on the stream of U.S. good endowments. In particular, at the start of period $t$, the holder of one share of U.S. equity receives a dividend of $D_{t}=\left(P_{t}^{\mathrm{us}} / P_{t}\right) Y_{t}$, where $Y_{t}$ is the endowment of the U.S. good, measured in terms of the U.S. consumption basket. The ex-dividend price of U.S. equity in period $t$ is $Q_{t}$, again measured in terms of U.S. consumption. A share of E.U. equity pays a period- $t$ dividend of $\hat{D}_{t}=\left(\hat{P}_{t}^{\mathrm{EU}} / \hat{P}_{t}\right) \hat{Y}_{t}$ and has an ex-dividend price of $\hat{Q}_{t}$, where $\hat{Y}_{t}$ is the period- $t$ endowment of the E.U. good. Notice that $\hat{Q}_{t}$ and $\hat{D}_{t}$ are measured relative to the E.U. consumption basket. Households can also hold one-period real U.S. and E.U. bonds. The gross return on holding U.S. bonds between periods $t$ and $t+1$ is $R_{t}$, measured in terms of U.S. consumption; the analogous return on E.U. bonds is $\hat{R}_{t}$, measured in terms of E.U. consumption.

Households face restrictions on their asset holdings: U.S. households are prohibited from holding shares of E.U. equity, and E.U. households are prohibited from holding U.S. equity. In addition to their holdings of domestic equity, households can hold domestic and foreign bonds subject to a collateral constraint (discussed below). Let $B_{i, t}^{\mathrm{US}}, B_{i, t}^{\mathrm{EU}}$ and $A_{i, t}^{\mathrm{US}}$ respectively denote the number of U.S. bonds, E.U. bonds and the number of shares of U.S. equity held by U.S. household $i$ in period $t$. The budget constraint facing the household is

$$
B_{i, t}^{\mathrm{US}}+\mathcal{E}_{t} B_{i, t}^{\mathrm{EU}}+Q_{t} A_{i, t}^{\mathrm{US}}+C_{i, t}=R_{t-1} B_{i, t-1}^{\mathrm{US}}+\mathcal{E}_{t} \hat{R}_{t-1} B_{i, t-1}^{\mathrm{EU}}+A_{i, t-1}^{\mathrm{US}}\left(Q_{t}+D_{t}\right) .
$$


The budget constraint facing a typical E.U. household is

$$
\hat{B}_{i, t}^{\mathrm{US}} / \mathcal{E}_{t}+\hat{B}_{i, t}^{\mathrm{EU}}+\hat{Q}_{t} \hat{A}_{i, t}^{\mathrm{EU}}+\hat{C}_{i, t}=R_{t-1} \hat{B}_{i, t-1}^{\mathrm{US}} / \mathcal{E}_{t}+\hat{R}_{t-1} \hat{B}_{i, t-1}^{\mathrm{EU}}+\hat{A}_{i, t-1}^{\mathrm{EU}}\left(\hat{Q}_{t}+\hat{D}_{t}\right),
$$

where $\hat{B}_{i, t}^{\mathrm{US}}, \hat{B}_{i, t}^{\mathrm{EU}}$ and $\hat{A}_{i, t}^{\mathrm{EU}}$ respectively denote the number of U.S. bonds, E.U. bonds and the number of shares of E.U. equity held by E.U. household $i$ in period $t$.

The asset market clearing conditions are straightforward. Both U.S. and E.U bonds are in zero net supply so the bond market clearing conditions are

$$
0=\int_{0}^{1} B_{i, t}^{\mathrm{US}} d i+\int_{0}^{1} \hat{B}_{i, t}^{\mathrm{US}} d i \quad \text { and } \quad 0=\int_{0}^{1} B_{i, t}^{\mathrm{EU}} d i+\int_{0}^{1} \hat{B}_{i, t}^{\mathrm{EU}} d i
$$

The supplies of the U.S. and E.U. equities are normalized to one, so market clearing requires that

$$
1=\int_{0}^{1} A_{i, t}^{\mathrm{US}} d i \quad \text { and } \quad 1=\int_{0}^{1} \hat{A}_{i, t}^{\mathrm{EU}} d i
$$

\section{Household Decision-Making}

Households choose consumption and their portfolios to maximize expected utility subject to the budget constraint and a collateral constraint that prevents the use of Ponzi-schemes in international debt markets. For the case of U.S. household $i$, the constraint takes the form of a lower bound on U.S. bond holdings:

$$
B_{i, t}^{\mathrm{US}} \geq-(1+\varkappa) \mathcal{E}_{t} B_{i, t}^{\mathrm{EU}},
$$

where $\varkappa>0$. The constraint implies that U.S. households can borrow in the domestic bond market up to the point where the real vale of their debt is $(1+\varkappa)$ times the value of their foreign bond holdings. The constraint facing E.U. household $i$ takes an analogous form:

$$
\hat{B}_{i, t}^{\mathrm{EU}} \geq-(1+\varkappa) \hat{B}_{i, t}^{\mathrm{US}} / \mathcal{E}_{t} .
$$

Market clearing in the goods markets requires that aggregate demand from U.S. and E.U. households matches the world endowment of each traded good:

$$
Y_{t}=\int_{0}^{1} C_{i, t}^{\mathrm{US}} d i+\int_{0}^{1} \hat{C}_{i, t}^{\mathrm{US}} d i \quad \text { and } \quad \hat{Y}_{t}=\int_{0}^{1} C_{i, t}^{\mathrm{EU}} d i+\int_{0}^{1} \hat{C}_{i, t}^{\mathrm{EU}} d i
$$

I assume that the $\log$ endowments, $y_{t}=\ln Y_{t}$ and $\hat{y}_{t}=\ln \hat{Y}_{t}$, follow non-stationary unit root processes:

$$
\begin{array}{rll}
y_{t}=\mathfrak{T}_{t}+z_{t} & \text { and } & \hat{y}_{t}=\mathfrak{T}_{t}+\hat{z}_{t}, \quad \text { with } \\
\mathfrak{T}_{t}=\mathfrak{T}_{t-1}+g+u_{t}, & z_{t}=\rho z_{t-1}+e_{t} & \text { and } \quad \hat{z}_{t}=\rho \hat{z}_{t-1}+\hat{e}_{t} .
\end{array}
$$

Here $\mathfrak{T}_{t}$ identifies the stochastic trend, while $z_{t}$ and $\hat{z}_{t}$ denote the cyclical components that follow $\operatorname{AR}(1)$ processes with $1>\rho>0$. The three endowment shocks, $u_{t}, e_{t}$ and $\hat{e}_{t}$ are mutually uncorrelated mean-zero 
normal random variables, with variances $\sigma_{u}^{2}, \sigma_{e}^{2}$ and $\sigma_{e}^{2}$, respectively. In the absence of any shocks, both endowments grow at rate $g$.

The constraints in (23) and (24) have several noteworthy implications. First, they do not limit the total amount of borrowing by any household. For example, (23) implies an upper bound of $\varkappa \mathcal{E}_{t} B_{i, t}^{\mathrm{EU}}$ on the value of net international debt held by a U.S. household, rather than a hard borrowing limit. Second, the constraints do not restrict households' choice of debt instrument until they bind. For example, U.S. household can borrow by selling either U.S. or E.U. bonds while $B_{i, t}^{\mathrm{US}}+(1+\varkappa) \mathcal{E}_{t} B_{i, t}^{\mathrm{EU}}>0 .{ }^{5}$ Note, however, that (23) and (24) do exclude the possibility of using equity as collateral. Since households are precluded from holding foreign equity in this simple model, it makes little sense for them to accept foreign equity as collateral when lending internationally.

It proves useful to express the consumption and portfolio decisions facing households in terms of portfolio shares and financial wealth. Let $W_{i, t}$ denote the real wealth of U.S. household $i$ at the start of period $t$ and let $\alpha_{i, t}^{\mathrm{EQ}}$ and $\alpha_{i, t}^{\mathrm{FB}}$ identify the fraction of wealth held in domestic equity and foreign bonds at the end of period $t$ :

$$
\alpha_{i, t}^{\mathrm{EQ}}=Q_{t} A_{i, t}^{\mathrm{US}} /\left(W_{i, t}-C_{i, t}\right) \quad \text { and } \quad \alpha_{i, t}^{\mathrm{FB}}=\mathcal{E}_{t} B_{i, t}^{\mathrm{EU}} /\left(W_{i, t}-C_{i, t}\right) .
$$

The problem facing U.S. household $i$ may now be written as

$$
\begin{aligned}
& \operatorname{Max}_{\left\{C_{i, t}^{\mathrm{US}}, C_{i, t}^{\mathrm{EU}}, \alpha_{i, t}^{\mathrm{EQ}}, \alpha_{i, t}^{\mathrm{EB}}\right\}} \mathbb{E}_{t} \sum_{j=0}^{\infty} \beta^{j} \mathcal{U}\left(\mathcal{C}\left(C_{i, t+j}^{\mathrm{US}}, C_{i, t+j}^{\mathrm{EU}}\right), H_{t+j}\right) \\
& \text { s.t. } W_{i, t+1}=R_{i, t+1}^{\mathrm{W}}\left(W_{i, t}-C_{i, t}\right) \quad \text { and } \\
& N_{i, t}=\left(1-\alpha_{i, t}^{\mathrm{EQ}}+\varkappa \alpha_{i, t}^{\mathrm{FB}}\right)\left(W_{i, t}-C_{i, t}\right) \geq 0 .
\end{aligned}
$$

Equation (27b) rewrites the budget constraint in terms of wealth and the real return on the households' portfolio:

$$
R_{i, t+1}^{\mathrm{W}}=R_{t}+\alpha_{i, t}^{\mathrm{EQ}}\left(R_{t+1}^{\mathrm{EQ}}-R_{t}\right)+\alpha_{i, t}^{\mathrm{FB}}\left(\left(\mathcal{E}_{t+1} / \mathcal{E}_{t}\right) \hat{R}_{t}-R_{t}\right)
$$

where $R_{t+1}^{\mathrm{EQ}}=\left(Q_{t+1}+D_{t+1}\right) / Q_{t}$ is the real return on U.S. equity. Equation (27c) rewrites the collateral restriction in (23) using the portfolio shares.

The problem facing E.U. household $i$ is analogous:

$$
\begin{array}{ll} 
& \operatorname{Max}_{\left\{\hat{C}_{i, t}^{\mathrm{US}}, \hat{C}_{i, t}^{\mathrm{Eu}}, \hat{\alpha}_{i, t}^{\mathrm{EQ}}, \hat{\alpha}_{i, t}^{\mathrm{EB}}\right\}} \mathbb{E}_{t} \sum_{j=0}^{\infty} \beta^{j} \mathcal{U}\left(\mathcal{C}\left(\hat{C}_{i, t+j}^{\mathrm{EU}}, \hat{C}_{i, t+j}^{\mathrm{US}}\right), \hat{H}_{t+j}\right) \\
\text { s.t. } & \hat{W}_{i, t+1}=\hat{R}_{i, t+1}^{\mathrm{W}}\left(\hat{W}_{i, t}-\hat{C}_{i, t}\right) \quad \text { and } \\
& \hat{N}_{i, t}=\left(1-\hat{\alpha}_{i, t}^{\mathrm{EQ}}+\varkappa \hat{\alpha}_{i, t}^{\mathrm{FB}}\right)\left(\hat{W}_{i, t}-\hat{C}_{t}\right) \geq 0 .
\end{array}
$$

Here $\hat{\alpha}_{i, t}^{\mathrm{EQ}}$ and $\hat{\alpha}_{i, t}^{\mathrm{FB}}$ are the fractions of wealth invested in E.U. equity and foreign (i.e., U.S.) bonds:

$$
\hat{\alpha}_{i, t}^{\mathrm{EQ}}=\hat{Q}_{t} \hat{A}_{i, t}^{\mathrm{EU}} /\left(\hat{W}_{i, t}-\hat{C}_{i, t}\right) \quad \text { and } \quad \hat{\alpha}_{i, t}^{\mathrm{FB}}=\left(\hat{B}_{i, t}^{\mathrm{US}} / \mathcal{E}_{t}\right)\left(\hat{W}_{i, t}-\hat{C}_{i, t}\right),
$$

\footnotetext{
${ }^{5}$ In equilibrium households borrow by selling domestic bonds, so $B_{i, t}^{\mathrm{US}}<0$ and $\hat{B}_{i, t}^{\mathrm{EU}}<0$.
} 
$\hat{W}_{i, t}$ is real wealth (measured in terms of E.U. consumption) at the start of period $t$, and $\hat{R}_{i, t+1}^{\mathrm{w}}$ is the real return on the household's portfolio:

$$
\hat{R}_{i, t+1}^{\mathrm{W}}=\hat{R}_{t}+\hat{\alpha}_{i, t}^{\mathrm{EQ}}\left(\hat{R}_{t+1}^{\mathrm{EQ}}-\hat{R}_{t}\right)+\hat{\alpha}_{i, t}^{\mathrm{FB}}\left(\left(\mathcal{E}_{t} / \mathcal{E}_{t+1}\right) R_{t}-\hat{R}_{t}\right)
$$

with $\hat{R}_{t+1}^{\mathrm{EQ}}=\left(\hat{Q}_{t+1}+\hat{D}_{t+1}\right) / \hat{Q}_{t}$.

Since households within each country have the same preferences and face the same constraints, we can focus on the behavior of a representative U.S. and E.U. household without loss of generality. Hereafter, I drop the $i$ subscripts on consumption and the portfolio shares to simplify notation.

\subsection{Equilibrium}

An equilibrium comprises a sequence for the real exchange rate $\left\{\mathcal{E}_{t}\right\}$, real interest rates $\left\{R_{t}\right.$ and $\left.\hat{R}_{t}\right\}$, and equity returns $\left\{R_{t}^{\mathrm{EQ}}\right.$ and $\left.\hat{R}_{t}^{\mathrm{EQ}}\right\}$, consistent with market clearing in the goods and asset markets given the optimal consumption and portfolio decisions of households and the exogenous endowments. In this model finding the equilibrium processes for $\left\{\mathcal{E}_{t}, R_{t}, \hat{R_{t}}, R_{t}^{\mathrm{EQ}}\right.$ and $\left.\hat{R}_{t}^{\mathrm{EQ}}\right\}$ is complicated by the presence of incomplete markets, portfolio choice, and occasionally binding collateral constraints. This combination of features precludes the use of standard solution methods, so I develop a new procedure that combines barrier methods with second-order approximations around the model's stochastic steady state. This section provides an overview of the solution procedure. A more complete description of how I solve for the equilibrium is contained in the appendix.

\section{Barrier Methods}

Barrier methods are widely used in the optimal control literature to solve optimization problems involving inequality constraints (see Forsgren Anders and Wright, 2002). The basic idea is to modify the objective function so that the optimizing agent is penalized as his actions bring him closer to the barrier described by the inequality constraint. The advantage of this approach is that it converts the original optimization problem with inequality constraints into one with only equality constraints. I then use a set of second-order approximations to solve for the equilibrium exchange-rate and return processes that clear markets given the consumption and portfolio decisions of households from the modified optimization problems. Preston and Roca (2007) and Kim, Kollmann, and Kim (2010) use barrier methods in this way to solve incomplete markets' models with heterogenous agents. Here I extend the approach to solve a model that also includes portfolio choice.

Following Kim, Kollmann, and Kim (2010), I modify the sub-utility functions for the representative U.S. 
and E.U. households to

$$
\mathcal{U}\left(C_{t}, H_{t}, N_{t}\right)=\frac{1}{1-\gamma}\left\{\left(C_{t}-H_{t}\right)^{1-\gamma}-1\right\}+\frac{\mu \bar{N}_{t}}{\left(\bar{C}_{t} \bar{S}\right)^{\gamma}}\left\{\ln \left(\frac{N_{t}}{\bar{N}_{t}}\right)-\left(\frac{N_{t}-\bar{N}_{t}}{\bar{N}_{t}}\right)\right\}
$$

and

$$
\mathcal{U}\left(\hat{C}_{t}, \hat{H}_{t}, \hat{N}_{t}\right)=\frac{1}{1-\gamma}\left\{\left(\hat{C}_{t}-\hat{H}_{t}\right)^{1-\gamma}-1\right\}+\frac{\mu \bar{N}_{t}}{\left(\bar{C}_{t} \bar{S}\right)^{\gamma}}\left\{\ln \left(\frac{\hat{N}_{t}}{\bar{N}_{t}}\right)-\left(\frac{\hat{N}_{t}-\bar{N}_{t}}{\bar{N}_{t}}\right)\right\}
$$

where $\mu>0$ and bars denote the values of variables in the steady state (defined below). These modifications penalize households as their portfolio choices bring them closer to their respective collateral constraints. In particular, as U.S. households' bond holdings close in on the point where the constraint binds, $N_{t}=$ $\left(1-\alpha_{t}^{\mathrm{EQ}}+\varkappa \alpha_{t}^{\mathrm{FB}}\right)\left(W_{t}-C_{t}\right)$ nears zero, and the last term on the right-hand-side of (31a) approaches its limiting value of $-\infty$. Similarly, the last term in (31b) approaches $-\infty$ when E.U. households near the point where their collateral constraint binds. The term preceding $\{$.$\} governs the rate at with the utility cost rise$ as the household approaches the collateral constraint. In particular, small values for the barrier parameter $\mu$ imply that the costs only become significant in a close neighborhood of the constraint. Notice, also, that both terms in parentheses disappear when bond holdings are at their steady state values.

We can understand how these modifications affect households' decision-making by comparing the firstorder conditions from the original optimization problems with those from maximizing (12) subject to (27b) with $\mathcal{U}\left(C_{i, t}, H_{t}, N_{i, t}\right)$ replacing $\mathcal{U}\left(C_{i, t}, H_{t}\right)$ and those from maximizing (15) subject to (29b) with $\mathcal{U}\left(\hat{C}_{i, t}, \hat{H}_{t}, \hat{N}_{i, t}\right)$ replacing $\mathcal{U}\left(\hat{C}_{i, t}, \hat{H}_{t}\right)$. Both sets of first-order conditions for a typical U.S. household can be written as

$$
\begin{aligned}
& 1=\beta \mathbb{E}_{t}\left[\left(\frac{C_{t+1}}{C_{t}}\right)^{-\gamma}\left(\frac{S_{t+1}}{S_{t}}\right)^{-\gamma} R_{t+1}^{\mathrm{EQ}}\right] \\
& 1=\beta \mathbb{E}_{t}\left[\left(\frac{C_{t+1}}{C_{t}}\right)^{-\gamma}\left(\frac{S_{t+1}}{S_{t}}\right)^{-\gamma} \frac{\mathcal{E}_{t+1} \hat{R}_{t}}{\mathcal{E}_{t}}\right]+(1+\varkappa) \mathcal{B}_{t} \quad \text { and } \\
& 1=\beta \mathbb{E}_{t}\left[\left(\frac{C_{t+1}}{C_{t}}\right)^{-\gamma}\left(\frac{S_{t+1}}{S_{t}}\right)^{-\gamma} R_{t}\right]+\mathcal{B}_{t} .
\end{aligned}
$$

When the first-order conditions are computed from the original U.S. household's problem in (27), $\mathcal{B}_{t}=$ $C_{t}^{\gamma} S_{t}^{\gamma} \mathcal{L}_{t}$, where $\mathcal{L}_{t}$ is the Lagrange multiplier on the collateral constraint in $(27 \mathrm{c})$. Thus, $\mathcal{B}_{t}$ is positive if and only if the U.S. constraint in (23) binds (i.e., when $N_{t}=0$ ). The first-order conditions from the modified optimization problem also take the form of (32) with

$$
\mathcal{B}_{t}=\mu\left(\frac{C_{t} S_{t}}{\left.\overline{C_{t}}\right)^{\gamma}}\right)^{\gamma}\left\{\frac{\bar{N}_{t}}{N_{t}}-1\right\}
$$

Note that $\mathcal{B}_{t} \rightarrow \infty$ as $N_{t}$ approaches zero for any positive value of $\mu$; that is as the household moves closer to the point where the collateral constraint binds. Thus, in contrast to the original problem, the optimal bond holdings in the modified problem are chosen so that the constraint never actually binds. The importance of this distinction depends on the size of the barrier parameter, $\mu$. In particular, if we consider a sequence of 
solutions to the modified problem as $\mu$ takes smaller and smaller values, the sequence will converge to the solution of the original problem in the limit as $\mu \rightarrow 0$ (see, e.g., Forsgren Anders and Wright, 2002). I will examine the robustness of the models' equilibrium properties to alternative choices for $\mu$ that are close to zero.

\section{Approximations}

I use a set of second-order approximations to the households' first-order conditions from the modified optimization problems and the market clearing conditions to find the equilibrium process for the real exchange rate, real interest rates, and other endogenous variables. In some models, incomplete risk-sharing induces non-stationary dynamics in household wealth so there is no unique non-stochastic steady state to use as an approximation point. ${ }^{6}$ Here I use the stochastic steady state. This is the point at which the exogenous surplus ratios, $s_{t}$ and $\hat{s}_{t}$, equal their long run value of $\bar{s}$, and the cyclical components in the endowment processes, $z_{t}$ and $\hat{z}_{t}$, equal zero so the endowments of U.S. and E.U. goods are equal and follow the stochastic trend (i.e., $y_{t}=\hat{y}_{t}=\mathfrak{T}_{t}$ ). Under these circumstances, households expect both endowments to grow at rate $g$, (i.e., $\mathbb{E}_{t} \Delta y_{t+i}=\mathbb{E}_{t} \Delta \hat{y}_{t+i}=g$, for all $i>0$ ), but they do not expect any future changes in the surplus ratios (i.e., $\mathbb{E}_{t} s_{t+i}=\mathbb{E}_{t} \hat{s}_{t+i}=\bar{s}$ for all $i>0$ ). Importantly, households also recognize that future endowments and surplus ratios are subject to shocks. It is this recognition that future shocks will affect the exogenous processes that differentiates the stochastic steady state from its conventional non-stochastic counterpart.

Beyond its conceptual appeal, the use of the stochastic steady state has two technical advantages. First, it allows us to identify a point around which to approximate the equilibrium dynamics without any further embellishment to the model. ${ }^{7}$ Second, it identifies the steady state portfolio allocations because assets do not have the same riskless return. I discuss these aspects of the solution procedure below.

The Stochastic Steady State To identify the stochastic steady state (hereafter, just the "steady state"), I focus four equilibrium conditions: the first-order conditions determining households' bond holdings, and the goods market clearing conditions. Combining the first-order conditions for E.U. bonds to eliminate the real interest rate, ignoring the Lagrange multipliers and simplifying, we find that

$$
\begin{aligned}
\varepsilon_{t}=\ln \mathbb{E}_{t}\left[\exp \left(\Delta c y_{t+1}+\Delta s_{t+1}+\Delta z_{t+1}\right)^{-\gamma} \exp \left(\varepsilon_{t+1}\right)\right] & \\
& -\ln \mathbb{E}_{t}\left[\exp \left(\Delta \hat{c} \hat{y}_{t+1}+\Delta \hat{s}_{t+1}+\Delta \hat{z}_{t+1}\right)^{-\gamma}\right]
\end{aligned}
$$

where $c y_{t}=c_{t}-y_{t}$ and $c \hat{y}_{t}=\hat{c}_{t}-\hat{y}_{t}$. Similarly, the first-order conditions for U.S. bonds imply that

$$
\begin{aligned}
\varepsilon_{t}=\ln \mathbb{E}_{t}\left[\exp \left(\Delta c y_{t+1}+\Delta s_{t+1}+\Delta z_{t+1}\right)^{-\gamma}\right] & \\
& -\ln \mathbb{E}_{t}\left[\exp \left(\Delta \hat{y}_{t+1}+\Delta \hat{s}_{t+1}+\Delta \hat{z}_{t+1}\right)^{-\gamma} \exp \left(-\varepsilon_{t+1}\right)\right] .
\end{aligned}
$$

\footnotetext{
${ }^{6}$ See Obstfeld and Rogoff (1996), Baxter, Jermann, and King (1998), Engel and Matsumoto (2009), and Kollmann (2006).

${ }^{7}$ Embellishments for inducing stationarity include the introduction of endogenous discounting in households' preferences, asset-holding costs and (ad hoc) debt-elastic interest rates, as discussed in Schmitt-Grohe and Uribe (2003).
} 
These difference equations pin down the equilibrium log real exchange rate in terms of the future growth in the endowments, surplus ratios and the consumption-output ratios, $c y_{t}$ and $\hat{c} \hat{y}_{t}{ }^{8}$ They encapsulate the idea that the exchange rate acts as an asset price determined by the equilibrium in international bond markets. Of course the real exchange rate also acts as a relative price via its affects on the terms of trade. This facet is reflected in the goods market clearing conditions. Substituting for the households' demands (i.e., $C_{t}^{\mathrm{US}}=\eta\left(P_{t}^{\mathrm{US}} / P_{t}\right)^{-\theta} C_{t}, C_{t}^{\mathrm{EU}}=(1-\eta)\left(P_{t}^{\mathrm{EU}} / P_{t}\right)^{-\theta} C_{t}, \hat{C}_{t}^{\mathrm{EU}}=\eta\left(\hat{P}_{t}^{\mathrm{EU}} / \hat{P}_{t}\right)^{-\theta} \hat{C}_{t}$ and $\left.\hat{C}_{t}^{\mathrm{US}}=(1-\eta)\left(\hat{P}_{t}^{\mathrm{US}} / \hat{P}_{t}\right)^{-\theta} \hat{C}_{t}\right)$ and relative prices with the terms of trade in $(25)$ produces

$$
1=\eta\left(\eta+(1-\eta) \mathcal{T}_{t}^{1-\theta}\right)^{\frac{\theta}{1-\theta}} \exp \left(c y_{t}\right)+(1-\eta)\left(\eta \mathcal{T}_{t}^{1-\theta}+(1-\eta)\right)^{\frac{\theta}{1-\theta}} \exp \left(c \hat{y}_{t}+\hat{z}_{t}-z_{t}\right)
$$

and

$$
1=(1-\eta)\left(\eta \mathcal{T}_{t}^{\theta-1}+(1-\eta)\right)^{\frac{\theta}{1-\theta}} \exp \left(c y_{t}+z_{t}-\hat{z}_{t}\right)+\eta\left(\eta+(1-\eta) \mathcal{T}_{t}^{\theta-1}\right)^{\frac{\theta}{1-\theta}} \exp \left(c \hat{y}_{t}\right),
$$

where

$$
\mathcal{T}_{t}=\left\{\frac{(1-\eta)-\eta \exp \left(\varepsilon_{t}\right)^{1-\theta}}{(1-\eta) \exp \left(\varepsilon_{t}\right)^{1-\theta}-\eta}\right\}^{\frac{1}{1-\theta}}
$$

Equations (33) - (34) comprise a closed system that determines the behavior of $\varepsilon_{t}, c y_{t}$ and $\hat{c} \hat{y}_{t}$ from the exogenous processes for $z_{t}, \hat{z}_{t}, s_{t}$ and $\hat{s}_{t}$. Let $\varepsilon_{t}=\mathcal{F}\left(z_{t}, \hat{z}_{t}, s_{t}-\bar{s}, \hat{s}_{t}-\bar{s}\right)$ denote the solution to (33) - (34), for some some function $\mathcal{F}($.). I define the steady state value for the log real exchange rate as

$$
\bar{\varepsilon}=\mathcal{F}(0,0,0,0)
$$

In words, $\bar{\varepsilon}$ is the value for log real exchange that is consistent with equilibrium in the international asset and goods' markets when collateral constraints are not binding and when the current endowments of U.S. and E.U. goods are equal and both surplus ratios are at their long-run value. I further restrict my attention to symmetric steady states where the effects of U.S. shocks $v_{t}$ and $e_{t}$ on U.S. (E.U.) variables are the same as the effects of E.U. shocks $\hat{v}_{t}$ and $\hat{e}_{t}$ on E.U. (U.S.) variables.

This definition of the steady state real exchange rate has several noteworthy features. First, the value for $\bar{\varepsilon}$ depends on households' expectations of future shocks to the endowments and surplus ratios conditioned on current steady state information $\left\{y_{t}=\hat{y}_{t}=\mathfrak{T}_{t}, s_{t}=\hat{s}_{t}=\bar{s}\right\}$ via the conditional expectations on the right-hand-side of (33). ${ }^{9}$ Notice, also, that the steady state is defined with reference to the behavior of the exogenous variables, not the endogenous variables. In particular, it is the point where the distribution of $\left\{z_{t+1}, \hat{z}_{t+1}, s_{t+1}, \hat{s}_{t+1}\right\}$ conditioned on period- $t$ information is constant. In contrast, the conditional moments of the real exchange rate depend on the form of $\mathcal{F}($.$) . Since \mathcal{F}($.) is a nonlinear function, $\mathbb{E}_{t} \mathcal{F}\left(e_{t+1}, \hat{e}_{t+1}, \omega(\bar{s}) v_{t+1}, \omega(\bar{s}) \hat{v}_{t+1}\right)$ need not equal $\bar{\varepsilon}$ so the expected depreciation rate in the steady

\footnotetext{
${ }^{8}$ The $\log$ ratios of U.S. and E.U. consumption to output are $c_{t}-y_{t}+\frac{1}{1-\theta} \ln \left(\eta+(1-\eta) \mathcal{T}_{t}^{1-\vartheta}\right)$ and $\hat{c}_{t}-\hat{y}_{t}+\frac{1}{1-\theta} \ln \left(\eta+(1-\eta) \mathcal{T}_{t}^{\theta-1}\right)$ when measured in terms of the domestic consumption baskets. Consequently, $c y_{t}$ and $c \hat{y}_{t}$ should really be thought of as the adjusted log ratios that value endowments when the terms of trade are one.

${ }^{9}$ If the economy is at the steady state in period $t, \Delta z_{t+1}=e_{t+1}, \Delta \hat{z}_{t+1}=\hat{e}_{t+1}, \Delta s_{t+1}=\omega(\bar{s}) v_{t+1}$ and $\Delta \hat{s}_{t+1}=\omega(\bar{s}) \hat{v}_{t+1}$ so (33) shows that $\bar{\varepsilon}$ depends on the uncertainty households' face concerning period- $t+1$ shocks.
} 
state may differ from zero. Of course, in the limit as the variance of the exogenous shocks disappears, $\mathbb{E}_{t} \mathcal{F}\left(e_{t+1}, \hat{e}_{t+1}, \omega(\bar{s}) v_{t+1}, \omega(\bar{s}) \hat{v}_{t+1}\right) \rightarrow \bar{\varepsilon}$, so the expected deprecation rate in the steady state converges to zero. Finally, note that the steady state values for the consumption-output ratios can be computed as the solutions to (34) with $\varepsilon_{t}=\bar{\varepsilon}$ and $z_{t}=\hat{z}_{t}=0$.

The nonlinearities (33) - (34) are too complex to find the form of $\mathcal{F}($.$) analytically, so \mathcal{F}($.$) and hence$ the steady-state real exchange rate must be approximated. To do this, I use the method of undetermined coefficients. First, I conjecture that $\bar{\varepsilon}=0$ and that $\mathcal{F}($.$) can be well-approximated by \pi_{z}\left(z_{t}-\hat{z}_{t}\right)+\pi_{s}\left(s_{t}-\hat{s}_{t}\right)$, where $\pi_{z}$ and $\pi_{s}$ are unknown coefficients. I then take log-linear approximations to the first-order conditions governing the households' holdings of U.S. and E.U bonds, and the goods market clearing conditions. I verify that these approximate equilibrium conditions are satisfied when $\varepsilon_{t}=\pi_{z}\left(z_{t}-\hat{z}_{t}\right)+\pi_{s}\left(s_{t}-\hat{s}_{t}\right)$ and determine the values for $\pi_{z}$ and $\pi_{s}$ in terms of the models' parameters. This establishes zero as a candidate value for the steady state value for $\varepsilon_{t}$ that satisfies approximate equilibrium conditions. Finally, I check that this candidate value is locally unique. The Appendix shows that if $\mathcal{F}($.$) is approximated by \bar{\varepsilon}+\pi_{z}\left(z_{t}-\hat{z}_{t}\right)+\pi_{s}\left(s_{t}-\hat{s}_{t}\right)$, the only value for $\bar{\varepsilon}$ in the neighborhood of zero that solves the system of approximate equilibrium conditions is zero.

This approximation to the true value of $\bar{\varepsilon}$ has a number of sensible economic implications. First, in the steady state aggregate consumption is equalized across countries (i.e., $c y_{t}=\hat{c} \hat{y}_{t}=0$ solves (34) so $c_{t}=y_{t}=\mathfrak{T}_{t}=\hat{y}_{t}=\hat{c}_{t}$ ). This means that trade is balanced between the two countries. By definition U.S. exports and imports are determined by E.U households' demand for U.S. goods, and U.S. demand for E.U. goods, respectively. So, when measured in terms of the U.S. consumption basket, U.S. exports and imports are given by

$$
\begin{aligned}
\mathfrak{X}_{t}=(1-\eta)\left(\hat{P}_{t}^{\mathrm{US}} / \hat{P}_{t}\right)^{1-\theta} \mathcal{E}_{t} \hat{C}_{t}=(1-\eta)\left(\eta \mathcal{T}_{t}^{1-\theta}+(1-\eta)\right)^{-1} \mathcal{E}_{t} \hat{C}_{t} \quad \text { and } \\
\mathfrak{M}_{t}=(1-\eta)\left(P_{t}^{\mathrm{EU}} / P_{t}\right)^{1-\theta} C_{t}=(1-\eta)\left(\eta \mathcal{T}_{t}^{\theta-1}+(1-\eta)\right)^{-1} C_{t} .
\end{aligned}
$$

In the steady state these expressions simplify to $\mathfrak{X}_{t}=(1-\eta) \hat{C}_{t}$ and $\mathfrak{M}_{t}=(1-\eta) C_{t}$ so there is a zero trade balance between the countries. The approximation also implies that real interest rates are constant and equal across countries. Since the approximation for $\mathcal{F}($.$) is linear, \mathbb{E}_{t} \Delta \varepsilon_{t+1}=0$ in the steady state. Consequently, the steady state risk premium is also zero because $\mathbb{E}_{t} \Delta \varepsilon_{t+1}+\hat{r}_{t}-r_{t}=\delta_{t}$.

Portfolio Shares Equilibrium portfolios allocations are not well-defined in the non-stochastic steady state because all financial assets have the same riskless return. This is not the case here because in the stochastic steady state households recognize that future shocks will affect the returns on individually assets differently.

I identify the portfolio shares from the households' budget constraints and two ratios: the saving-toconsumption ratio, $\Lambda_{t}^{\mathrm{w}}=\left(W_{t}-C_{t}\right) / C_{t}$, and the equity price-to-dividend ratio, $\Lambda_{t}^{\mathrm{Q}}=Q_{t} / D_{t}$. From the U.S. 
first-order condition in (32) we find that

$$
1=\beta \mathbb{E}_{t}\left[\left(\frac{C_{t+1}}{C_{t}}\right)^{-\gamma}\left(\frac{S_{t+1}}{S_{t}}\right)^{-\gamma} R_{t+1}^{\mathrm{W}}\right]+\mathcal{B}_{t}\left(1-\alpha_{t}^{\mathrm{EQ}}+\varkappa \alpha_{t}^{\mathrm{FB}}\right)
$$

Substituting for $R_{t+1}^{\mathrm{w}}$ from the budget constraint in (27b) and re-arranging the result gives

$$
\Lambda_{t}^{\mathrm{w}}=\beta \mathbb{E}_{t}\left[\left(1+\Lambda_{t+1}^{\mathrm{w}}\right)\left(\frac{C_{t+1}}{C_{t}}\right)^{1-\gamma}\left(\frac{S_{t+1}}{S_{t}}\right)^{-\gamma}\right]+\mathcal{B}_{t} N_{t} / C_{t}
$$

Thus, the U.S. savings-to-consumption ratio depends on expectations concerning future surplus ratios and equilibrium consumption growth. ${ }^{10}$ The first-order conditions in (32) also imply that

$$
\Lambda_{t}^{\mathrm{Q}}=\beta \mathbb{E}_{t}\left[\left(1+\Lambda_{t+1}^{\mathrm{Q}}\right)\left(\frac{C_{t+1}}{C_{t}}\right)^{1-\gamma}\left(\frac{S_{t+1}}{S_{t}}\right)^{-\gamma} \exp \left(\Delta d c_{t+1}\right)\right]
$$

where $d c_{t}=\ln \left(D_{t} / C_{t}\right)$. Goods market clearing implies that $D_{t}=C_{t}+\mathfrak{X}_{t}-\mathfrak{M}_{t}$, so the log dividendconsumption ratio can be written as

$$
d c_{t}=\ln \left\{1+\left(\frac{\mathfrak{X}_{t}}{\mathfrak{M}_{t}}-1\right) \frac{\mathfrak{M}_{t}}{C_{t}}\right\}=\ln \left\{1+\frac{1-\eta}{\eta \mathcal{T}_{t}^{\theta-1}+(1-\eta)}\left(\frac{\mathfrak{X}_{t}}{\mathfrak{M}_{t}}-1\right)\right\}
$$

where from $(35)$

$$
\frac{\mathfrak{X}_{t}}{\mathfrak{M}_{t}}=\frac{\eta \mathcal{T}_{t}^{\theta-1}+(1-\eta)}{\eta \mathcal{T}_{t}^{1-\theta}+(1-\eta)} \exp \left(\varepsilon_{t}+\hat{c} \hat{y}_{t}-c y_{t}+\hat{z}_{t}-z_{t}\right)
$$

(38) and (39) imply that the equilibrium dividend-consumption ratio depends on $\varepsilon_{t}, c y_{t}, \hat{c} y_{t} z_{t}$ and $\hat{z}_{t}$. Thus, (37) represents a difference equation in $\Lambda_{t}^{\mathrm{Q}}$ that can be solved given the exogenous processes for endowments and the surplus ratio and the approximate equilibrium processes for consumption-output ratio and the real exchange rate. Analogous equations determine the equity price-to-dividend and savings-to-consumption ratios in the E.U. (i.e., $\hat{\Lambda}_{t}^{\mathrm{Q}}$ and $\hat{\Lambda}_{t}^{\mathrm{w}}$ ).

The $\Lambda_{t}^{\mathrm{Q}}$ and $\Lambda_{t}^{\mathrm{W}}$ ratios allow us to determine the share of equities in U.S. households' portfolios. Since households hold the entire stock of domestic equity, the U.S. equity share is given by $\alpha_{t}^{\mathrm{EQ}}=Q_{t} /\left(W_{t}-C_{t}\right)$. Combining this expression with the definitions of $\Lambda_{t}^{\mathrm{Q}}$, and $d c_{t}$ produces

$$
\alpha_{t}^{\mathrm{EQ}}=\frac{\Lambda_{t}^{\mathrm{Q}}}{\Lambda_{t}^{\mathrm{W}}} \frac{D_{t}}{C_{t}}=\frac{\Lambda_{t}^{\mathrm{Q}}}{\Lambda_{t}^{\mathrm{W}}}\left(1+\frac{\mathfrak{X}_{t}-\mathfrak{M}_{t}}{C_{t}}\right) .
$$

Thus, the share of equities in U.S. households' portfolios depends on the ratios $\Lambda_{t}^{\mathrm{Q}}$ and $\Lambda_{t}^{\mathrm{w}}$, and the net exports-to-consumption ratio. In the steady state net exports are zero, so $D_{t}=C_{t}$ and the solutions to (36), (37) and their E.U. counterparts are constants (i.e., $\Lambda_{t}^{\mathrm{Q}}=\bar{\Lambda}^{\mathrm{Q}}, \Lambda_{t}^{\mathrm{w}}=\bar{\Lambda}^{\mathrm{w}}$ and so on). The steady state equity shares are therefore given by $\bar{\alpha}^{\mathrm{EQ}}=\bar{\Lambda}^{\mathrm{Q}} / \bar{\Lambda}^{\mathrm{w}}$ and $\overline{\hat{\alpha}}^{\mathrm{EQ}}=\overline{\hat{\Lambda}}^{\mathrm{Q}} / \overline{\hat{\Lambda}}^{\mathrm{w}}$. In practice, my approximation to the steady state produces values for $\bar{\Lambda}^{\mathrm{Q}}, \overline{\hat{\Lambda}}^{\mathrm{Q}}, \bar{\Lambda}^{\mathrm{w}}$ and $\overline{\hat{\Lambda}}^{\mathrm{w}}$ that are almost equal, so the steady state U.S. and

\footnotetext{
${ }^{10}$ When the first-order conditions are computed from the original optimization problem, $\mathcal{B}_{t} N_{t}=0$ by complimentary slackness. This is not guaranteed when the first-order conditions are computed from the modified optimization problem, but in practice the $\mathcal{B}_{t} N_{t} / C_{t}$ term has a negligible impact on the values of $\Lambda_{t}^{\mathrm{w}}$ I compute.
} 
E.U. equity shares are very close to unity.

To identify U.S. households' bond holdings, I first combine the log version of the budget constraint in (27b) with the definition of $\Lambda_{t}^{\mathrm{w}}$ to give

$$
\Delta c_{t+1}=r_{t+1}^{\mathrm{w}}+\ln \Lambda_{t}^{\mathrm{w}}-\ln \left(\Lambda_{t+1}^{\mathrm{w}}+1\right)
$$

I next combine this expression with an continuous-time approximation to the log return on wealth

$$
r_{t+1}^{\mathrm{w}}=r_{t}+\alpha_{t}^{\prime} e r_{t+1}+\frac{1}{2} \alpha_{t}^{\prime}\left(\operatorname{diag}\left(\mathbb{V}_{t}\left(e r_{t+1}\right)\right)-\mathbb{V}_{t}\left(e r_{t+1}\right)\right) \alpha_{t}
$$

where $\alpha_{t}^{\prime}=\left[\alpha_{t}^{\mathrm{EQ}}, \alpha_{t}^{\mathrm{FB}}\right]$ is the vector of portfolio shares, $e r_{t+1}^{\prime}=\left[r_{t+1}^{\mathrm{EQ}}-r_{t}, \Delta \varepsilon_{t+1}+\hat{r}_{t}-r_{t}\right]$ is a vector of $\log$ excess returns on equity and foreign bonds (measured in terms of U.S. consumption), and $\mathbb{V}_{t}($.$) is the$ variance conditioned on period- $t$ information. ${ }^{11}$ Finally, I combine (38) with (42) to compute the conditional covariance between consumption growth and the real exchange rate. Re-arranging the resulting expression

$$
\alpha_{t}^{\mathrm{FB}}=\frac{\mathbb{C V}_{t}\left(\varepsilon_{t+1}, \Delta c_{t+1}\right)}{\mathbb{V}_{t}\left(\varepsilon_{t+1}\right)}-\alpha_{t}^{\mathrm{EQ}} \frac{\mathbb{C V}_{t}\left(\varepsilon_{t+1}, r_{t+1}^{\mathrm{EQ}}\right)}{\mathbb{V}_{t}\left(\varepsilon_{t+1}\right)}+\frac{\mathbb{C V}_{t}\left(\varepsilon_{t+1}, \ln \left(\Lambda_{t+1}^{\mathrm{w}}+1\right)\right)}{\mathbb{V}_{t}\left(\varepsilon_{t+1}\right)}
$$

where $r_{t+1}^{\mathrm{EQ}}$ is the $\log$ return on U.S. equity. By definition, $r_{t+1}^{\mathrm{EQ}}=\ln \left(\Lambda_{t+1}^{Q}+1\right)-\ln \left(\Lambda_{t}^{\mathrm{Q}}\right)+\Delta d c_{t+1}+$ $\Delta c_{t+1}$, so all the terms on the right-hand-side are readily computed from the equilibrium behavior of real exchange rate, consumption, $\Lambda_{t}^{\mathrm{Q}}, \Lambda_{t}^{\mathrm{W}}$ and $d c_{t}$. In the approximate steady state, (43) simplifies to $\alpha_{t}^{\mathrm{FB}}=$ $-\mathbb{C V}_{t}\left(\varepsilon_{t+1}, d c_{t+1}\right) / \mathbb{V}_{t}\left(\varepsilon_{t+1}\right)$, which is a positive constant, $\bar{\alpha}^{\mathrm{FB}}$. This means that the steady state value of $N_{t}$ is $\varkappa \bar{\alpha}^{\mathrm{FB}} \bar{\Lambda}^{\mathrm{W}} C_{t}>0$, so the U.S. collateral constraint does not bind. E.U. households' bond holdings are determined from these results and the market clearing conditions in (21). In particular, the foreign bond share is $\hat{\alpha}_{t}^{\mathrm{FB}}=-\hat{B}^{\mathrm{US}} /\left(\mathcal{E}_{t} \hat{W}_{t}-\mathcal{E}_{t} \hat{C}_{t}\right)=\left(\alpha_{t}^{\mathrm{FB}}+\alpha_{t}^{\mathrm{EQ}}-1\right)\left(\Lambda_{t}^{\mathrm{w}} / \hat{\Lambda}_{t}^{\mathrm{W}}\right)\left(C_{t} / \mathcal{E}_{t} \hat{C}_{t}\right)$. Clearly, $\hat{\alpha}_{t}^{\mathrm{FB}}=\bar{\alpha}^{\mathrm{FB}}>0$ in the steady state, so the E.U. collateral constraint doesn't bind. These results confirm that we can ignore the Lagrange multipliers on the collateral constraints when computing the steady state real exchange rate as an approximate solution to (33).

Equilibrium Dynamics I use the set of second-order approximations to the households' first-order conditions from the modified optimization problems and the market clearing conditions around the steady state to characterize the equilibrium process for the real exchange rate, consumption, real interest rates, trade flows, dividends and the $\Lambda_{t}^{\mathrm{Q}}, \Lambda_{t}^{\mathrm{w}}, \hat{\Lambda}_{t}^{\mathrm{Q}}$ and $\hat{\Lambda}_{t}^{\mathrm{w}}$ ratios. These processes are conditionally heteroskedastic. Recall that the sensitivity of the surplus ratios to future risk shocks varies with the current surplus ratio, so insofar as the surplus ratios affect the endogenous variables, they display conditional heteroskedasticity. As a consequence, time-varying conditional second moments are a source of variation in the foreign exchange risk premium and in households' savings and portfolio decisions. The appendix provides a complete list of the approximations used to derive the equilibrium dynamics.

\footnotetext{
${ }^{11}$ This is not a standard second-order approximation to the log of the return on wealth in (28). Campbell and Viceira (2002) derive the approximation by applying Ito's lemma to the log return on wealth when the prices of individual assets follow continuous-time diffusion processes. Notice that the vector of portfolio shares $\alpha_{t}$ appears multiplicatively, and not in deviations from its steady state value.
} 


\section{Results}

This section examines whether the model can account for the behavior of real exchange rates and other macro variables. I parameterize the model so that habits exhibit behavior similar to that found in other studies and the variance of the equilibrium real depreciation rate, real interest and consumption growth differentials match estimates from actual data. I then study the roles played by endowment and risk shocks as drivers of real exchange rates and other macro variables. This analysis address three key questions. First, can a model that incorporates both endowment and risk shocks account for observed behavior of exchange rates and other macro variables? Second, are risk shocks an important driver of exchange rates? Third, do risk shocks have significant macro effects? As we shall see, the analysis provides an affirmative answer to all three questions.

\subsection{Parameterization}

The model contains 14 parameters: the preference parameters, $\beta, \gamma, \eta$ and $\theta$; the parameters governing habits, $\phi, \bar{s}, s_{\max }$ and $\omega$; the parameters of the endowment processes, $\rho, g, \sigma_{e}^{2}$ and $\sigma_{u}^{2}$; the collateral constraint, $\varkappa$, and the barrier parameter, $\mu$. I assign values to a first subset of these parameters that appear elsewhere in the literature. The values of a second subset are calibrated to key ratios, and a final subset are chosen so that the model matches moments in the data. This hybrid approach strikes a balance between two goals. On one hand I want some aspects of the model to be comparable with others in the literature, so I assign values to many of the preference and habit parameters that have been used elsewhere. On the other, my aim is to investigate whether the model can account for the behavior of exchange rates, so the values of the other parameters are chosen to match important moments in the data. The values of all the parameters are summarized in Table 4.

The model is parameterized so that one period corresponds to one quarter. $\beta$ is set equal to 0.99 , while $\gamma$ and $\eta$ are assigned standard values of 2 and 0.85 , respectively, so households have a strong bias towards the consumption of domestic goods. The value for the long run growth rate, $g$, is chosen so that the steady state real interest rate in both countries equals 1.5 per cent (per year).

Let $\sigma_{s}^{2}$ denote the unconditional variance of $s_{t}$ and $\hat{s}_{t}$. The surplus processes in (13) and (17) imply that $\sigma_{s}^{2}=\omega\left(s_{\max }-\bar{s}\right) /\left(1-\phi^{2}\right)$. I set $\phi$ equal to 0.92 and $\bar{s}=\ln (\bar{S})$ equal to $\ln (0.05)$ so that the average consumption surplus ratio is 5 percent. The upper bound on the consumption surplus ratio $s_{\max }=\ln \left(S_{\max }\right)$ is determined as $\sigma_{s}^{2}\left(1-\phi^{2}\right) / \omega+\bar{s}$, where the values for $\sigma_{s}^{2}$ and $\phi$ are chosen to match the moments described below. This produces a value for $S_{\max }$ of 5.5 per cent.

I set the values of four parameters to match moments in the data: (i) the variance of the real depreciation rate for the USD verses the EUR, (ii) the variance in the per capita consumption growth differential between the US and Euro area, (iii) the variance of the real interest differential between the US and Euro area, and (iv) the first-order autocorrelation in the real interest differential. Sample moments are calculated at the quarterly frequency from data spanning 1990:I to 2007:IV (132 observations). Real interest rates are computed as the fitted values from an $\operatorname{AR}(2)$ regression for the ex post real return on Eurodeposits (i.e., the 3 -month nominal Eurodeposit rate minus realized inflation). I choose the values for $\sigma_{s}^{2}, \omega, \rho$ and $\sigma_{e}^{2}$ so the 
Table 4: Parameterization

\begin{tabular}{|c|c|c|}
\hline Symbol & Parameter & Value \\
\hline$\beta$ & discount function & 0.990 \\
\hline$\gamma$ & utility curvature & 2.000 \\
\hline$\eta$ & home good share & 0.850 \\
\hline$\theta$ & elasticity of substitution & 0.110 \\
\hline$\phi$ & autocorrelation in consumption-surplus & 0.920 \\
\hline $\bar{S}$ & average log consumption-surplus & 0.050 \\
\hline$S_{\max }$ & upper bound on log consumption-surplus ${ }^{\dagger}$ & 0.051 \\
\hline$\omega$ & variance sensitivity $^{\dagger}$ & 0.148 \\
\hline$\rho$ & autocorrelation in endowments ${ }^{\dagger}$ & 0.769 \\
\hline$\sigma_{e}$ & standard deviation of endowment shocks* ${ }^{\dagger}$ & 0.010 \\
\hline$g$ & steady state growth rate & 0.028 \\
\hline$\varkappa$ & collateral constraint & 0.300 \\
\hline$\mu$ & barrier parameter & 0.030 \\
\hline
\end{tabular}

unconditional moments computed from the equilibrium of the model match the four sample moments. This procedure produces values for $\omega$ of 0.148 . The implied semi-elasticity of the real interest differential with respect to variations in $s_{t}-\hat{s}_{t}$ is 0.012 . This is very close to the value of 0.1 used in Verdelhan (2010). ${ }^{12}$

In actual economies the relative prices of domestic- and foreign-produced consumer goods are relatively unresponsive to quarterly variations in spot exchange rates because the effects are absorbed by the production and distribution sectors. These sectors are absent in this simple model. Consequently, variations in the real exchange rate are directly reflected in the relative prices that drive households's consumption decisions. To compensate for this feature, I treat $\theta$ as a composite parameter, $\theta^{*}(1-\varsigma)$, where $\varsigma$ denotes the fraction of exchange rate variations absorbed by the un-modeled production and distribution sectors, and $\theta^{*}$ is the "true" elasticity of substitution. Setting $\theta^{*}$ equal to 0.72, as in Hnatkovska (2010) and Corsetti, Dedola, and Leduc (2008), and $\varsigma$ equal to 0.85 , gives a value for $\theta$ of $0.11 .{ }^{13}$ Again, I discuss the robustness of my main results to alternative values for $\theta$ below.

The remaining parameters are $\varkappa$ and $\mu$. Because the foreign asset and liability portfolios of actual countries contain more than the default-free debt included in the model, there is no simple and direct way to calibrate either of these parameters. Instead, I choose values for $\varkappa$ and $\mu$ that imply "reasonable" restrictions on the degree of international borrowing. $\varkappa$ determines the upper bound on the ratio of foreign liabilities to

\footnotetext{
${ }^{12}$ The variance of endowment growth, $\sigma_{u}^{2}$, governs the long run correlation between consumption growth in each country. I set the value of $\sigma_{u}^{2}$ so that this correlation in the model matches the sample correlation in US and Euro-area data. The value of this parameter does not affect the dynamics discussed below.

${ }^{13}$ Obviously, this is a very reduced-form approach of capturing the low rate of exchange-rate pass-through we observe empirically (see, e.g., Campa and Goldberg, 2008) For a recent discussion of the possible reasons for low pass-through, see Devereux and Yetman (2010).
} 
assets that a country can accumulate. In U.S. case, the constraint implies that $-B_{t}^{\mathrm{US}} / \mathcal{E}_{t} B_{t}^{\mathrm{EU}}<1+\varkappa$, so the upper bound is $1+\varkappa$. These limits are readily translated into an upper bound on the net foreign liability to income ratio for each country along the steady state growth path. I set $\varkappa$ equal to 0.3 , which implies an upper bound of 200 percent. Since actual debt to GDP ratios rarely approach these levels without any perceived risk of default, this choice for $\varkappa$ places a rather weak restriction on international borrowing in the model. In the appendix I show that the value for $\mu$ determines the semi-elasticity of the risk premium with respect to variations in the log ratio of foreign liabilities to assets. I set $\mu$ equal to 0.03 . in the baseline parameterization, and consider the robustness of the equilibrium to alternate values.

\subsection{Model Moments}

Table 5 provides a comparison of key moments computed from the equilibrium of the model against estimates computed from U.S. and Euro-area data. Panel A shows that when the model is solved using the parameter values from Table 4, the variance of the real depreciation rate, consumption growth differential and real interest differential match the sample variances estimated in the data. Notice that the variance of the real depreciation rate is approximately four times larger than the variance of the consumption growth differential, which in turn is 30 percent larger than the variance of the interest differential. The model accounts for these differences via the influence of the the risk shocks.

Table 5: Comparison of Data and Model Moments

\begin{tabular}{|c|c|c|c|}
\hline & & Data & Model \\
\hline \multicolumn{4}{|l|}{ A: Variances } \\
\hline$\Delta \varepsilon_{t}$ & real depreciation rate ${ }^{\dagger}$ & 19.787 & 19.787 \\
\hline$\Delta c_{t}-\Delta \hat{c}_{t}$ & consumption growth differential ${ }^{\dagger}$ & 2.448 & 2.448 \\
\hline$r_{t}-\hat{r}_{t}$ & real interest rate differential ${ }^{\dagger}$ & 1.739 & 1.739 \\
\hline \multicolumn{4}{|c|}{ B: First Order Autocorrelation } \\
\hline$r_{t}-\hat{r}_{t}$ & real interest rate differential ${ }^{\dagger}$ & 0.833 & 0.833 \\
\hline$\Delta \varepsilon_{t}$ & real depreciation & -0.116 & -0.043 \\
\hline$\Delta c_{t}-\Delta \hat{c}_{t}$ & consumption growth differential & -0.233 & -0.090 \\
\hline \multicolumn{4}{|c|}{ C: Exchange Rate Puzzles } \\
\hline $\mathbb{C} \mathbb{R}\left(\Delta \varepsilon_{t}, \Delta c_{t}-\Delta \hat{c}_{t}\right)$ & Backus-Smith & -0.103 & -0.407 \\
\hline$\beta_{1}$ & Real U.I.P. & -2.950 & -1.424 \\
\hline
\end{tabular}

Panel B of Table 5 compares the autocorrelation properties of the real interest differential, depreciation rate and consumption growth differential. Recall that the parameters were not chosen to match the latter two autocorrelations, so a comparison is informative about the ability of the model to replicate these features 
of the data. As the table shows, the model has no trouble replicating the lack of serial correlation in the real depreciation rate because risk-shocks are the dominant drivers of the real depreciation rate and there is little serial correlation in $\Delta s_{t}$ and $\Delta \hat{s}_{t}$.

The consumption growth differential displays a greater degree of serial correlation in both the data and the model. To understand why, consider the following equation derived from first-order approximations to the goods market clearing conditions in (35)

$$
\Delta c_{t}-\Delta \hat{c}_{t}=(2 \varphi-1)\left(\Delta y_{t}-\Delta \hat{y}_{t}\right)-4 \theta(1-\eta) \varphi \Delta \varepsilon_{t}
$$

where $\varphi=\eta /(2 \eta-1)>0$. Since the model produces little autocorrelation in the real depreciation rate, serial correlation in $\Delta y_{t}-\Delta \hat{y}_{t}$ is the prime source of serial correlation in the consumption growth differential. Indeed, the value for $\rho$ of 0.77 implies autocorrelation in $\Delta c_{t}-\Delta \hat{c}_{t}$ equal to -0.11 when the depreciation rate is serially uncorrelated.

Panel C of Table 5 compares the exchange-rate behavior in the model and data along two key dimensions. The first line compares the sample correlation between the real depreciation rate and the consumption growth differential computed from US and Euro-area data with the unconditional correlation computed from the model. Under complete markets, the real depreciation rate must match the difference between the growth in U.S. and E.U. marginal utility: i.e.,

$$
\Delta \varepsilon_{t}=\gamma\left(\Delta c_{t}-\Delta \hat{c}_{t}\right)+\gamma\left(\Delta s_{t}-\Delta \hat{s}_{t}\right)
$$

Clearly, there must be a positive correlation between the depreciation rate and the consumption growth differential if variations in the surplus differential are absent. Backus and Smith (1993) first pointed to this discrepancy between the negative sample correlations found across many country pairs and the theoretical correlation implied by a complete markets model where households have isoelastic, time-separable utility. Here the presence of incomplete markets and risk shocks break this simple link, producing a strongly negative correlation of -0.41 .

The second row of Panel C compares the slope coefficient from the Fama regression for the real USD/EUR reported in Table 3, with the theoretical value implied by the model. As the table shows, the theoretical value is negative but above the estimate of -2.99 computed from the USD/EUR data. Since the model is calibrated to match the variance of the real interest differential, this difference reflects a discrepancy between the value of $\mathbb{C V}\left(\delta_{t}, r_{t}-\hat{r}_{t}\right)$ in the model and its sample counterpart. Variations in the risk premium covary negatively with the interest differential but not strongly enough to produce a coefficient of $-2.99 .{ }^{14}$ I examine the mechanism driving variations in the risk premium and interest differential below.

\footnotetext{
${ }^{14}$ It is worth noting that the discrepancy between the coefficient estimate in Table 3 and the model-implied value is not statistically significant: a t-test for the null that the coefficient equals -1.424 is not significant at the 5 percent level.
} 
Figure 2: Plots of $R_{h}^{\nabla r}$ (solid) and $R_{h}^{\nabla r^{\mathrm{u}}}$ (dashed) implied by the model

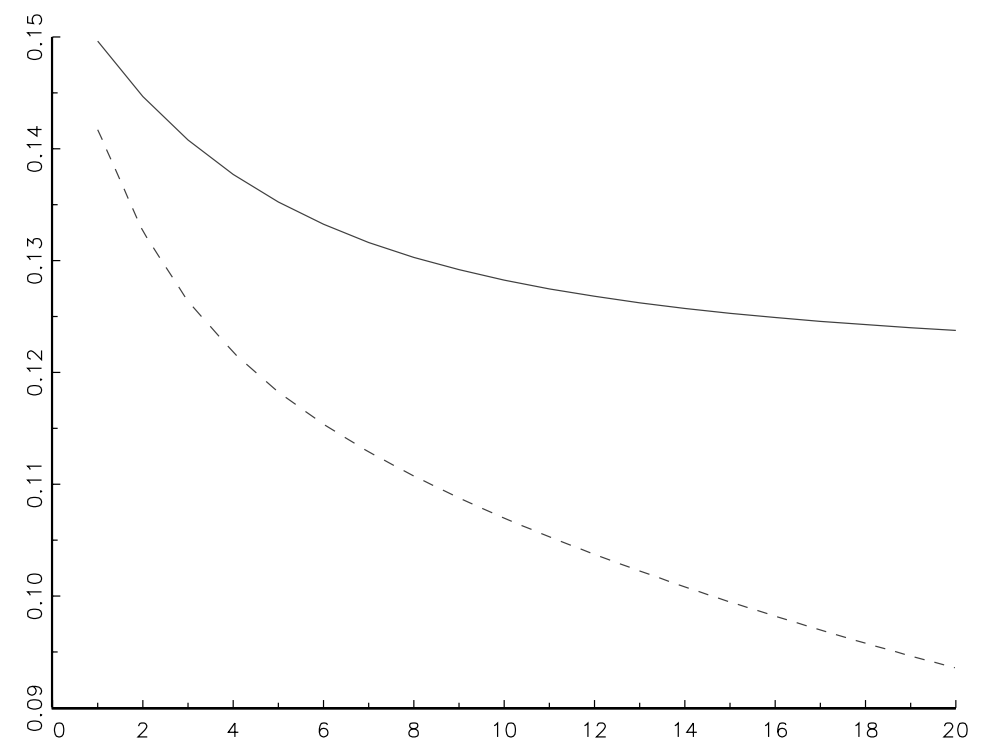

\subsection{Identifying Dark Matter}

Let us now turn to the central issue: Can the model replicate the plots of the estimated variance ratios for the G-7 currencies in Figure 1? Recall that $\mathcal{R}_{h}^{\nabla r}$ identifies the fraction of the variance in the $h$-period depreciation rate that can be attributed to variations in the interest differential, while $\mathcal{R}_{h}^{\nabla r^{u}}$ identifies the fraction attributable to news concerning future differentials. Figure 2 plots the values of $\mathcal{R}_{h}^{\nabla r}$ and $\mathcal{R}_{h}^{\nabla r^{u}}$ for horizons of 1 to 20 quarters computed from the equilibrium real exchange rate and interest differential processes implied by the model. Clearly, the plots have the same general shape as the estimates for the G7 currencies in Figure 1. More specifically, Figure 2 shows that real interest differentials are a minor (proximate) driver of real depreciation rates in the model, with $\mathcal{R}_{h}^{\nabla r}$ falling from 15 to 13 per cent as the horizon rises from one to 20 quarters. This ratio is comparable to the short-horizon estimates of $\mathcal{R}_{h}^{\nabla r}$ for the USD/CAN and USD/JPY in Table 2, but is well above the estimates for other currencies such as the USD/GBP and USD/EUR. Figure 2 also shows that news concerning future interest differentials is comparatively more important as a driver of real depreciation rates at short horizons. The values for $\mathcal{R}_{h}^{\nabla r^{v}}$ fall more quickly than $\mathcal{R}_{h}^{\nabla r}$ as the horizon increases, but they do not fall to the estimated values for $\mathcal{R}_{h}^{\nabla r^{v}}$ in the G7 currencies reported in Table 2.

The general message conveyed by Figure 2 is clear. In this model variations in interest differentials are not the main (proximate) driver of depreciation rates. More precisely, endowment and risk shocks affect equilibrium real interest rates, but these effects play a minor role in the determining how exchange rates respond to the shocks. Instead, variations in exchange rate rates are primarily driven the effects endowment and risk shocks have on current and future risk premia. Indeed, in this model there is a unique steady-state real exchange rate so variations in the risk premia must account for all the effects of exchange-rate dark matter. 


\subsection{Dark Matter and Macroeconomics}

I now examine whether the risk shocks needed to account for these exchange-rate moments have significant macroeconomic implications. For this purpose, I first compare the transmission of endowment and risk shocks to exchange rates and other macroeconomic variables in equilibria with different degrees of risksharing. I then examine the relative importance of risk and endowment shocks as drivers of exchange-rate and macroeconomic variations.

Analyzing the effects of endowment and risk shocks is complicated by the presence of incomplete markets and the collateral constraints. It therefore proves useful to compare the impulse responses of different shocks with their counterparts in an equilibrium where markets are complete and the collateral constraints are absent. The appendix shows that this equilibrium can be computed as a special case where the barrier parameter $\mu$ equals zero.

\section{Endowment Shocks}

Figure 3 shows the impulse responses of the real exchange rate, consumption, real interest rates and the risk premium following a one standard deviation positive shock to the U.S. endowment process. Overall, the plots show that incomplete risk-sharing and the borrowing constraints have little effect on how the economy responds to the effects of the endowment shock. ${ }^{15}$ In both versions of the model there is a real depreciation, and rise (fall) in U.S. (E.U.) consumption and a fall (slight rise) in U.S. (E.U.) interest rates. The only qualitative difference appears in the behavior of the risk premium, which rises very slightly in the incomplete markets equilibrium while remaining unchanged when markets are complete.

The economics behind these plots is straightforward. At pre-existing consumption levels, the positive shock to the U.S. endowment requires a deterioration in the U.S. terms of trade (i.e., a fall in $P_{t}^{\mathrm{US}} / P_{t}^{\mathrm{EU}}$ ) to maintain goods market clearing. Since this, in turn, implies a real depreciation of the dollar, under complete risk sharing there must also be a rise in relative consumption, $C_{t} / \hat{C}_{t}$, to maintain the equality of marginal utility across countries. Panel B in Figure 3 shows that this is achieved by a larger rise in U.S. consumption than the fall in E.U. consumption because the former has a larger impact on the demand for U.S. goods in the presence of home-bias $(\eta>1 / 2)$. This asymmetry carries over into real rates. Panel $\mathrm{C}$ shows that the U.S. real rate falls further than the rise in the E.U. rate because expected consumption growth in the U.S. is much lower than in the E.U. until the effects of the shock dissipate.

The response of the economy under incomplete markets is very similar. To understand why, it is useful to return to the accounting identity linking the real exchange rate to interest rates and the risk premium in equation (2). Since $\varepsilon_{t}=0$ in the steady state, the identity implies that

$$
\varepsilon_{t}=\mathbb{E}_{t} \sum_{i=0}^{\infty}\left\{\hat{r}_{t+i}-r_{t+i}\right\}-\mathbb{E}_{t} \sum_{i=0}^{\infty} \delta_{t+i} .
$$

\footnotetext{
${ }^{15}$ Since the solution method incorporates second-order approximations, the effects of a shock depend on the initial state of the economy. The impulse responses shown in Figures 3 and 4 are computed under the assumption that the economy is initially in the steady-state. Note, also, that each plot shows the response per one percent of the shock, not the actual response.
} 
Figure 3: Impulse Responses to a Positive U.S. Endowment Shock
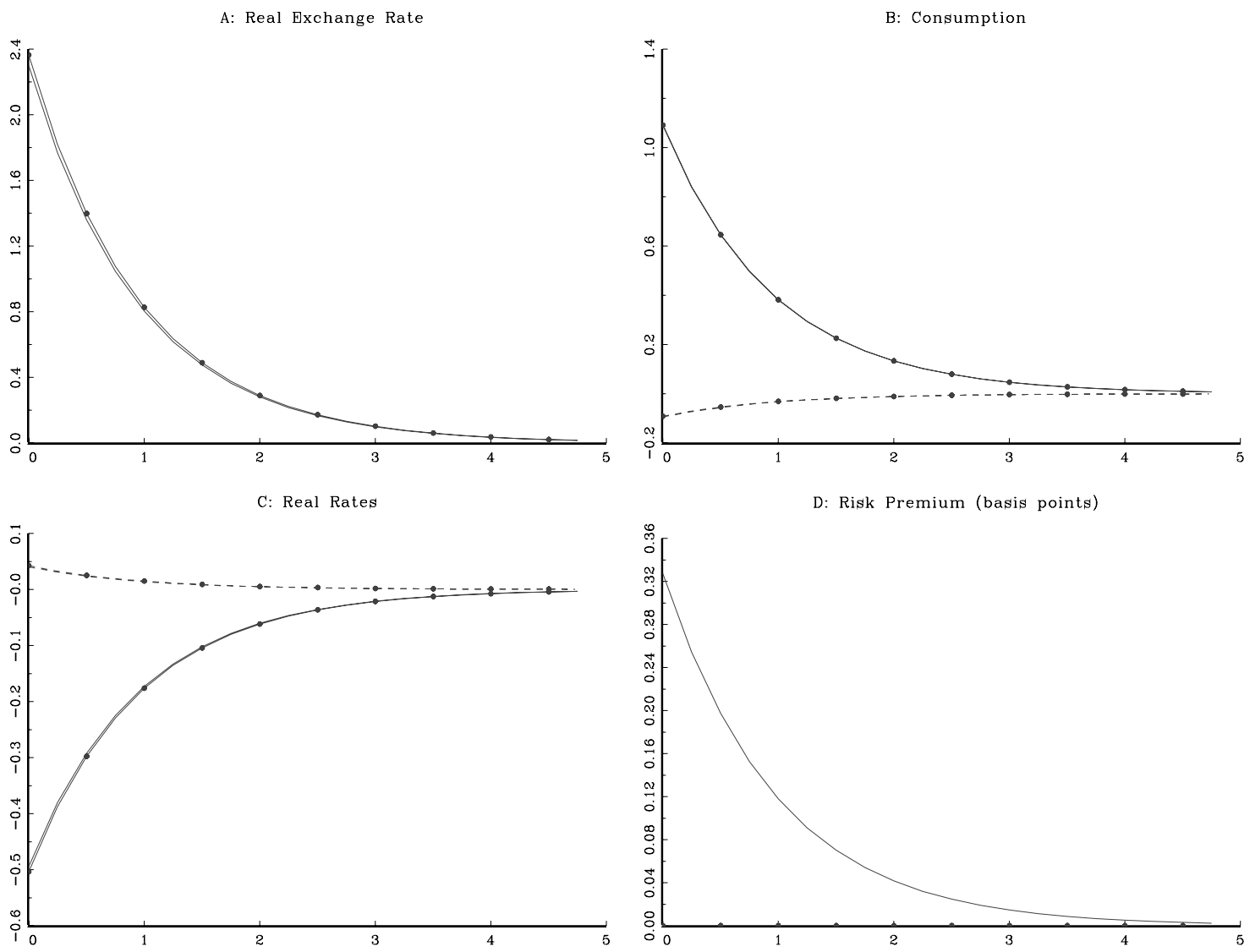

Notes: The plots show the response of each variable to a one standard deviation positive shock to the U.S. endowment process. The vertical axis in each plot shows the response per one percent of the shock. Responses from the complete markets version of the model (without collateral constraints) are indicated by plots with bullets. In panels B and C, U.S. and E.U. variables are identified by the solid and dashed plots, respectively. The horizontal axis measures the time elapsed since the shock in quarters.

We can approximate the terms on the right-hand-side from the households' first-order conditions as

$$
\begin{aligned}
& r_{t}-\hat{r}_{t}=\gamma \mathbb{E}_{t}\left[\Delta c_{t+1}+\Delta s_{t+1}\right]-\gamma \mathbb{E}_{t}\left[\Delta \hat{c}_{t+1}+\Delta \hat{s}_{t+1}\right] \\
&+\frac{1}{2} \gamma^{2}\left\{\mathbb{V}_{t}\left(c_{t+1}+s_{t+1}\right)-\mathbb{V}_{t}\left(\hat{c}_{t+1}+\hat{s}_{t+1}\right)\right\}+\mu\left(n_{t}-\hat{n}_{t}\right), \quad \text { and } \\
& \delta_{t}=\frac{1}{2} \gamma \mathbb{C} \mathbb{V}_{t}\left(c_{t+1}+\hat{c}_{t+1}, \varepsilon_{t+1}\right)+\frac{1}{2} \gamma \mathbb{C} \mathbb{V}_{t}\left(s_{t+1}+\hat{s}_{t+1}, \varepsilon_{t+1}\right)+\frac{1}{2} \mu \varkappa\left(n_{t}-\hat{n}_{t}\right) .
\end{aligned}
$$

Substituting these expressions into (45) and simplifying, produces

$$
\begin{gathered}
\varepsilon_{t}=\gamma\left(c_{t}-\hat{c}_{t}\right)+\gamma\left(s_{t}-\hat{s}_{t}\right)+\mathbb{E}_{t} \sum_{i=0}^{\infty} \chi_{t+i}, \quad \text { where } \\
\chi_{t}=\frac{1}{2} \gamma^{2}\left\{\mathbb{V}_{t}\left(c_{t+1}+s_{t+1}\right)-\mathbb{V}_{t}\left(\hat{c}_{t+1}+\hat{s}_{t+1}\right)\right\}-\frac{1}{2} \gamma \mathbb{C} \mathbb{V}_{t}\left(s_{t+1}+\hat{s}_{t+1}, \varepsilon_{t+1}\right)-\frac{1}{2} \mu(2+\varkappa)\left(n_{t}-\hat{n}_{t}\right) .
\end{gathered}
$$


Thus, the log real exchange rate is pushed away from the level that equates marginal utility across countries when $\mathbb{E}_{t} \sum_{i=0}^{\infty} \chi_{t+i}$ differs from zero. Endowment endowment shocks have no effect on the conditional variance of future consumption or the surplus ratios, so the first two terms on the right-hand-side of (49) equal zero and $\chi_{t}$ is determined by the effects of the collateral constraints. Recall that the collateral constraints facing U.S. and E.U. households take the form of $N_{t} \geq 0$ and $\hat{N}_{t} \geq 0$, so $n_{t}-\hat{n}_{t}=\ln \left(N_{t} / \hat{N}_{t}\right)$ rises as E.U. households move closer to their constraint and/or U.S. households move away from theirs. This is exactly what happens following the U.S. endowment shock because it raises the wealth of U.S. households and lowers the wealth of E.U. households. Indeed Panel D of Figure 3 shows that this induces a rise in the risk premium, but the effect is very small. E.U. households move towards their collateral constraint, but nowhere near the point where it binds. Consequently, although $\mathbb{E}_{t} \sum_{i=0}^{\infty} \chi_{t+i}$ is negative immediately following the endowment shock, the gap between $\varepsilon_{t}$ and $\gamma\left(c_{t}-\hat{c}_{t}\right)$ is economically insignificant.

In sum, therefore, the presence of the collateral constraints does affect how the real exchange rate responds to the endowment shock, but the effects are very small because households remain well away from the point where the constraints bind. As we shall see, this similarity in the behavior of exchange rates under complete and incomplete markets settings breaks down when we examine the effects of risk shocks. ${ }^{16}$

\section{Risk Shocks}

Figure 4 plots the impulse responses of exchange rates, consumption, interest rates and the risk premium to a risk shock that lowers the U.S. surplus ratio from it initial steady state value by one standard deviation. This shock makes U.S. households more risk averse; increasing the local curvature of their utility by approximately 6.5 per cent. Unlike Figure 3, the plots in Figure 4 show that incomplete risk-sharing and the collateral constraints have a large effect on how the economy responds to the shock.

Once again, let us first consider the response of the economy under complete markets. At pre-existing consumption levels, the risk shock raises the marginal utility of U.S. households so there must be an immediate appreciation in the real exchange rate to share risk across countries. This appreciation also induces an improvement in the U.S. terms of trade so, in the presence of home bias, there must be a rise in U.S. consumption and fall in E.U. consumption to clear goods markets. Panel B shows that these responses imply a fall (rise) in expected future U.S. (E.U.) consumption growth following the shock.

The response of real interest rates and the risk premium are depicted in Panel C. The households' first-order conditions imply that real interest rates are well-approximated by

$$
\begin{aligned}
& r_{t}=-\ln \beta+\gamma \mathbb{E}_{t} \Delta c_{t+1}+\gamma \mathbb{E}_{t} \Delta s_{t+1}-\frac{1}{2} \gamma^{2} \mathbb{V}_{t}\left(c_{t+1}+s_{t+1}\right), \quad \text { and } \\
& \hat{r}_{t}=-\ln \beta+\gamma \mathbb{E}_{t} \Delta \hat{c}_{t+1}+\gamma \mathbb{E}_{t} \Delta \hat{s}_{t+1}-\frac{1}{2} \gamma^{2} \mathbb{V}_{t}\left(\hat{c}_{t+1}+\hat{s}_{t+1}\right) .
\end{aligned}
$$

Risk shocks affect interests rates indirectly via consumption growth, and directly via the last two terms

\footnotetext{
${ }^{16}$ The small effects of market incompleteness are reminiscent of the results obtained by Cole and Obstfeld (1991) but the mechanism is different. In their model variations in the terms of trade exactly offset changes in the endowments to keep households' wealth constant. Here wealth changes but this does not materially affect the sharing of risks among households.
} 
Figure 4: Impulse Responses to a U.S. Risk Shock
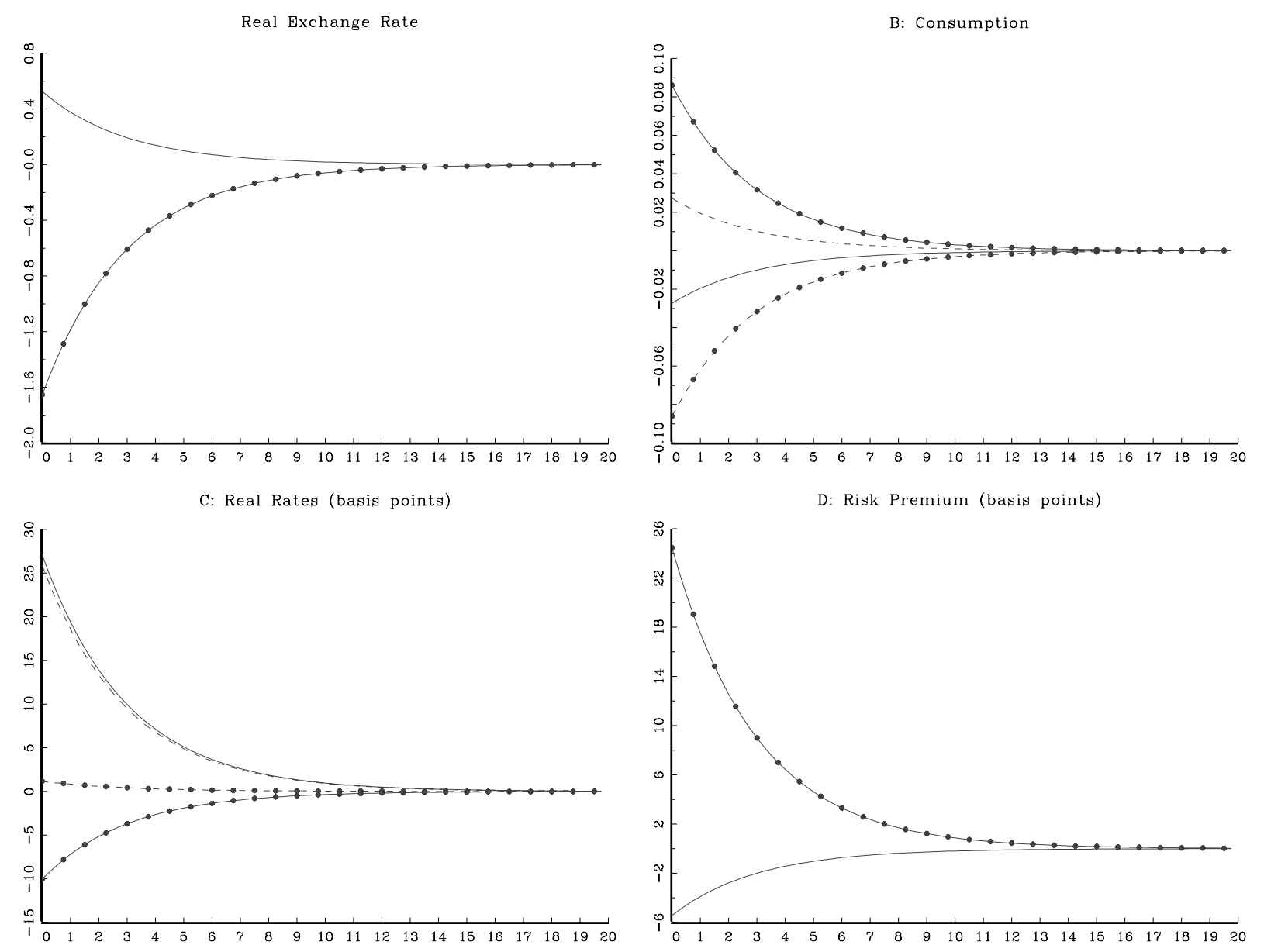

Notes: The plots show the response of each variable to a one standard deviation negative shock to the U.S. log surplus ratio. Responses are measured per one percent of the shock. Responses from the complete markets version of the model without borrowing constraints are indicated by plots with bullets. In panels B and C, U.S. and E.U. variables are identified by the solid and dashed plots, respectively. The horizontal axis measures the time elapsed since the shock in quarters.

on the right-hand-side of each equation. In particular, the negative U.S. risk shock raises both $\gamma \mathbb{E}_{t} \Delta s_{t+1}$ and $\gamma^{2} \mathbb{V}_{t}\left(c_{t+1}+s_{t+1}\right)$ because U.S. households anticipate a future rise in the log surplus ratio and greater volatility in marginal utility. These effects act on the equilibrium real interest rate in opposite directions. The rise in $\gamma \mathbb{E}_{t} \Delta s_{t+1}$ puts upward pressure on the real interest rate because households want to borrow more, while in the increase in $\gamma^{2} \mathbb{V}_{t}\left(c_{t+1}+s_{t+1}\right)$ induces greater precautionary saving. In this calibration of the model risk-shocks are very persistent $(\phi=0.92)$, so the rise in $\gamma \mathbb{E}_{t} \Delta s_{t+1}$ is small and the precautionary savings channel dominates. Consequently, as Panel C shows, the risk shock drives down U.S. interest rates. Precautionary saving also exerts downward pressure on the E.U. rate via a rise in $\gamma^{2} \mathbb{V}_{t}\left(\hat{c}_{t+1}+\hat{s}_{t+1}\right)$, but the effect is dominated by the increase in $\mathbb{E}_{t} \Delta \hat{c}_{t+1}$ induced by goods market clearing and risk sharing. As a result there is a very small rise in $\hat{r}_{t}$. The combined effect is a fall in the interest differential, $r_{t}-\hat{r}_{t}$, of 11 basis points per one percent of the risk-shock.

Panel D shows that the U.S. risk-shock has a much larger effect on the risk premium; it rises by more than 
twice the fall in the interest differential. The reason for this rise is apparent from the responses in Panels $\mathrm{A}$ and $\mathrm{B}$. There we saw that market clearing induced a real appreciation in the dollar but little change in total consumption, $c_{t}+\hat{c}_{t}$. So, when risk shocks are the dominant source of exchange-rate variations, $\mathbb{C V}_{t}\left(c_{t+1}+\hat{c}_{t+1}, \varepsilon_{t+1}\right)$ is close to zero and the equation for the risk premium in (47) simplifies to

$$
\delta_{t}=\frac{1}{2} \gamma \mathbb{C} \mathbb{V}_{t}\left(s_{t+1}+\hat{s}_{t+1}, \varepsilon_{t+1}\right)
$$

The plots in Panel A imply that $\varepsilon_{t}$ is positively correlated with $s_{t}-\hat{s}_{t}$, so the covariance on the right is proportional to $\mathbb{V}_{t}\left(s_{t+1}\right)-\mathbb{V}_{t}\left(\hat{s}_{t+1}\right)$. When the risk shock hits, $s_{t}$ falls and $\mathbb{V}_{t}\left(s_{t+1}\right)$ rises, so the risk premium jumps upward. Intuitively, the risk-shock makes E.U. bonds less attractive to U.S. households as a hedge against future unexpected changes in the real exchange rate, so the equilibrium risk premium (i.e., expected excess return) has to rise to compensate. Notice that this rise more than offsets the fall in the interest differential so the equilibrium expected depreciation rate, $\mathbb{E}_{t} \Delta \varepsilon_{t+1}=r_{t}-\hat{r}_{t}+\delta_{t}$, increases immediately following the shock in a manner consistent with the response of the real exchange rate show in Panel A.

The economy responds to risk shocks in an entirely different manner when markets are incomplete and households face collateral constraints. In particular, Figure 4 shows that the same U.S. risk shock induces a real depreciation of the dollar, a fall in the risk premium and relative consumption. To understand the source of these differences, consider first the direct effects of the shock on the value of U.S. equites, $Q_{t}$. Recall that $Q_{t}=\Lambda_{t}^{\mathrm{Q}} D_{t}$ where $\Lambda_{t}^{\mathrm{Q}}$ satisfies (37). Inspection of this equation reveals that $\Lambda_{t}^{\mathrm{Q}}$ must fall as the risk-shock hits even when the future paths for consumption and dividends remain unchanged. Intuitively, since the shock increases the risk aversion of U.S. households, market clearing requires that the expected return on equity must rise in compensation so there is an immediate fall in $Q_{t}$. The risk shock also affects household saving. Equation (36) shows that $\Lambda_{t}^{\mathrm{w}}=\left(W_{t}-C_{t}\right) / C_{t}$ falls by the same amount as $\Lambda_{t}^{\mathrm{Q}}$. This means that U.S. households reduce their savings by the same amount as their capital loss on equities so $\alpha_{t}^{\mathrm{Q}}$ remains at one and $N_{t}=\left(1-\alpha_{t}^{\mathrm{Q}}+\varkappa \alpha_{t}^{\mathrm{FB}}\right)\left(W_{t}-C_{t}\right)=\varkappa \alpha_{t}^{\mathrm{FB}} Q_{t}$ falls towards the lower bound of zero via the capital loss on equities. ${ }^{17}$ In sum, therefore, the direct effect of the risk shock is to push U.S. households towards their collateral constraint.

The indirect effects of risk shock now come into play. In particular, U.S. households' demand to hold E.U. bonds rather than U.S. bonds rises because the former are more valuable as collateral. This portfolio shift puts downward pressure on the equilibrium risk premium. So, ceteris paribus, the equilibrium real exchange rate must jump to a path consistent with future appreciation, like the path shown in the Panel A of Figure 4. This triggers an immediate deterioration in the U.S. terms of trade, so U.S. consumption falls and E.U. consumption rises to clear the goods markets, as shown in Panel B.

These adjustments of the exchange rate and consumption have several further consequences. First, the rise in $\varepsilon_{t}$ reduces the real value of U.S. dividends because $D_{t}=\left(P_{t}^{\mathrm{US}} / P_{t}\right) Y_{t}$ and the depreciation lowers the relative price of U.S. goods. As a result, the rise in $\varepsilon_{t}$ magnifies the size of the capital loss U.S. households suffer on their equity holdings. The rise in $\varepsilon_{t}$ also produces a capital gain for E.U. households on their equity holdings because it raises the value of dividends, $\hat{D}_{t}=\left(\hat{P}_{t}^{\mathrm{Eu}} / \hat{P}_{t}\right) \hat{Y}_{t}$, via an increase in the relative price of

\footnotetext{
${ }^{17}$ Risk-shocks have very small effects on $\alpha_{t}^{\mathrm{FB}}$, so the fall in $N_{t}$ closely matches the fall in $Q_{t}$.
} 
E.U. goods. ${ }^{18}$ These revaluation effects push U.S. households towards and E.U. households away from their respective collateral constraints.

The second set of consequences concern the behavior of real interest rates. In the presence of the collateral constraints, equilibrium interest rates are approximated by

$$
\begin{aligned}
& r_{t}=-\ln \beta+\gamma \mathbb{E}_{t} \Delta c_{t+1}+\gamma \mathbb{E}_{t} \Delta s_{t+1}-\frac{1}{2} \gamma^{2} \mathbb{V}_{t}\left(c_{t+1}+s_{t+1}\right)+\mu\left(n_{t}-\bar{n}_{t}\right), \quad \text { and } \\
& \hat{r}_{t}=-\ln \beta+\gamma \mathbb{E}_{t} \Delta \hat{c}_{t+1}+\gamma \mathbb{E}_{t} \Delta \hat{s}_{t+1}-\frac{1}{2} \gamma^{2} \mathbb{V}_{t}\left(\hat{c}_{t+1}+\hat{s}_{t+1}\right)+\mu\left(\hat{n}_{t}-\bar{n}_{t}\right) .
\end{aligned}
$$

Under complete markets, the risk shock has offsetting effects on the U.S. interest rate via an increase in $\mathbb{E}_{t} \Delta s_{t+1}$ and $\mathbb{V}_{t}\left(c_{t+1}+s_{t+1}\right)$. In this equilibrium there is also a fall in $n_{t}$ and a rise in $\mathbb{E}_{t} \Delta c_{t+1}$ induced by goods market clearing. Panel $\mathrm{C}$ of Figure 4 shows that the feedback effect on expected consumption growth dominates so the risk shock raises the U.S. real interest rate. The risk shock affects the E.U. interest rate through three channels. First, goods market clearing implies that $\mathbb{E}_{t} \Delta \hat{c}_{t+1}<0$ following the shock. Second, the fall in $s_{t}$ implies greater volatility in the future exchange rate, so $\mathbb{V}_{t}\left(\hat{c}_{t+1}+\hat{s}_{t+1}\right)$ rises because E.U. consumption is partially driven by changes in the terms of trade. Third, $\hat{n}_{t}$ rises as the valuation effects pull E.U. households away from their collateral constraint. Panel C shows that this last channel dominates. E.U. interest rise following the U.S. risk shock by almost as much as U.S. interest rates.

Final, we turn to the risk premium. As in the complete markets case, risk shocks induce insignificant variations in $c_{t}+\hat{c}_{t}$ so (47) simplifies to

$$
\delta_{t}=\frac{1}{2} \gamma \mathbb{C V}_{t}\left(s_{t+1}+\hat{s}_{t+1}, \varepsilon_{t+1}\right)+\frac{1}{2} \mu \varkappa\left(n_{t}-\hat{n}_{t}\right) .
$$

Risk shocks affect the risk premium via two channels: a borrowing channel identified by a change in $n_{t}-\hat{n}_{t}$, and a hedging channel identified by a change in $\mathbb{C V}_{t}\left(s_{t+1}+\hat{s}_{t+1}, \varepsilon_{t+1}\right)$. As noted above, the effect of the risk shock on the value of U.S. equities pulls U.S. households towards their collateral constraint so $n_{t}$ falls and the risk premium is pushed below zero. This direct effect on the risk premium is amplified in two ways. First the valuation effects of the real depreciation raise $\hat{n}_{t}$ and push $n_{t}$ lower as E. U. households move further from their constraint while U.S. households are pulled closer. Second, the risk shock makes E.U. bonds a better exchange-rate hedge. Households recognize that the transmission of the U.S. risk shock that lowers $s_{t}$ also leads to a real depreciation, or, more generally, induce a negative correlation between $\varepsilon_{t}$ and $s_{t}-\hat{s}_{t}$. This means that the covariance term is proportional to $\mathbb{V}_{t}\left(\hat{s}_{t+1}\right)-\mathbb{V}_{t}\left(s_{t+1}\right)=\omega\left(s_{t}-\hat{s}_{t}\right)$. When $s_{t}$ falls following the U.S. risk shock, households understand that E.U. bonds have become a better hedge against future unexpected exchange-rate variations, so the equilibrium risk premium must fall to compensate.

There are three important points to take away from this discussion: First, incomplete risk-sharing and the collateral constraints play an important role in the transmission of risk shocks to exchange rates and other variables. Risk shocks affect the exchange rate because the capital loss of U.S. equities pushes U.S. households towards their constraint. If the constraints were absent, there would be no need for the risk premium to adjust so the effects of the shock would not be transmitted internationally via the depreciation

\footnotetext{
${ }^{18}$ Expectations concerning future consumption and dividend growth also influence $\Lambda_{t}^{\mathrm{Q}}, \Lambda_{t}^{\mathrm{w}}$ and their E.U. counterparts, but the effects are very small and so can safely be ignored for the purpose of this discussion.
} 
of the exchange rate. Similarly, if households had access to an array of assets that permitted complete risk-sharing, the exchange rate would simply adjust to clear goods markets and equate marginal utilities so there would be little role for the risk premium.

The second point concerns the behavior of consumption and habits. Under complete markets, risk shocks make households' habits more volatile than consumption. To see why, I use the identity $h_{t}=h_{t}-c_{t}+c_{t}$ to write

$$
\mathbb{V}_{t}\left(h_{t+1}\right)=\mathbb{V}_{t}\left(h_{t+1}-c_{t+1}\right)+2 \mathbb{C} \mathbb{V}_{t}\left(h_{t+1}-c_{t+1}, c_{t+1}\right)+\mathbb{V}_{t}\left(c_{t+1}\right)
$$

By definition $h_{t}-c_{t}=\ln \left[1-\exp \left(s_{t}\right)\right]$, so we can rewrite this expression as

$$
\begin{aligned}
\mathbb{V}_{t}\left(h_{t+1}\right)-\mathbb{V}_{t}\left(c_{t+1}\right) & =\mathbb{V}_{t}\left(\ln \left[1-\exp \left(s_{t+1}\right)\right]\right)+2 \mathbb{C} \mathbb{V}_{t}\left(\ln \left[1-\exp \left(s_{t+1}\right)\right], c_{t+1}\right) \\
& \simeq\left(\frac{\bar{S}}{1-\bar{S}}\right)^{2} \mathbb{V}_{t}\left(s_{t+1}\right)-\frac{2 \bar{S}}{1-\bar{S}} \mathbb{C V}_{t}\left(s_{t+1}, c_{t+1}\right) .
\end{aligned}
$$

Under complete markets, an increase U.S. households' risk aversion lowers $s_{t}$ and leads to a domestic consumption boom via an improvement in the terms of trade. More generally, risk shocks produce a negative covariance between consumption and the surplus ratio, so the last term on the right-hand-side is positive and $\mathbb{V}_{t}\left(h_{t+1}\right)>\mathbb{V}_{t}\left(c_{t+1}\right)$. It is hard to square this implication with the idea that habits respond slowly to consumption. Indeed, it directly contradicts the assumption in standard habit specifications, such as CC, where consumption is exogenous. In contrast, risk shocks induce a positive covariance between the surplus and consumption ratio when markets are incomplete, so habits display less volatility than equilibrium consumption.

The third point concerns the behavior of interest rates and the risk premium. In both versions of the model risk shocks generate a larger response from the risk premium than from the real interest differential, $r_{t}-\hat{r}_{t}$, and the responses are in the opposite directions. This means that variations in the risk premium are the dominant force changing the expected depreciation rate, and by extension the real exchange rate. It also means that the population value for the slope coefficient in the real U.I.P regression (9), $\beta_{1}$, is negative in both versions of the model ( $\beta_{1}$ equals -1.424 and -1.015 under incomplete and complete markets, respectively). The behavior of individual interest rates is quite different. Under complete markets, the U.S. risk shock lowers the domestic interest rate but leaves foreign interest rates unaffected. As in Verdelhan (2010), greater risk aversion among U.S. households pushes down the U.S. real interest rate via precautionary saving, but here the effect is magnified by an expected fall in domestic consumption growth. In contrast, an increase in U.S. risk-aversion induces an increase in both U.S. and E.U. real interest rates when markets are incomplete. The key difference here is that U.S. households expect consumption to grow in the future as the U.S. terms of trade improve, so the desire to smooth consumption dominates the effects of precautionary saving and the collateral constraint. Intertemporal smoothing and precautionary saving also affect E.U. interest rates, but here the wealth effects dominate by pushing E.U. households further away from their collateral constraint. 


\section{Variance Decompositions}

Figures 3 and 4 showed how endowment and risk shocks were transmitted to exchange rates and other marco variables in environments with different degrees of risk sharing. I now examine the relative importance of risk and endowment shocks as drivers of exchange-rate variations and the dynamics of macro variables. For this purpose I calculate the variance ratios $\mathbb{V}\left(x_{t} \mid \sigma_{e}^{2}=0\right) / \mathbb{V}\left(x_{t}\right)$, where $\mathbb{V}\left(x_{t} \mid \sigma_{e}^{2}=0\right)$ denotes the unconditional variance of variable $x_{t}$ computed from the equilibrium of the model in the absence of endowment shocks (i.e., in an equilibrium when their variance, $\sigma_{e}^{2}$, is zero), and $\mathbb{V}\left(x_{t}\right)$ denotes the variance when both endowment and risk shocks are present. This variance ratio measures the fraction of the variability in $x_{t}$ that can be attributable to risk shocks.

Column (a) of Table 6 reports the variance ratios for the variables listed in the left-hand column computed from the equilibrium with incomplete markets and collateral constraints. The variance ratios in the other columns are computed from equilibria that use the benchmark values for all the parameters (from Table 4) except the parameter shown at the head of each column. A comparison of the ratios in column (a) with those in columns (b) -(h) reveals the degree to which the variance contribution of risk-shocks is robust across alternative parameterizations. In particular, there is full risk-sharing when $\mu=0$, so column (b) shows the contribution of risk-shocks when markets are complete. Columns (c) and (d) show the effects of reducing the values of the barrier and collateral parameters from their benchmark levels of $\mu=0.03$ and $\varkappa=0.3$, while columns (e) and (f) show the effect of different specifications for households preferences. Finally, columns (g) and (f) report the variance ratios computed in equilibria with different specifications for the endowment processes. In column (g) I report the effect of raising the AR coefficient, $\rho$, to 0.95 from its benchmark level of 0.77 . This change makes endowment shocks more persistent that risk shocks. In column (h) I show the effect of doubling the standard deviation of endowment stocks.

Three key features of the table stand out. First, risk shocks are the overwhelmingly dominant driver of real change rate variations across all variants of the model. In all but two cases, the variance ratios reported in row (i) are very close to one. The two exceptions occur in columns (d) and (h). The ratio in column (d) shows that risk shocks play a somewhat reduced role when foreign bonds are less valuable as collateral (i.e., when $\varkappa$ is smaller). In this case, risk shocks have smaller direct effects on the risk premia as households respond to capital gains and loss on the equity holdings, so their ultimate impact on the real exchange rate is reduced. Increasing the variance of the endowment shocks reduces the contribution of risk shocks to the

volatility of depreciation rates for obvious reasons. Nevertheless, the ratio in column (h) shows that the variance of endowments shocks would have to be a great deal larger than in the benchmark parameterization before risk shocks cease to be the dominate driver of the deprecation rate.

The second feature concerns the contribution of risk shocks to the variability of real trade flows. In row (ii) we see that risk shocks are the dominant driver of variations in the log ratio of exports to imports across all the model variants. To a first-order approximation,

$$
\ln \left(\mathfrak{X}_{t} / \mathfrak{M}_{t}\right)=[1-2 \varphi(1-\theta)] \varepsilon_{t}-\left(c_{t}-\hat{c}_{t}\right)
$$

so trade flows reflect variations in the real exchange rate (terms of trade) and the consumption differential. If 


\section{Table 6: Variance Decompositions}

\begin{tabular}{lcccccccc}
\hline \hline$x_{t}$ & $(\mathrm{a})$ & $(\mathrm{b})$ & $(\mathrm{c})$ & $(\mathrm{d})$ & $(\mathrm{e})$ & $(\mathrm{f})$ & $(\mathrm{g})$ & $(\mathrm{h})$ \\
& & $\mu=0$ & $\mu=0.015$ & $\varkappa=0.1$ & $\theta=0.2$ & $\eta=0.6$ & $\rho=0.95$ & $\sigma_{e} \times 2$ \\
\hline & & & & & & & & \\
& & & & & & & \\
(i) $\Delta \varepsilon_{t}$ & 0.982 & 0.998 & 0.996 & 0.772 & 0.979 & 0.989 & 0.983 & 0.883 \\
& & & & & & & & \\
(ii) $\ln \left(\mathfrak{X}_{t} / \mathfrak{M}_{t}\right)$ & 0.989 & 0.999 & 0.998 & 0.792 & 0.971 & 0.983 & 0.919 & 0.898 \\
& & & & & & & & \\
(iii) $\Delta c_{t}-\Delta \hat{c}_{t}$ & 0.695 & 0.952 & 0.921 & 0.110 & 0.883 & 0.981 & 0.540 & 0.233 \\
(iv) $r_{t}-\hat{r}_{t}$ & 0.631 & 0.990 & 0.961 & 0.111 & 0.586 & 0.733 & 0.866 & 0.180 \\
(v) $r_{t}$ & 0.998 & 0.966 & 1.000 & 0.996 & 0.998 & 0.999 & 1.000 & 0.989 \\
(vi) $c_{t}-\mathfrak{T}_{t}$ & 0.571 & 0.921 & 0.873 & 0.068 & 0.793 & 0.954 & 0.417 & 0.151
\end{tabular}

Notes: The table reports the fraction of the unconditional variance attributable to risk shocks for each of the variables listed in the left-hand column: $\mathbb{V}\left(x \mid \sigma_{e}^{2}=0\right) / \mathbb{V}(x)$. The variance ratios reported in column (a) are computed from the incomplete markets equilibrium with collateral constraints using the benchmark parameter values reported in Table 4. The ratios in columns (b) - (h) are computed from the equilibrium with benchmark values for the parameters except the one shown at the head of each column. $c_{t}-\mathfrak{T}_{t}$ denotes the cyclical component of U.S. aggregate consumption.

real exchange rates are much more volatile than relative consumption (as they are in the data and the model variants), and risk-shocks account for most exchange rate volatility, then they must also be the dominant driver of trade flows.

Finally, rows (iii) - (vi) of Table 6 show that the risk shocks have substantial macroeconomic effects, they are the dominant drives of the consumption growth and real interest differentials, real interest rates and the cyclical component of U.S. consumption, $c_{t}-\mathfrak{T}_{t}$, across most model variants. Again, the notable exception appears in column (d). When foreign bonds are less valuable as collateral the international transmission of risk shocks via the risk premia is dampened, so the effects are absorbed by interest rates rather than domestic consumption and the consumption differential.

\section{Conclusion}

The main message of this paper is very simple. Variations in current and expected future real interest differentials have played a very minor role as the proximate determinant of the changes in real exchange rates for major currencies over short- and medium-term horizons in the post-Bretton Woods era. Instead, exchange-rate dark matter has been the dominate driver of real depreciation rates through its affects on expected excess returns and/or the expected long-run real exchange rate. To understand the nature of this 
dark matter, I developed a novel open-economy DSGE model in which the risk shocks driving households' habits worked in conjunction with collateral constraints and incomplete markets. The model not only shows that risk shocks can account for the role of dark matter in real exchange-rate dynamics, but also that these same shocks have significant macroeconomic implications. This analysis suggests that exchange rates appear disconnected from traditional fundamentals because they are particularly susceptible to risk shocks that play an important role in international macroeconomics.

Finally, let me offer a some perspective on these results. First, my empirical analysis in Section 1 used VARs to estimate variations in expected future real rate differentials, rather than data on agents' forecasts. Thus, it is possible that my analysis over-estimates the contribution of dark matter because agents' actual forecasts for future real interest differentials were varying far more than one could identify from any VAR. However, if this were really the explanation for my empirical results, we would be left to wonder what was making agents' interest-rate forecasts so volatile. Remember that according to my calculations dark matter accounts for approximately 90 percent of the variance in real depreciation rates at a five-year horizon, so adding a little more volatility to agents' interest-rate forecasts will not eliminate the role of dark matter.

The second perspective concerns the structure of the DSGE model. Following CC, the model is reversedengineered to surmount some of the known pitfalls of existing open-economy models, such as their failure to replicate the Backus-Smith and Real UIP Puzzles. A model that could not account for these longstanding exchange-rate puzzles would be of little use in understanding the forces driving exchanges rates and macroeconomic variables. At the same time, the model does not provide any micro foundations for the assumption that all households within a country are subject to the same risk shock. This modeling approach is very much in line with the asset-pricing literature, but clearly there is more work to be done here. The model also abstracts from many other features; such as production, price-setting, nontraded goods, a government or financial institutions. Adding these features to the model is conceptually straightforward, but they would have obscured my purpose here. More importantly, adding these features to the model would give greater scope for risk shocks to affect real macroeconomics activity via channels like the financial accelerator. Such a model would also provide some entirely new conceptual space for analyzing macro-prudential risk management, capital controls and international macroeconomic policies.

\section{References}

Bacchetta, P. and E. Van Wincoop. 2010. "Infrequent portfolio decisions: A solution to the forward discount puzzle." The American Economic Review 100 (3):870-904.

Backus, D. and G. Smith. 1993. "Consumption and Real Exchange Rates in Dynamic Exchange Economies with Nontraded Goods." Journal of International Economics 35 (3-4):297-316.

Balassa, B. 1964. "The Purchasing-Power Parity Doctrine: A Reappraisal." The Journal of Political Economy $72(6): 584-596$.

Bansal, R. and A. Yaron. 2004. "Risks for the long run: A potential resolution of asset pricing puzzles." The Journal of Finance 59 (4):1481-1509. 
Bansal, Ravi and Ivan Shaliastovich. 2010. "A Long-Run Risks Explanation of Predictability Puzzles in Bond and Currency Markets." Tech. rep., Fuqua School of Business, Duke University.

Baxter, Marianne, Urban J. Jermann, and Robert G. King. 1998. "Nontraded Goods, Nontraded Factors, and International Non-diversification." Journal of International Economics 44 (2):211-229.

Blanchard, Olivier, Francesco Giavazzi, and Filipa Sa. 2005. "International Investors, the U.S. Current Account, and the Dollar." Brookings Papers on Economic Activity 2005 (1):1-49. URL http://www. jstor.org/stable/3805081.

Campa, Jose Manuel and Linda S. Goldberg. 2008. "Pass-Through of Exchange Rates to Consumption Prices: What Has Changed and Why?" In International Financial Issues in the Pacific Rim: Global Imbalances, Financial Liberalization, and Exchange Rate Policy (NBER-EASE Volume 17), NBER Chapters. National Bureau of Economic Research, Inc, 139-176. URL http://ideas.repec.org/h/nbr/nberch/6982.html.

Campbell, J.Y. and J.H. Cochrane. 1999. "By force of habit: A consumption-based explanation of aggregate stock market behavior." Journal of political Economy 107 (2):205-251.

Campbell, J.Y. and L.M. Viceira. 2002. Strategic Asset Allocation: Portfolio Choice for Long-Term Investors. Oxford University Press.

Cole, Harold L. and Maurice Obstfeld. 1991. "Commodity trade and international risk sharing: How much do financial markets matter?" Journal of Monetary Economics 28 (1):3 - 24. URL http: //www.sciencedirect.com/science/article/pii/030439329190023H.

Corsetti, Giancarlo, Luca Dedola, and Sylvain Leduc. 2008. "International Risk Sharing and the Transmission of Productivity Shocks." Review of Economic Studies 75 (2):443-473.

Devereux, M.B. and A. Sutherland. 2010. "Solving for Country Portfolios in Open Economy Macro Models." Journal of the European Economic Association forthcoming.

Devereux, M.B. and J. Yetman. 2010. "Price adjustment and exchange rate pass-through." Journal of International Money and Finance 29 (1):181-200.

Devereux, Michael B and Charles Engel. 2002. "Exchange rate pass-through, exchange rate volatility, and exchange rate disconnect." Journal of Monetary Economics 49 (5):913-940. URL http://ideas.repec. org/a/eee/moneco/v49y2002i5p913-940.html.

Duarte, M. and A.C. Stockman. 2005. "Rational speculation and exchange rates." Journal of Monetary Economics $52(1): 3-29$.

Engel, C. 1999. "Accounting for US Real Exchange Rate Changes." Journal of Political Economy 107 (3):507.

Engel, C. and K.D. West. 2006. "Taylor Rules and the Deutschmark-Dollar Real Exchange Rate." Journal of Money, Credit, and Banking 38 (5):1175-1194. 
Engel, Charles. 2011. "The Real Exchange Rate, Real Interest Rates, and the Risk Premium." Working Paper 17116, National Bureau of Economic Research. URL http://www.nber.org/papers/w17116.

Engel, Charles, Nelson C. Mark, and Kenneth D. West. 2008. Exchange Rate Models Are Not As Bad As You Think. University of Chicago Press, 381-441. URL http://www.nber.org/chapters/c4075.

Engel, Charles and Akito Matsumoto. 2009. "The International Diversification Puzzle When Goods Prices Are Sticky: It's Really about Exchange-Rate Hedging, Not Equity Portfolios." American Economic Journal: Macroeconomics 1 (2):155-88.

Evans, Martin D. D. 2011. Exchange-Rate Dynamics. Princeton Series in International Finance. Princeton University Press.

Evans, Martin D. D. and Viktoria Hnatkovska. 2005a. "International Capital Flows, Returns and World Financial Integration." Working Paper 11701, National Bureau of Economic Research. URL http://www . nber.org/papers/w11701.

_ 2005b. "Solving General Equilibrium Models with Incomplete Markets and Many Assets." Working Paper 318, National Bureau of Economic Research. URL http://www.nber.org/papers/t0318.

—. 2007. "International Financial Integration and the Real Economy." IMF Staff Papers 54:220-269.

Evans, Martin D. D. and Karen K Lewis. 1995. "Do long-term swings in the dollar affect estimates of the risk premia?" Review of Financial Studies 8 (3):709-742.

Fama, E.F. 1984. "Spot and forward exchange rates." Journal of Monetary Economics 14 (3):319-338.

Forsgren Anders, Philip Gill and Margaret Wright. 2002. "Interior Methods for Nonlinear Optimization." SIAM Review 44:525-597.

Froot, K.A. and R.H. Thaler. 1990. "Anomalies: foreign exchange." The Journal of Economic Perspectives $4(3): 179-192$.

Henderson, D.W. and K. Rogoff. 1982. "Negative net foreign asset positions and stability in a world portfolio balance model." Journal of International Economics 13 (1-2):85-104.

Hnatkovska, Viktoria. 2010. "Home bias and high turnover: Dynamic portfolio choice with incomplete markets." Journal of International Economics 80 (1):113 - 128.

Jonen, Benjamin and Simon Scheuring. 2011. "Time-Varying International Diversification and the Forward Premium." Tech. rep., Banking Institute, University of Zurich.

Kim, S.H., R. Kollmann, and J. Kim. 2010. "Solving the incomplete market model with aggregate uncertainty using a perturbation method." Journal of Economic Dynamics and Control 34 (1):50-58.

Kollmann, R. 2001. "The exchange rate in a dynamic-optimizing business cycle model with nominal rigidities: a quantitative investigation." Journal of International Economics 55 (2):243-262. 
. 2006. "International Portfolio Equilibrium and the Current Account: A Dynamic General Equilibrium Perspective." Mimeo, Free University of Brussels.

Kouri, Pentti J. K. 1976. "The Exchange Rate and the Balance of Payments in the Short Run and in the Long Run: A Monetary Approach." The Scandinavian Journal of Economics 78 (2):280-304. URL http://www. jstor.org/stable/3439930.

Lombardo, G. and A. Sutherland. 2007. "Computing second-order-accurate solutions for rational expectation models using linear solution methods." Journal of Economic Dynamics and Control 31 (2):515-530.

Mark, N.C. 2009. "Changing Monetary Policy Rules, Learning, and Real Exchange Rate Dynamics." Journal of Money, Credit and Banking 41 (6):1047-1070.

Meese, R.A. and K. Rogoff. 1983. "Empirical Exchange Rate Models of the Seventies: Do They Fit Out of Sample?" Journal of International Economics 14 (1-2):3-24.

Mendoza, Enrique G. 2010. "Sudden Stops, Financial Crises, and Leverage." The American Economic Review 100 (5):1941-1966. URL http://www. ingentaconnect.com/content/aea/aer/2010/00000100/ $00000005 /$ art00001.

Moore, Michael J. and Maurice J. Roche. 2009. "For Rich or for Poor: When does Uncovered Interest Parity Hold?" Working Paper, Queen's University Belfast .

Moore, Michael J and Maurice J Roche. 2010. "Solving exchange rate puzzles with neither sticky prices nor trade costs." Journal of International Money and Finance 29 (6):1151-1170. URL http://linkinghub. elsevier.com/retrieve/pii/S0261560610000343.

Obstfeld, M. and K. Rogoff. 2001. "The Six Major Puzzles in International Macroeconomics: Is There a Common Cause?" NBER Macroeconomics Annual 2000 .

2003. "Risk and Exchange Rates* Maurice Obstfeld and Kenneth S. Rogoff." Economic Policy in the International Economy: Essays in Honor of Assaf Razin .

Obstfeld, M. and K.S. Rogoff. 1996. Foundations of International Macroeconomics. MIT Press Cambridge, MA.

Pagan, Adrian. 1984. "Econometric Issues in the Analysis of Regressions with Generated Regressors." International Economic Review 25 (1):pp. 221-247. URL http://www.jstor.org/stable/2648877.

Pavlova, A. and R. Rigobon. 2010. "International Macro-Finance." Tech. rep., National Bureau of Economic Research.

Preston, Bruce and Mauro Roca. 2007. "Incomplete Markets, Heterogeneity and Macroeconomic Dynamics." Working Paper 13260, National Bureau of Economic Research. URL http://www.nber.org/papers/ w13260. 
Samuelson, P.A. 1964. "Theoretical Notes on Trade Problems." The Review of Economics and Statistics $46(2): 145-154$.

Schmitt-Grohe, Stephanie and Martin Uribe. 2003. "Closing small open economy models." Journal of International Economics 61 (1):163-185.

Trimble, V. 1987. "Existence and nature of dark matter in the universe." Annual Review of Astronomy and Astrophysics 25:425-472.

Van Wincoop, Eric and Cedric Tille. 2007. "International Capital Flows." Working Paper 12856, National Bureau of Economic Research. URL http://www.nber.org/papers/w12856.

Verdelhan, A. 2010. "A Habit-Based Explanation of the Exchange Rate Risk Premium." The Journal of Finance 65 (1):123-146.

White, H. 1980. "A heteroskedasticity-consistent covariance matrix estimator and a direct test for heteroskedasticity." Econometrica: Journal of the Econometric Society :817-838.

\section{Appendix.}

This appendix describes the procedure I use to compute the equilibrium process for the real exchange rate and other variables. The procedure adapts the two-step solution method in Lombardo and Sutherland (2007) to the set of second-order and continuous-time approximations of the model's equilibrium conditions. First I summarize these equations. I then present the approximations and describe the solution method.

\section{Equilibrium Conditions}

The model's equilibrium conditions comprise the households' first-order conditions, the market clearing conditions and the exogenous processes for the endowments and consumption surplus ratios. The first-order conditions for the U.S. and E.U. households are :

$$
\begin{aligned}
& 1=\beta \mathbb{E}_{t}\left[\left(\frac{C_{t+1}}{C_{t}}\right)^{-\gamma}\left(\frac{S_{t+1}}{S_{t}}\right)^{-\gamma} R_{t+1}^{\mathrm{EQ}}\right], \\
& 1=\beta \mathbb{E}_{t}\left[\left(\frac{C_{t+1}}{C_{t}}\right)^{-\gamma}\left(\frac{S_{t+1}}{S_{t}}\right)^{-\gamma} \frac{\mathcal{E}_{t+1} \hat{R}_{t}}{\mathcal{E}_{t}}\right]+(1+\varkappa) \mathcal{B}_{t} \\
& 1=\beta \mathbb{E}_{t}\left[\left(\frac{C_{t+1}}{C_{t}}\right)^{-\gamma}\left(\frac{S_{t+1}}{S_{t}}\right)^{-\gamma} R_{t}\right]+\mathcal{B}_{t},
\end{aligned}
$$




$$
\begin{aligned}
& 1=\beta \mathbb{E}_{t}\left[\left(\frac{\hat{C}_{t+1}}{\hat{C}_{t}}\right)^{-\gamma}\left(\frac{\hat{S}_{t+1}}{\hat{S}_{t}}\right)^{-\gamma} \hat{R}_{t+1}^{\mathrm{EQ}}\right] \\
& 1=\beta \mathbb{E}_{t}\left[\left(\frac{\hat{C}_{t+1}}{\hat{C}_{t}}\right)^{-\gamma}\left(\frac{\hat{S}_{t+1}}{\hat{S}_{t}}\right)^{-\gamma} \frac{\mathcal{E}_{t} R_{t}}{\mathcal{E}_{t+1}}\right]+(1+\varkappa) \hat{\mathcal{B}}_{t} \quad \text { and } \\
& 1=\beta \mathbb{E}_{t}\left[\left(\frac{\hat{C}_{t+1}}{\hat{C}_{t}}\right)^{-\gamma}\left(\frac{\hat{S}_{t+1}}{\hat{S}_{t}}\right)^{-\gamma} \hat{R}_{t}\right]+\hat{\mathcal{B}}_{t} .
\end{aligned}
$$

where

$$
\mathcal{B}_{t}=\mu\left(\frac{C_{t} S_{t}}{\overline{C_{t}}{ }}\right)^{\gamma}\left\{\frac{\bar{N}_{t}}{N_{t}}-1\right\} \quad \text { and } \quad \hat{\mathcal{B}}_{t}=\mu\left(\frac{\hat{C}_{t} \hat{S}_{t}}{\left.\overline{C_{t}}\right)^{\gamma}}\right)^{\gamma}\left\{\frac{\bar{N}_{t}}{\hat{N}_{t}}-1\right\} \text {. }
$$

I use (52a) and (53a) to identify the ratios of equity prices to dividends, $\Lambda_{t}^{Q}=Q_{t} / D_{t}$ and $\hat{\Lambda}_{t}^{Q}=\hat{Q}_{t} / \hat{D}_{t}$ :

$$
\begin{aligned}
\Lambda_{t}^{\mathrm{Q}} & =\beta \mathbb{E}_{t}\left[\left(\frac{C_{t+1}}{C_{t}}\right)^{-\gamma}\left(\frac{S_{t+1}}{S_{t}}\right)^{-\gamma}\left(\Lambda_{t+1}^{\mathrm{Q}}+1\right) \frac{D_{t+1}}{D_{t}}\right] \quad \text { and } \\
\hat{\Lambda}_{t}^{\mathrm{Q}} & =\beta \mathbb{E}_{t}\left[\left(\frac{\hat{C}_{t+1}}{\hat{C}_{t}}\right)^{-\gamma}\left(\frac{\hat{S}_{t+1}}{\hat{S}_{t}}\right)^{-\gamma}\left(\hat{\Lambda}_{t+1}^{\mathrm{Q}}+1\right) \frac{\hat{D}_{t+1}}{\hat{D}_{t}}\right]
\end{aligned}
$$

The savings-to-consumption ratios, $\Lambda_{t}^{\mathrm{w}}=\left(W_{t}-C_{t}\right) / C_{t}$ and $\hat{\Lambda}_{t}^{\mathrm{w}}=\left(\hat{W}_{t}-\hat{C}_{t}\right) / \hat{C}_{t}$, are determined by

$$
\begin{aligned}
& \Lambda_{t}^{\mathrm{w}}=\beta \mathbb{E}_{t}\left[\left(\frac{C_{t+1}}{C_{t}}\right)^{1-\gamma}\left(\frac{S_{t+1}}{S_{t}}\right)^{-\gamma}\left(\Lambda_{t+1}^{\mathrm{w}}+1\right)\right]+\mathcal{B}_{t} N_{t} / C_{t} \quad \text { and } \\
& \hat{\Lambda}_{t}^{\mathrm{w}}=\beta \mathbb{E}_{t}\left[\left(\frac{\hat{C}_{t+1}}{\hat{C}_{t}}\right)^{1-\gamma}\left(\frac{\hat{S}_{t+1}}{\hat{S}_{t}}\right)^{-\gamma}\left(\hat{\Lambda}_{t+1}^{\mathrm{w}}+1\right)\right]+\widehat{\mathcal{B}}_{t} \hat{N}_{t} / \hat{C}_{t} .
\end{aligned}
$$

Goods market clearing requires that

$$
\begin{aligned}
& Y_{t}=\eta\left(\eta+(1-\eta) \mathcal{T}_{t}^{1-\theta}\right)^{\frac{\theta}{1-\theta}} C_{t}+(1-\eta)\left(\eta \mathcal{T}_{t}^{1-\theta}+(1-\eta)\right)^{\frac{\theta}{1-\theta}} \hat{C}_{t}, \quad \text { and } \\
& \hat{Y}_{t}=(1-\eta)\left(\eta \mathcal{T}_{t}^{\theta-1}+(1-\eta)\right)^{\frac{\theta}{1-\theta}} C_{t}+\eta\left(\eta+(1-\eta) \mathcal{T}_{t}^{\theta-1}\right)^{\frac{\theta}{1-\theta}} \hat{C}_{t},
\end{aligned}
$$

while market clearing in the equity and bond markets requires that

$$
\alpha_{t}^{\mathrm{Q}}=Q_{t} /\left(W_{t}-C_{t}\right), \quad \hat{\alpha}_{t}^{\mathrm{Q}}=\hat{Q}_{t} /\left(\hat{W}_{t}-\hat{C}_{t}\right), \quad B_{t}^{\mathrm{US}}+\hat{B}_{t}^{\mathrm{US}}=0 \quad \text { and } \quad B_{t}^{\mathrm{EU}}+\hat{B}_{t}^{\mathrm{EU}}=0 .
$$

Goods market clearing also implies that real dividends are related to aggregate consumption and the trade flows by

$$
D_{t}=C_{t}+\mathfrak{X}_{t}-\mathfrak{M}_{t}, \quad \text { and } \quad \hat{D}_{t}=\hat{C}_{t}+\left(\mathfrak{M}_{t}-\mathfrak{X}_{t}\right) / \mathcal{E}_{t}
$$


where

$$
\mathfrak{X}_{t}=(1-\eta)\left(\eta \mathcal{T}_{t}^{1-\theta}+(1-\eta)\right)^{-1} \mathcal{E}_{t} \hat{C}_{t} \quad \text { and } \quad \mathfrak{M}_{t}=(1-\eta)\left(\eta \mathcal{T}_{t}^{\theta-1}+(1-\eta)\right)^{-1} C_{t}
$$

Combining the bond and equity market clearing conditions in (21) and (22) with the aggregated budget constraint for U.S. households in (19) and the equation for dividends in (58) gives the following expression for the consolidated U.S. budget constraint:

$$
F A_{t}-F L_{t}=X_{t}-M_{t}-R_{t}^{\mathrm{FL}} F L_{t-1}+R_{t}^{\mathrm{FA}} F A_{t-1}
$$

where $\mathcal{E}_{t} B_{t}^{\mathrm{EU}}=F A_{t}$ and $\hat{B}_{t}^{\mathrm{US}}=F L_{t}$, and where $R_{t}^{\mathrm{FA}}=\mathcal{E}_{t} \hat{R}_{t-1} / \mathcal{E}_{t-1}$ and $R_{t}^{\mathrm{FL}}=R_{t-1}$. In equilibrium households hold long positions in foreign bonds (i.e., $B_{t}^{\mathrm{EU}}>0$ and $\hat{B}_{t}^{\mathrm{US}}>0$ ) so $F A_{t}$ and $F L_{t}$ denote the real value of U.S. foreign assets and liabilities.

The exogenous processes for the log surplus ratios follow

$$
s_{t+1}=(1-\phi) \bar{s}+\phi s_{t}+\omega\left(s_{t}\right) v_{t+1} \quad \text { and } \quad \hat{s}_{t+1}=(1-\phi) \bar{s}+\phi \hat{s}_{t}+\omega\left(\hat{s}_{t}\right) \hat{v}_{t+1}
$$

where $v_{t}$ and $\hat{v}_{t}$ are mean-zero, unit variance i.i.d. shocks, and

$$
\omega(\mathrm{s})=\left\{\begin{array}{cl}
\sqrt{\omega\left(s_{\max }-\mathrm{s}\right)} & \mathrm{s} \leq s_{\max } \\
0 & \mathrm{~s}>s_{\max }
\end{array} .\right.
$$

The log endowments follow

$$
y_{t}=\mathfrak{T}_{\mathfrak{t}}+z_{t} \quad \text { and } \quad \hat{y}_{t}=\mathfrak{T}_{\mathfrak{t}}+\hat{z}_{t}
$$

with

$$
\mathfrak{T}_{\mathfrak{t}}=\mathfrak{T}_{\mathfrak{t}-1}+g+u_{t}, \quad z_{t}=\rho z_{t-1}+e_{t} \quad \text { and } \quad \hat{z}=\rho \hat{z}_{t-1}+\hat{e}_{t}
$$

where $u_{t}, e_{t}$ and $\hat{e}_{t}$ are mean-zero i.i.d. shocks with variances $\sigma_{u}^{2}$ and $\sigma_{e}^{2}$, respectively.

\section{The Steady State}

To determine the steady state, I first write the goods market clearing conditions in (56) as

$$
c y_{t}=-\mathcal{H}\left(\tau_{t},-\xi_{t}\right) \quad \text { and } \quad \hat{c} \hat{y}_{t}=-\mathcal{H}\left(-\tau_{t}, \xi_{t}\right)
$$

where $\xi_{t}=c y_{t}-\hat{c} \hat{y}_{t}+z_{t}-\hat{z}_{t}$ and

$$
\mathcal{H}(\tau, \xi)=\ln \left\{\left[\eta\left(\eta+(1-\eta) \exp (\tau)^{1-\theta}\right]^{\frac{\theta}{1-\theta}}+(1-\eta)\left[\eta \exp (\tau)^{1-\theta}+(1-\eta)\right]^{\frac{\theta}{1-\theta}} \exp (\xi)\right\}\right.
$$


Let $\bar{\tau}$ and $\bar{\xi}$ denote the steady state values of $\tau_{t}$ and $\xi_{t}$ that are to be determined. Taking a first-order approximation to (63) around $\bar{\tau}$ and $\bar{\xi}$ produces

$$
\begin{aligned}
{\left[\begin{array}{c}
c y_{t}-\overline{c y} \\
c y_{t}-\bar{c}_{t}
\end{array}\right]=} & \frac{1}{\Xi}\left[\begin{array}{cc}
1-\mathcal{H}_{\xi}(-\bar{\tau}, \bar{\xi}) & -\mathcal{H}_{\xi}(\bar{\tau},-\bar{\xi}) \\
-\mathcal{H}_{\xi}(-\bar{\tau}, \bar{\xi}) & 1-\mathcal{H}_{\xi}(\bar{\tau},-\bar{\xi})
\end{array}\right]\left[\begin{array}{c}
\mathcal{H}_{\xi}(\bar{\tau},-\bar{\xi}) \\
-\mathcal{H}_{\xi}(-\bar{\tau}, \bar{\xi})
\end{array}\right]\left(z_{t}-\hat{z}_{t}\right) \\
& +\frac{1}{\Xi}\left[\begin{array}{cc}
1-\mathcal{H}_{\xi}(-\bar{\tau}, \bar{\xi}) & -\mathcal{H}_{\xi}(\bar{\tau},-\bar{\xi}) \\
-\mathcal{H}_{\xi}(-\bar{\tau}, \bar{\xi}) & 1-\mathcal{H}_{\xi}(\bar{\tau},-\bar{\xi})
\end{array}\right]\left[\begin{array}{c}
-\mathcal{H}_{\tau}(\bar{\tau},-\bar{\xi}) \\
\mathcal{H}_{\tau}(-\bar{\tau}, \bar{\xi})
\end{array}\right]\left(\tau_{t}-\bar{\tau}\right),
\end{aligned}
$$

where

$$
\Xi=\left(1-\mathcal{H}_{\xi}(-\bar{\tau}, \bar{\xi})\right)\left(1-\mathcal{H}_{\xi}(\bar{\tau},-\bar{\xi})\right)-\mathcal{H}_{\xi}(\bar{\tau},-\bar{\xi}) \mathcal{H}_{\xi}(-\bar{\tau}, \bar{\xi})
$$

I also use log-normal approximations to the first-order conditions determining bond holdings.

$$
\begin{aligned}
r_{t} & =-\ln \beta+\gamma \mathbb{E}_{t}\left(\Delta c_{t+1}+\Delta s_{t+1}\right)-\frac{1}{2} \gamma^{2} \mathbb{V}_{t}\left(c_{t+1}+s_{t+1}\right), \\
\hat{r}_{t} & =-\ln \beta+\gamma \mathbb{E}_{t}\left(\Delta \hat{c}_{t+1}+\Delta \hat{s}_{t+1}\right)-\frac{1}{2} \gamma^{2} \mathbb{V}_{t}\left(\hat{c}_{t+1}+\hat{s}_{t+1}\right), \\
\mathbb{E}_{t} \Delta \varepsilon_{t+1}+\hat{r}_{t} & =-\ln \beta+\gamma \mathbb{E}_{t}\left(\Delta c_{t+1}+\Delta s_{t+1}\right)-\frac{1}{2} \mathbb{V}_{t}\left(\varepsilon_{t+1}-\gamma\left(c_{t+1}+s_{t+1}\right)\right) \\
\mathbb{E}_{t} \Delta \varepsilon_{t+1}-r_{t} & =\ln \beta-\gamma \mathbb{E}_{t}\left(\Delta \hat{c}_{t+1}+\Delta \hat{s}_{t+1}\right)+\frac{1}{2} \mathbb{V}_{t}\left(\varepsilon_{t+1}+\gamma\left(c_{t+1}+s_{t+1}\right)\right) .
\end{aligned} \quad \text { and }
$$

Rewriting these equations in terms of $c y_{t}$ and $c y_{t}$ and simplifying gives

$$
\begin{aligned}
& \delta_{t}= \frac{1}{2} \gamma \mathbb{C V}_{t}\left(\varepsilon_{t+1}, z_{t+1}+\hat{z}_{t+1}\right)+\frac{1}{2} \gamma \mathbb{C V}_{t}\left(\varepsilon_{t+1}, c y_{t+1}+\hat{c} y_{t+1}\right)+\frac{1}{2} \gamma \mathbb{C V}_{t}\left(\varepsilon_{t+1}, s_{t+1}+\hat{s}_{t+1}\right) \\
& r_{t}-\hat{r}_{t}=\gamma \mathbb{E}_{t}\left(\Delta c y_{t+1}+\Delta z_{t+1}+\Delta s_{t+1}\right)-\gamma \mathbb{E}_{t}\left(\Delta c \hat{y}_{t+1}+\Delta \hat{z}_{t+1}+\Delta \hat{s}_{t+1}\right) \\
&+\frac{1}{2} \gamma^{2}\left\{\mathbb{V}_{t}\left(\hat{c} y_{t+1}+\hat{z}_{t+1}+\hat{s}_{t+1}\right)-\mathbb{V}_{t}\left(c y_{t+1}+z_{t+1}+s_{t+1}\right)\right\}
\end{aligned}
$$

Combining these expressions with the identity $\mathbb{E}_{t} \Delta \varepsilon_{t+1}=r_{t}-\hat{r}_{t}+\delta_{t}$ produces the approximate counterpart to (33). The link between this international asset market condition and the market clearing approximations in (63) is provided by the log terms of trade in $(34 \mathrm{c}): \tau_{t}=\mathcal{J}\left(\varepsilon_{t}\right)$, which I approximate as

$$
\tau_{t}=\bar{\tau}+\mathcal{J}_{\varepsilon}(\bar{\varepsilon})\left(\varepsilon_{t}-\bar{\varepsilon}\right)
$$

In the steady state, $z_{t}=\hat{z}_{t}=0$, so (63) implies that $\bar{\xi}=\mathcal{H}(-\bar{\tau}, \bar{\xi})-\mathcal{H}(\bar{\tau},-\bar{\xi})$. Rearranging this expression, produces $\bar{\xi}=\mathcal{G}(\bar{\tau})$ where $\mathcal{G}(\tau)=\mathcal{H}(-\tau, 0)-\mathcal{H}(\tau, 0)$. Furthermore, $\mathcal{G}_{\tau}(\tau)<0$ when there is consumption home bias.

To show that $\bar{\varepsilon}=0$ is a candidate value for the steady state real exchange rate, I verify that

$$
\varepsilon_{t}=\pi_{z}\left(z_{t}-\hat{z}_{t}\right)+\pi_{s}\left(s_{t}-\hat{s}_{t}\right)
$$

solves (64), (65) and (66) when $\bar{\varepsilon}=\bar{\tau}=0$ and $\bar{\xi}=\mathcal{G}(0)=0$. The values for $\pi_{z}$ and $\pi_{s}$ are determined by 
applying the method of undetermined coefficients as

$$
\pi_{z}=\frac{(2 \varphi-1) \gamma(1-\rho)}{(1-\rho)+4 \theta(1-\eta)(1-\rho) \varphi^{2} / \eta} \quad \text { and } \quad \pi_{s}=\frac{\gamma\left(1-\phi-\frac{1}{2} \gamma \omega\right)}{\left[1+4 \theta \gamma(1-\eta) \varphi^{2} / \eta\right]\left(1-\phi-\frac{1}{2} \gamma \omega\right)} .
$$

The corresponding approximations for the log consumption-output ratios are found by combining (64), (66) and (67).

Now suppose that

$$
\mathcal{F}(.)=\tilde{\varepsilon}+\pi_{z}\left(z_{t}-\hat{z}_{t}\right)+\pi_{s}\left(s_{t}-\hat{s}_{t}\right)
$$

for some value $\tilde{\varepsilon}$ close to zero. If the economy is in the steady state at $t,(65 \mathrm{a})$ simplifies to

$$
\begin{aligned}
\delta_{t} & =\frac{1}{2} \gamma \mathbb{C V}_{t}\left(\varepsilon_{t+1}, c y_{t+1}+\hat{c} y_{t+1}\right) \quad \text { and } \\
r_{t}-\hat{r}_{t} & =\frac{1}{2} \gamma^{2}\left\{\mathbb{V}_{t}\left(\hat{c} y_{t+1}+\hat{z}_{t+1}+\hat{s}_{t+1}\right)-\mathbb{V}_{t}\left(c y_{t+1}+z_{t+1}+s_{t+1}\right)\right\}
\end{aligned}
$$

because (64) and (66) imply that $\mathbb{E}_{t} \Delta c y_{t+1}=\mathbb{E}_{t} \Delta \hat{c} y_{t+1}$ for any value of $\bar{\tau}$ and $\bar{\xi}$. In a symmetric steady state, the variance terms in (69b) are equal, so $r_{t}=\hat{r}_{t}$ and $\mathbb{E}_{t} \Delta \varepsilon_{t+1}=\delta_{t}$. Since the approximation in (68) implies that $\mathbb{E}_{t} \Delta \varepsilon_{t+1}=0, \tilde{\varepsilon}$ can differ from zero if and only if there are non-zero values for $\bar{\tau}$ and $\bar{\xi}$ such that (64) and (68) together imply that $\mathbb{C V}_{t}\left(\varepsilon_{t+1}, c y_{t+1}+\hat{c} y_{t+1}\right)=0$. Inspection of (64) reveals that this will be true when

$$
\frac{1-2 \mathcal{H}_{\xi}(\bar{\tau},-\bar{\xi})}{1-2 \mathcal{H}_{\xi}(-\bar{\tau}, \bar{\xi})}=\frac{\mathcal{H}_{\tau}(\bar{\tau},-\bar{\xi})}{\mathcal{H}_{\tau}(-\bar{\tau}, \bar{\xi})}
$$

Combining this expression with $\bar{\xi}=\mathcal{G}(\bar{\tau})$ and approximating both the numerator and denominators around $\bar{\tau}=0$ produces

$$
\frac{1-2(1-\eta)-2 \eta(1-\eta)\left[\theta(2 \eta-1)+\frac{4(1-\eta) \theta \eta}{(2 \eta-1)}\right] \bar{\tau}}{1-2(1-\eta)+2 \eta(1-\eta)\left[\theta(2 \eta-1)+\frac{4(1-\eta) \theta \eta}{(2 \eta-1)}\right] \bar{\tau}}=\frac{2 \eta \theta(1-\eta)+\eta \theta(1-\eta) \bar{\tau}}{2 \eta \theta(1-\eta)-\eta \theta(1-\eta) \bar{\tau}}
$$

It is easy to check that the only solution to this equation is $\bar{\tau}=0$ when the parameters of the model are set to their calibrated values, so the corresponding value for $\tilde{\varepsilon}$ must be zero.

Let $\mathcal{X}_{t}=\left[1, z_{t}, \hat{z}_{t}, s_{t}, \hat{s}_{t}, \mathfrak{T}_{t}\right]^{\prime}$ denote the vector of exogenous variables which follows $\mathcal{X}_{t+1}=\mathcal{A X}_{t}+\zeta_{t+1}$ with $\operatorname{vec}\left(\mathbb{V}_{t}\left(\zeta_{t+1}\right)\right)=\Omega \mathcal{X}_{t}$. The solutions to (64), (65) and (66) when $\bar{\varepsilon}=0$ can be written as $\varepsilon_{t}=l_{\varepsilon} \mathcal{X}_{t}$, $c y_{t}=l_{c y} \mathcal{X}_{t}$, and $\hat{c} y_{t}=l_{\hat{c} y} \mathcal{X}_{t}$, so equilibrium consumption is approximated by $c_{t}=c y_{t}+z_{t}+\mathfrak{T}_{t}=l_{c} \mathcal{X}_{t}$ and $\hat{c}_{t}=\hat{c} \hat{y}_{t}+\hat{z}_{t}+\mathfrak{T}_{t}=l_{\hat{c}} \mathcal{X}_{t}$. The steady state value for the saving-to-consumption ratio, $\bar{\Lambda}^{\mathrm{w}}$, is computed from the log normal approximation to $(36)$ with $\mathcal{B}_{t} N_{t}=0$ :

$$
\begin{gathered}
\lambda_{t}^{\mathrm{w}}=\ln \beta-\left(1-\kappa^{\mathrm{w}}\right) \ln \left(1-\kappa^{\mathrm{w}}\right)+(1-\gamma) \mathbb{E}_{t}\left[\Delta c_{t+1}-\gamma \Delta s_{t+1}+\kappa^{\mathrm{w}} \lambda_{t+1}^{\mathrm{w}}\right] \\
+\frac{1}{2} \mathbb{V}_{t}\left((1-\gamma) c_{t+1}-\gamma s_{t+1}+\kappa^{\mathrm{w}} \lambda_{t+1}^{\mathrm{w}}\right)
\end{gathered}
$$

where $\kappa^{\mathrm{w}}=\bar{\Lambda}^{\mathrm{w}} /\left(1+\bar{\Lambda}^{\mathrm{w}}\right)$. In particular, let $\lambda_{t}^{w}=l_{\lambda}^{\mathrm{w}} \mathcal{X}_{t}$, for some unknown vector of coefficients, $l_{\lambda}^{\mathrm{w}}$. Then 
(70) implies that

$$
l_{\lambda}^{\mathrm{W}}=[\ln \beta-(1-\kappa) \ln (1-\kappa)-\kappa \ln \kappa] l_{1}+\left[(1-\gamma) l_{c}-\gamma l_{s}\right](\mathcal{A}-I)+\kappa^{\mathrm{w}} l_{\lambda}^{\mathrm{w}} \mathcal{A}+\frac{1}{2}\left(l_{\lambda \lambda}^{\mathrm{w}} \otimes l_{\lambda \lambda}^{\mathrm{w}}\right) \Omega
$$

where $l_{\lambda \lambda}^{\mathrm{w}}=(1-\gamma) l_{c}-\gamma l_{s}+\kappa^{\mathrm{w}} l_{\lambda}^{\mathrm{w}}$ and the vectors $l_{1}, l_{z}$ and $l_{s}$ pick out $1, z_{t}$ and $s_{t}$ from $\mathcal{X}_{t}$, respectively. The first element in $l_{\lambda}^{\mathrm{w}}$ identifies the steady state value of $\ln \Lambda_{t}^{\mathrm{w}}$.

The steady state value for the equity price-to-dividend ratio, $\bar{\Lambda}^{\mathrm{Q}}$, is computed in a similar manner from the log normal approximation to (37):

$$
\begin{gathered}
\lambda_{t}^{\mathrm{Q}}=\ln \beta-\left(1-\kappa^{\mathrm{Q}}\right) \ln \left(1-\kappa^{\mathrm{Q}}\right)+(1-\gamma) \mathbb{E}_{t}\left[\Delta c_{t+1}-\gamma \Delta s_{t+1}+\Delta d c_{t+1}+\kappa^{\mathrm{Q}} \lambda_{t+1}^{\mathrm{Q}}\right] \\
+\frac{1}{2} \mathbb{V}_{t}\left((1-\gamma) c_{t+1}-\gamma s_{t+1}+d c_{t+1}+\kappa^{\mathrm{Q}} \lambda_{t+1}^{\mathrm{Q}}\right),
\end{gathered}
$$

where $\kappa^{\mathrm{Q}}=\bar{\Lambda}^{\mathrm{Q}} /\left(1+\bar{\Lambda}^{\mathrm{Q}}\right)$. Approximating (38) and (39) around the steady state produces

$$
d c_{t}=(1-\eta)\left(\varepsilon_{t}+\hat{c} \hat{y}_{t}-c y_{t}+z_{t}-\hat{z}_{t}\right)-2 \varphi(1-\eta)(1-\theta) \varepsilon_{t}=l_{d c} \mathcal{X}_{t}
$$

so (71) implies that $\lambda_{t}^{Q}=l_{\lambda}^{Q} \mathcal{X}_{t}$ where

$$
l_{\lambda}^{\mathrm{Q}}=\left[\ln \beta-\left(1-\kappa^{\mathrm{Q}}\right) \ln \left(1-\kappa^{\mathrm{Q}}\right)-\kappa^{\mathrm{Q}} \ln \kappa^{\mathrm{Q}}\right] l_{1}+\left[(1-\gamma) l_{c}-\gamma l_{s}+l_{d c}\right](\mathcal{A}-I)+\kappa^{\mathrm{Q}} l_{\lambda}^{\mathrm{Q}} \mathcal{A}+\frac{1}{2}\left(l_{\lambda \lambda}^{\mathrm{Q}} \otimes l_{\lambda \lambda}^{\mathrm{Q}}\right)
$$

and

$$
l_{\lambda \lambda}^{\mathrm{Q}}=(1-\gamma) l_{c}-\gamma l_{s}+l_{d c}+\kappa^{\mathrm{Q}} l_{\lambda}^{\mathrm{Q}} .
$$

The first element in $l_{\lambda}^{\mathrm{Q}}$ identifies the steady state value of $\ln \Lambda_{t}^{\mathrm{Q}}$. The steady state values of $\ln \hat{\Lambda}_{t}^{\mathrm{w}}$ and $\ln \hat{\Lambda}_{t}^{\mathrm{Q}}$ are computed in an analogous manner. 


\section{Approximations}

To approximate the first-order conditions associated by bond holdings, I rewrite (52b), (52c), (53b) and (53c) as

$$
\begin{gathered}
\beta \mathbb{E}_{t}\left[\left(\frac{C_{t+1}}{C_{t}}\right)^{-\gamma}\left(\frac{S_{t+1}}{S_{t}}\right)^{-\gamma} R_{t}\right]=1-\mu\left(\frac{\bar{C}_{t} \bar{S}}{C_{t} S_{t}}\right)^{-\gamma}\left[\exp \left(\bar{n}_{t}-n_{t}\right)-1\right], \\
\beta \mathbb{E}_{t}\left[\left(\frac{C_{t+1}}{C_{t}}\right)^{-\gamma}\left(\frac{S_{t+1}}{S_{t}}\right)^{-\gamma} \frac{\mathcal{E}_{t+1} \hat{R}_{t}}{\mathcal{E}_{t}}\right]=1-\mu(1+\varkappa)\left(\frac{\bar{C}_{t} \bar{S}}{C_{t} S_{t}}\right)^{-\gamma}\left[\exp \left(\bar{n}_{t}-n_{t}\right)-1\right] \\
\beta \mathbb{E}_{t}\left[\left(\frac{\hat{C}_{t+1}}{\hat{C}_{t}}\right)^{-\gamma}\left(\frac{\hat{S}_{t+1}}{\hat{S}_{t}}\right)^{-\gamma} \hat{R}_{t}\right]=1-\mu\left(\frac{\bar{C}_{t} \bar{S}}{\hat{C}_{t} \hat{S}_{t}}\right)^{-\gamma}\left[\exp \left(\bar{n}_{t}-\hat{n}_{t}\right)-1\right] \quad \text { and } \\
\beta \mathbb{E}_{t}\left[\left(\frac{\hat{C}_{t+1}}{\hat{C}_{t}}\right)^{-\gamma}\left(\frac{\hat{S}_{t+1}}{\hat{S}_{t}}\right)^{-\gamma} \frac{\mathcal{E}_{t} R_{t}}{\mathcal{E}_{t+1}}\right]=1-\mu(1+\varkappa)\left(\frac{\bar{C}_{t} \bar{S}}{\hat{C}_{t} \hat{S}_{t}}\right)^{-\gamma}\left[\exp \left(\bar{n}_{t}-\hat{n}_{t}\right)-1\right] .
\end{gathered}
$$

I take a standard log-normal approximation to the terms on the left-hand-side, and a second-order approximation to the natural $\log$ of the terms on the right-hand-side around the steady state. After some simplification, this produces

$$
\begin{aligned}
r_{t}= & -\ln \beta+\gamma \mathbb{E}_{t}\left(\Delta c_{t+1}+\Delta s_{t+1}\right)-\frac{1}{2} \gamma^{2} \mathbb{V}_{t}\left(c_{t+1}+s_{t+1}\right) \\
& +\mu\left(n_{t}-\bar{n}_{t}\right)-\frac{1}{2} \mu(\mu+1)\left(n_{t}-\bar{n}_{t}\right)^{2}, \\
\hat{r}_{t}= & -\ln \beta+\gamma \mathbb{E}_{t}\left(\Delta \hat{c}_{t+1}+\Delta \hat{s}_{t+1}\right)-\frac{1}{2} \gamma^{2} \mathbb{V}_{t}\left(\hat{c}_{t+1}+\hat{s}_{t+1}\right) \\
& +\mu\left(\hat{n}_{t}-\bar{n}_{t}\right)-\frac{1}{2} \mu(\mu+1)\left(\hat{n}_{t}-\bar{n}_{t}\right)^{2}, \\
\mathbb{E}_{t} \Delta \varepsilon_{t+1}+\hat{r}_{t}= & -\ln \beta+\gamma \mathbb{E}_{t}\left(\Delta c_{t+1}+\Delta s_{t+1}\right)-\frac{1}{2} \mathbb{V}_{t}\left(\varepsilon_{t+1}-\gamma\left(c_{t+1}+s_{t+1}\right)\right) \\
& +\mu(\varkappa+1)\left(n_{t}-\bar{n}_{t}\right)-\frac{1}{2} \mu(\varkappa+1)(\mu(\varkappa+1)+1)\left(n_{t}-\bar{n}_{t}\right)^{2} \\
\mathbb{E}_{t} \Delta \varepsilon_{t+1}-r_{t}= & \ln \beta-\gamma \mathbb{E}_{t}\left(\Delta \hat{c}_{t+1}+\Delta \hat{s}_{t+1}\right)+\frac{1}{2} \mathbb{V}_{t}\left(\varepsilon_{t+1}+\gamma\left(c_{t+1}+s_{t+1}\right)\right) \\
& -\mu(\varkappa+1)\left(\hat{n}_{t}-\bar{n}_{t}\right)+\frac{1}{2} \mu(\varkappa+1)(\mu(\varkappa+1)+1)\left(\hat{n}_{t}-\bar{n}_{t}\right)^{2} .
\end{aligned}
$$

Together, these equations imply that

$$
\begin{gathered}
\delta_{t}=\frac{1}{2} \gamma \mathbb{C V}_{t}\left(\varepsilon_{t+1}, c_{t+1}+s_{t+1}\right)+\frac{1}{2} \gamma \mathbb{C} \mathbb{V}_{t}\left(\varepsilon_{t+1}, \hat{c}_{t+1}+\hat{s}_{t+1}\right) \\
+\frac{1}{2} \mu \varkappa\left(n_{t}-\hat{n}_{t}\right)+\frac{1}{4} \mu \varkappa[1+\mu(2+\varkappa)]\left[\left(\hat{n}_{t}-\bar{n}_{t}\right)^{2}-\left(n_{t}-\bar{n}_{t}\right)^{2}\right] \\
r_{t}-\hat{r}_{t}=\gamma \mathbb{E}_{t}\left(\Delta c_{t+1}+\Delta s_{t+1}\right)-\gamma \mathbb{E}_{t}\left(\Delta \hat{c}_{t+1}+\Delta \hat{s}_{t+1}\right)+\frac{1}{2} \gamma^{2}\left\{\mathbb{V}_{t}\left(\hat{c}_{t+1}+\hat{s}_{t+1}\right)-\mathbb{V}_{t}\left(c_{t+1}+s_{t+1}\right)\right\} \\
+\mu\left(n_{t}-\hat{n}_{t}\right)+\frac{1}{2} \mu(\mu+1)\left[\left(\hat{n}_{t}-\bar{n}_{t}\right)^{2}-\left(n_{t}-\bar{n}_{t}\right)^{2}\right] .
\end{gathered}
$$


Equations (46) and (47) in the text reproduce these expressions without the terms involving $\left(\hat{n}_{t}-\bar{n}_{t}\right)^{2}$ and $\left(n_{t}-\bar{n}_{t}\right)^{2}$.

I approximate the equations determining the logs of $\Lambda_{t}^{\mathrm{Q}}, \hat{\Lambda}_{t}^{\mathrm{Q}}, \Lambda_{t}^{\mathrm{w}}$ and $\Lambda_{t}^{\mathrm{w}}$ in an analogous fashion from (54) and (55) as

$$
\begin{aligned}
& \lambda_{t}^{\mathrm{Q}}=\ln \beta-\left(1-\kappa^{\mathrm{Q}}\right) \ln \left(1-\kappa^{\mathrm{Q}}\right)+(1-\gamma) \mathbb{E}_{t}\left[\Delta c_{t+1}-\gamma \Delta s_{t+1}+\Delta d c_{t+1}+\kappa^{\mathrm{Q}} \lambda_{t+1}^{\mathrm{Q}}\right] \\
& +\frac{1}{2} \mathbb{V}_{t}\left((1-\gamma) c_{t+1}-\gamma s_{t+1}+d c_{t+1}+\kappa^{\mathrm{Q}} \lambda_{t+1}^{\mathrm{Q}}\right), \\
& \hat{\lambda}_{t}^{Q}=\ln \beta-\left(1-\kappa^{\mathrm{Q}}\right) \ln \left(1-\kappa^{\mathrm{Q}}\right)+(1-\gamma) \mathbb{E}_{t}\left[\Delta \hat{c}_{t+1}-\gamma \Delta \hat{s}_{t+1}+\Delta \hat{d} c_{t+1}+\kappa^{\mathrm{Q}} \hat{\lambda}_{t+1}^{\mathrm{Q}}\right] \\
& +\frac{1}{2} \mathbb{V}_{t}\left((1-\gamma) \hat{c}_{t+1}-\gamma \hat{s}_{t+1}+\hat{d} c_{t+1}+\kappa^{\mathrm{Q}} \hat{\lambda}_{t+1}^{\mathrm{Q}}\right), \\
& \lambda_{t}^{\mathrm{w}}=\ln \beta-\left(1-\kappa^{\mathrm{w}}\right) \ln \left(1-\kappa^{\mathrm{w}}\right)+(1-\gamma) \mathbb{E}_{t}\left[\Delta c_{t+1}-\gamma \Delta s_{t+1}+\kappa^{\mathrm{w}} \lambda_{t+1}^{\mathrm{w}}\right] \\
& +\frac{1}{2} \mathbb{V}_{t}\left((1-\gamma) c_{t+1}-\gamma s_{t+1}+\kappa^{\mathrm{w}} \lambda_{t+1}^{\mathrm{w}}\right)-\frac{1}{2} \varkappa(1-\eta)[1-\varkappa(1-\eta)]\left(n_{t}-\bar{n}_{t}\right)^{2} \\
& -\varkappa(1-\eta)\left(n_{t}-\bar{n}_{t}\right)\left[1+\gamma\left(s_{t}-\bar{s}\right)-\left(\lambda_{t}^{\mathrm{W}}-\lambda\right)-(1-\gamma)\left(c_{t}-\bar{c}_{t}\right)\right] \quad \text { and } \\
& \hat{\lambda}_{t}^{\mathrm{w}}=\ln \beta-\left(1-\kappa^{\mathrm{w}}\right) \ln \left(1-\kappa^{\mathrm{w}}\right)+(1-\gamma) \mathbb{E}_{t}\left[\Delta \hat{c}_{t+1}-\gamma \Delta \hat{s}_{t+1}+\kappa^{\mathrm{w}} \hat{\lambda}_{t+1}^{\mathrm{w}}\right] \\
& +\frac{1}{2} \mathbb{V}_{t}\left((1-\gamma) \hat{c}_{t+1}-\gamma \hat{s}_{t+1}+\kappa \hat{\lambda}_{t+1}^{\mathrm{w}}\right)-\frac{1}{2} \varkappa(1-\eta)[1-\varkappa(1-\eta)]\left(\hat{n}_{t}-\bar{n}_{t}\right)^{2} \\
& -\varkappa(1-\eta)\left(\hat{n}_{t}-\bar{n}_{t}\right)\left[1+\gamma\left(\hat{s}_{t}-\bar{s}\right)-\left(\hat{\lambda}_{t}^{\mathrm{w}}-\lambda\right)-(1-\gamma)\left(\hat{c}_{t}-\bar{c}_{t}\right)\right] .
\end{aligned}
$$

Here $\kappa^{\mathrm{Q}}=\bar{\Lambda}^{\mathrm{Q}} /\left(1+\bar{\Lambda}^{\mathrm{Q}}\right)$ and $\kappa^{\mathrm{Q}}=\bar{\Lambda}^{\mathrm{w}} /\left(1+\bar{\Lambda}^{\mathrm{w}}\right)$ where $\bar{\Lambda}^{\mathrm{w}}$ and $\bar{\Lambda}^{\mathrm{Q}}$ are the steady state values for $\Lambda_{t}^{\mathrm{w}}$ and $\Lambda_{t}^{\mathrm{Q}}$, identified above.

I approximate the other equilibrium conditions in a straightforward manner around the steady state real exchange rate rate. Using the definition in (18) we can approximate the log real exchange to second order by

$$
\varepsilon_{t}=(2 \eta-1) \tau_{t}
$$

To approximate the goods market clearing conditions, I use (56) to compute $\ln \left(Y_{t} / C_{t}\right)$ and $\ln \left(\hat{Y}_{t} / \hat{C}_{t}\right)$ and then take second-order approximations around the steady state of the resulting expressions. Simplifying the result using (75) produces

$$
\begin{aligned}
{\left[\begin{array}{c}
c_{t} \\
\hat{c}_{t}
\end{array}\right]=} & {\left[\begin{array}{cc}
\varphi & 1-\varphi \\
1-\varphi & \varphi
\end{array}\right]\left[\begin{array}{l}
y_{t} \\
\hat{y}_{t}
\end{array}\right]+\left[\begin{array}{c}
-2 \theta \varphi^{2}(1-\eta) / \eta \\
2 \theta \varphi^{2}(1-\eta) / \eta
\end{array}\right] \varepsilon_{t} } \\
& -\left[\begin{array}{ccc}
-\frac{1}{2}\left(4 \theta \eta^{2}-4 \theta \eta+1\right)(\eta-1) \theta \varphi^{2} / \eta & -\frac{1}{2} \eta(\eta-1) & \eta \theta(1-\eta)(2 \varphi-1) \\
-\frac{1}{2}\left(4 \theta \eta^{2}-4 \theta \eta+1\right)(\eta-1) \theta \varphi^{2} / \eta & -\frac{1}{2} \eta(\eta-1) & -\eta \theta(1-\eta)(2 \varphi-1)
\end{array}\right]\left[\begin{array}{c}
\varepsilon_{t}^{2} \\
\left(c_{t}-\hat{c}_{t}\right)^{2} \\
\varepsilon_{t}\left(c_{t}-\hat{c}_{t}\right)
\end{array}\right],
\end{aligned}
$$

where $\varphi=\eta /(2 \eta-1)>0$. Approximations for dividends and trade flows are derived in an analogous manner 
from (58) and (59) as

$$
\begin{aligned}
d_{t}-c_{t} & =(1-\eta) n x_{t}+\frac{1}{2} \eta(1-\eta) n x_{t}^{2}+\varphi(1-\theta)(1-\eta) \varepsilon_{t} n x_{t}, \\
\hat{d}_{t}-\hat{c}_{t} & =-(1-\eta) n x_{t}+\frac{1}{2} \eta(1-\eta) n x_{t}^{2}-\varphi(1-\theta)(1-\eta) \varepsilon_{t} n x_{t}, \\
x_{t} & =\ln (1-\eta)+[1-\varphi(1-\theta)] \varepsilon+\hat{c}_{t} \quad \text { and } \\
m_{t} & =\ln (1-\eta)+\varphi(1-\theta) \varepsilon_{t}+c_{t},
\end{aligned}
$$

where $n x_{t}=x_{t}-m_{t}$. Market clearing in the bond markets implies that $N_{t}=(1+\varkappa) \mathcal{E}_{t} B_{t}^{\mathrm{EU}}-\hat{B}_{t}^{\mathrm{US}}$ and $\hat{N}_{t}=(1+\varkappa) \hat{B}_{t}^{\mathrm{US}}-\mathcal{E}_{t} B_{t}^{\mathrm{EU}}$. We can use these two expressions to approximate the logs of $N_{t}$ and $\hat{N}_{t}$ by

$$
n_{t}=\ln \varkappa-\frac{1}{\varkappa} n f l_{t}-\frac{1}{2} \frac{1+\varkappa}{\varkappa^{2}} n f l_{t}^{2}+f a_{t} \quad \text { and } \quad \hat{n}_{t}=\ln \varkappa+\frac{1}{\varkappa} n f l_{t}-\frac{1}{2} \frac{1+\varkappa}{\varkappa^{2}} n f l_{t}^{2}+f l_{t}
$$

where $n f l_{t}=f l_{t}-f a_{t}$. Notice that $n_{t}-\hat{n}_{t}=-\frac{2}{\varkappa} n f l_{t}$ and $\delta_{t}=\frac{1}{2} \gamma \mathbb{C} \mathbb{V}_{t}\left(\varepsilon_{t+1}, c_{t+1}+s_{t+1}\right)+\frac{1}{2} \gamma \mathbb{C V} \mathbb{V}_{t}\left(\varepsilon_{t+1}, \hat{c}_{t+1}+\right.$ $\left.\hat{s}_{t+1}\right)+\frac{1}{2} \mu \varkappa\left(n_{t}-\hat{n}_{t}\right)$ to first order, so the value for $\mu$ determines the semi-elasticity of the risk premium with respect to variations in the log ratio of foreign liabilities to assets.

Finally, the consolidated budget constraint in (60) implies that

$$
\frac{F A_{t}}{R_{t}^{\mathrm{FA}} F A_{t-1}}-1+\frac{\mathfrak{M}_{t}}{R_{t}^{\mathrm{FA}} F A_{t-1}}=\frac{F L_{t}}{R_{t}^{\mathrm{FA}} F A_{t-1}}+\frac{\mathfrak{X}_{t}}{R_{t}^{\mathrm{FA}} F A_{t-1}}-\frac{R_{t}^{\mathrm{FL}}}{R_{t}^{\mathrm{FA}}} \frac{F L_{t-1}}{F A_{t-1}} .
$$

Taking second-order approximations to the terms on the left- and right-hand-sides, simplifying and taking conditional expectations produces

$$
\begin{aligned}
f l_{t}-f a_{t}=(1 & -\kappa) \mathbb{E}_{t} n x_{t+1}+\mathbb{E}_{t}\left[r_{t+1}^{\mathrm{FA}}-r_{t+1}^{\mathrm{FL}}\right]+\kappa \mathbb{E}_{t}\left(f l_{t+1}-f a_{t+1}\right) \\
& +\frac{1}{2} \kappa^{2} \mathbb{E}_{t}\left[\left(\Delta f l_{t+1}-r_{t+1}^{\mathrm{FL}}-\ln \kappa\right)^{2}-\left(\Delta f a_{t+1}-r_{t+1}^{\mathrm{FA}}-\ln \kappa\right)^{2}\right] \\
& +\frac{1}{2}(1-\kappa) \mathbb{E}_{t}\left[\left(x_{t+1}-r_{t+1}^{\mathrm{FL}}-f l_{t}-\ln (1-\kappa)\right)^{2}-\left(m_{t+1}-r_{t+1}^{\mathrm{FA}}-f a_{t}-\ln (1-\kappa)\right)^{2}\right] .
\end{aligned}
$$

\section{Solution Method}

The solution produces vectors of coefficients, $\pi_{a}$ and $\tilde{\pi}_{a}$, that link the equilibrium behavior of any endogenous variable $a_{t}$ to the exogenous variables by

$$
a_{t}=\bar{a}_{t}+\pi_{a} \mathcal{Z}_{t}+\tilde{\pi}_{a} \tilde{\mathcal{Z}}_{t}
$$

where $\mathcal{Z}_{t}=\left[z_{t}, \hat{z}_{t}, s_{t}-\bar{s}, \hat{s}_{t}-\bar{s}\right]^{\prime}$ and $\tilde{\mathcal{Z}}_{t}=\operatorname{vec}(\mathcal{Z}) . \bar{a}_{t}$ identifies the steady state value of stationary variables and the trend, $\mathfrak{T}_{t}$, in non-stationary variables. The exogenous processes for the endowments and log surplus ratios imply that

$$
\mathcal{Z}_{t+1}=\mathcal{A Z}_{t}+\mathcal{V}_{t+1} \quad \text { with } \quad \operatorname{vec}\left(V_{t}\left(\mathcal{V}_{t+1}\right)\right)=\Sigma_{0}+\Sigma \mathcal{Z}_{t}
$$

and

$$
\mathbb{E}_{t} \tilde{\mathcal{Z}}_{t+1}=(\mathcal{A} \otimes \mathcal{A}) \tilde{\mathcal{Z}}_{t}+\Sigma_{0}+\Sigma \mathcal{Z}_{t}
$$


In principle, the $\pi_{a}$ and $\tilde{\pi}_{a}$ vectors for each endogenous variable could be found by applying the method of undetermined coefficients to the set of second-order approximations presented above, but in practice it is more computationally efficient to use an iterative procedure based on Lombardo and Sutherland (2007).

The first step in this procedure is to find initial values for the $\pi_{a}$ vectors. For this purpose, I combine (73) with (76), (77) and (79) ignoring all the second-order terms. This produces the following system:

$$
\begin{aligned}
& \mathbb{E}_{t} \Delta \varepsilon_{t+1}= \delta_{t}+r_{t}-\hat{r}_{t}, \\
& r_{t}-\hat{r}_{t}= \gamma \mathbb{E}_{t}\left(\Delta c_{t+1}+\Delta s_{t+1}\right)-\gamma \mathbb{E}_{t}\left(\Delta \hat{c}_{t+1}+\Delta \hat{s}_{t+1}\right) \\
& \quad-\frac{1}{2} \gamma \mathbb{V}_{t}^{2}\left(c_{t+1}+s_{t+1}\right)+\frac{1}{2} \gamma^{2} \mathbb{V}_{t}\left(\hat{c}_{t+1}+\hat{s}_{t+1}\right)-\mu\left(\frac{\varkappa+2}{\varkappa}\right) n f l_{t}, \\
& \delta_{t}= \frac{1}{2} \gamma \mathbb{C V}_{t}\left(c_{t+1}+\hat{c}_{t+1}, \varepsilon_{t+1}\right)+\frac{1}{2} \gamma \mathbb{C V}_{t}\left(s_{t+1}+\hat{s}_{t+1}, \varepsilon_{t+1}\right)-\mu\left(\frac{\varkappa+2}{2}\right) n f l_{t}, \\
& n f l_{t}=(1-\kappa) \mathbb{E}_{t}\left[\left(\varepsilon_{t+1}+\hat{c}_{t+1}-c_{t+1}\right)-2 \varphi(1-\theta) \varepsilon_{t+1}\right]+\delta_{t}+\kappa \mathbb{E}_{t} n f l_{t+1}, \\
& c_{t}= \varphi y_{t}+(1-\varphi) \hat{y}_{t}-\left[2 \theta \varphi^{2}(1-\eta) / \eta\right] \varepsilon_{t} \quad \text { and } \\
& \hat{c_{t}}=(1-\varphi) y_{t}+\varphi \hat{y}_{t}+\left[2 \theta \varphi^{2}(1-\eta) / \eta\right] \varepsilon_{t} .
\end{aligned}
$$

Applying the method of undetermined coefficients to these equations using (80) produces

$$
a_{t}=\bar{a}_{t}+\pi_{a}^{(1)} \mathcal{Z}_{t} \quad \text { for } \quad a_{t}=\left\{\varepsilon_{t}, r_{t}-\hat{r}_{t}, \delta_{t}, n f l_{t}, c_{t}, \hat{c}_{t}\right\}
$$

Combing these expressions with (72), (74) and (77) produces

$$
a_{t}=\bar{a}_{t}+\pi_{a}^{(1)} \mathcal{Z}_{t} \quad \text { for } \quad a_{t}=\left\{r_{t}, \hat{r}_{t}, n_{t}, \hat{n}_{t}, \lambda_{t}^{Q}, \hat{\lambda}_{t}^{Q}, \lambda_{t}^{\mathrm{w}}, \hat{\lambda}_{t}^{\mathrm{w}}, x_{t}, m_{t}, d_{t}, \hat{d}_{t}, f a_{t}, f l_{t}\right\}
$$

The second step uses (84) and (85) to compute the second-order terms in (72), (74), (76), (77), (78) and (79). Notice that all of these terms in this system involve deviations from steady-state values, i.e., $\left(a_{t}-\bar{a}_{t}\right)\left(b_{t}-\bar{b}_{t}\right)$. They are computed as

$$
\begin{aligned}
\left(a_{t}-\bar{a}_{t}\right)\left(b_{t}-\bar{b}_{t}\right) & =\left(\pi_{a}^{(1)} \mathcal{Z}_{t}\right)\left(\pi_{b}^{(1)} \mathcal{Z}_{t}\right)=\left(\pi_{b}^{(1)} \otimes \pi_{a}^{(1)}\right) \tilde{\mathcal{Z}}_{t} \quad \text { and } \\
\mathbb{E}_{t}\left(a_{t+1}-\bar{a}_{t+1}\right)\left(b_{t+1}-\bar{b}_{t+1}\right) & =\left(\pi_{b}^{(1)} \otimes \pi_{a}^{(1)}\right)\left(\Sigma_{0}+\Sigma \mathcal{Z}_{t}\right)
\end{aligned}
$$

using the coefficient vectors $\pi_{a}^{(1)}$ and $\pi_{b}^{(1)}$ from the first step. The other terms in the system are assumed to take the form of

$$
a_{t}=\bar{a}_{t}+\pi_{a}^{(2)} \mathcal{Z}_{t}+\tilde{\pi}_{a}^{(2)} \tilde{\mathcal{Z}}_{t}
$$

where $\pi_{a}^{(2)}$ and $\tilde{\pi}_{a}^{(2)}$ are unknown coefficient vectors. Making these substitutions produces a system of linear equations in $\mathcal{Z}_{t}$ and $\tilde{\mathcal{Z}}_{t}$, so $\pi_{a}^{(2)}$ and $\tilde{\pi}_{a}^{(2)}$ can be determined by the method of undetermined coefficients. For 
example, from equation (76), we obtain

$$
\begin{array}{r}
\bar{c}_{t}+\pi_{c}^{(2)} \mathcal{Z}_{t}+\tilde{\pi}_{c}^{(2)} \tilde{\mathcal{Z}}_{t}=z_{t}+\left[\varphi \pi_{z}+(1-\varphi) \pi_{\hat{z}}\right] \mathcal{Z}_{t}-\left[2 \theta \varphi^{2}(1-\eta) / \eta\right]\left(\pi_{\varepsilon}^{(2)} \mathcal{Z}_{t}+\tilde{\pi}_{\varepsilon}^{(2)} \tilde{\mathcal{Z}}_{t}\right) \\
+\left[\frac{1}{2} \theta \varphi^{2}\left(4 \theta \eta^{2}-4 \theta \eta+1\right)(\eta-1) / \eta\right]\left(\pi_{\varepsilon}^{(1)} \otimes \pi_{\varepsilon}^{(1)}\right) \tilde{\mathcal{Z}}_{t} \\
+\frac{1}{2} \eta(\eta-1)\left(\left(\pi_{c}^{(1)}-\pi_{\hat{c}}^{(1)}\right) \otimes\left(\pi_{c}^{(1)}-\pi_{\hat{c}}^{(1)}\right)\right) \tilde{\mathcal{Z}}_{t} \\
-\eta \theta(1-\eta)(2 \varphi-1)\left(\left(\pi \otimes\left(\pi_{c}^{(1)}-\pi_{\hat{c}}^{(1)}\right)\right) \tilde{\mathcal{Z}}_{t} .\right.
\end{array}
$$

where $z_{t}^{\mathrm{C}}=\pi_{z} \mathcal{Z}_{t}$ and $\hat{z}_{t}=\pi_{\hat{z}} \mathcal{Z}_{t}$. Hence, equating coefficients gives

$$
\begin{aligned}
\pi_{c}^{(2)}= & \varphi \pi_{z}+(1-\varphi) \pi_{\hat{z}}-\left[2 \theta \varphi^{2}(1-\eta) / \eta\right] \pi_{\varepsilon}^{(2)} \text { and } \\
\tilde{\pi}_{c}^{(2)}= & -\left[2 \theta \varphi^{2}(1-\eta) / \eta\right] \tilde{\pi}_{\varepsilon}^{(2)}+\left[\frac{1}{2} \theta \varphi^{2}\left(4 \theta \eta^{2}-4 \theta \eta+1\right)(\eta-1) / \eta\right]\left(\pi_{\varepsilon}^{(1)} \otimes \pi_{\varepsilon}^{(1)}\right) \\
& \quad+\frac{1}{2} \eta(\eta-1)\left(\left(\pi_{c}^{(1)}-\pi_{\hat{c}}^{(1)}\right) \otimes\left(\pi_{c}^{(1)}-\pi_{\hat{c}}^{(1)}\right)\right)-\eta \theta(1-\eta)(2 \varphi-1)\left(\left(\pi \otimes\left(\pi_{c}^{(1)}-\pi_{\hat{c}}^{(1)}\right)\right) .\right.
\end{aligned}
$$

Notice that equation (86b) involves only $\tilde{\pi}^{(2)}$ and the $\pi^{(1)}$ vectors. This pattern applies across the system, so the $\tilde{\pi}^{(2)}$ vectors can be computed using the first-step estimates, $\pi^{(1)}$. The $\pi^{(2)}$ coefficients are determined by (86a) and similar equations derived from the system. This set of equations is similar to those determining $\pi^{(1)}$ except that it also involves terms like $\left(\pi_{b}^{(1)} \otimes \pi_{a}^{(1)}\right) \Sigma$ because $\mathcal{Z}_{t}$ affects $\mathbb{E}_{t}\left(a_{t+1}-\bar{a}_{t+1}\right)\left(b_{t+1}-\bar{b}_{t+1}\right)$. Consequently, the $\pi^{(2)}$ coefficients will generally differ from $\pi^{(1)}$. If the log surplus ratios were homoskedastic, $\Sigma$ would equal the null matrix, and $\pi^{(2)}$ would equal $\pi^{(1)}$ so only two steps would be necessary, as in Lombardo and Sutherland (2007)

To summarize, the solution procedure involves: (i) solving for $\pi^{(1)}$ from (83); (ii) solving for $\pi^{(2)}$ and $\tilde{\pi}_{c}^{(2)}$ using $\pi^{(1)}$ and the second-order approximations to the model's equilibrium conditions; and (iii) repeating step (ii) solving for $\pi^{(j)}$ and $\tilde{\pi}_{c}^{(j)}$ using $\pi^{(\mathrm{J}-1)}$ until $\pi^{(j)}=\pi^{(\mathrm{J}-1)}$. In practice, I find that $\pi^{(j)}-\pi^{(\mathrm{J}-1)}$ is very close to a vector of zeros for all the variables when $j=3$, so only one iteration is necessary.

Finally, applying the method of undetermined coefficients to the system in (83) when $\mu=0$, gives solutions in (84) such that $\varepsilon_{t}=\gamma\left(c_{t}-\hat{c}_{t}\right)+\gamma\left(s_{t}-\hat{s}_{t}\right)$, so the this version of the model produces equilibrium under complete markets. 